Florida International University FIU Digital Commons

3-23-2018

\title{
Recovery of Amphibian and Reptile Communities During Tropical Secondary Forest Succession
}

Michelle E. Thompson

Florida International University, mthom163@fiu.edu

DOI: $10.25148 /$ etd.FIDC006553

Follow this and additional works at: https://digitalcommons.fiu.edu/etd

Part of the Biology Commons, and the Ecology and Evolutionary Biology Commons

\section{Recommended Citation}

Thompson, Michelle E., "Recovery of Amphibian and Reptile Communities During Tropical Secondary Forest Succession" (2018). FIU Electronic Theses and Dissertations. 3701.

https://digitalcommons.fiu.edu/etd/3701 


\title{
FLORIDA INTERNATIONAL UNIVERSITY
}

Miami, Florida

\section{RECOVERY OF AMPHIBIAN AND REPTILE COMMUNITIES DURING TROPICAL SECONDARY FOREST SUCCESSION}

\author{
A dissertation submitted in partial fulfillment of \\ the requirements for the degree of \\ DOCTOR OF PHILOSOPHY \\ in \\ BIOLOGY \\ by
}

Michelle Elaine Thompson

2018 
To: Dean Michael R. Heithaus

College of Arts, Sciences and Education

This dissertation, written by Michelle Elaine Thompson, and entitled Recovery of Amphibian and Reptile Communities during Tropical Secondary Forest Succession having been approved in respect to style and intellectual content, is referred to you for judgment.

We have read this dissertation and recommend that it be approved.

$\begin{array}{r}\hline \text { Evelyn E. Gaiser } \\ \hline \text { Brian J. Halstead } \\ \hline \text { Joel T. Heinen } \\ \hline \text { John S. Kominoski } \\ \hline \text { Maureen A. Donnelly, Major Professor }\end{array}$

Date of Defense: March 23, 2018

The dissertation of Michelle Elaine Thompson is approved.

Dean Michael R. Heithaus College of Arts, Sciences and Education

Andrés G. Gil Vice President for Research and Economic Development and Dean of the University Graduate School

Florida International University, 2018 
(C) Copyright 2018 by Michelle Elaine Thompson

All rights reserved. 


\section{DEDICATION}

This dissertation is dedicated to my grandparents. 


\section{ACKNOWLEDGMENTS}

First and foremost, I would like to thank my advisor, Maureen Donnelly, who served as a never-ending source of inspiration, enthusiasm, and support. I cannot imagine completing this feat without Mo as an advisor. I deeply appreciate the freedom Mo gave me to pursue and develop my own research interests and her guidance in molding me into a better researcher, critical thinker, writer, and educator. I will also forever be in debt to several professors who had an impact on me early in my career, Frank Joyce, Federico Chinchilla, and Pati Ortiz, who showed me what it meant to be a tropical biologist and inspired me to pursue a career in tropical biology.

I am indebted to the Organization for Tropical Studies and Osa Conservation for helping me with project logistics and serving as research sites. I would like to thank a large list of landowners for allowing me to conduct research on their property, including, Selva Verde Lodge, Pozo Azul, Bijagual Ecological Reserve, Tirimbina Biological Reserve, Juan Manuel Ley, MINAE/SINAC, Bosque del Cabo, Rancho Tropical, Danta Corcovado Lodge, Daniela Solano, Finca El Bejuco, Finca Matisia, Gonzalo Ramirez, and Diego Luis Leon. I thank Adrian Forsyth and Brian Machovina for encouraging me to work at the Osa Conservation field station, I thank Carlos de la Rosa at La Selva Biological Station, and a great thanks to Robin Chazdon, who was gracious enough to share her field sites with me and introduce me to her wonderful BOSQUES team.

A very special thank you to Enrique Salicetti and Orlando Vargas whose friendships helped transform Sarapiquí into my home, who have a passion for the forest that is contagious, and who dedicated their time to many plant-ID sessions and good conversation. Enrique helped inspire and collaborate on rewarding side projects on glass 
frogs and fluffy, sleepy birds, and provided much motivation and support. Orlando watched over the famous Galleta, allowing me to sample in the Osa without worry.

Thank you to Jeanette Paniagua, Bernal Paniagua, Manuel Sánchez Méndoza, and Juan Carlos Cruz for their friendship and help in the field. Collaboration with Juan José Jiménez provided many opportunities for me to expand my research and engage with park guards and local community members of the Osa Peninsula. I was fortuitous to meet Reinaldo Aguilar in the middle of the forest, who helped connect me with MINAE/SINAC in the Osa Peninsula. I was lucky to have many wonderful volunteer field assistants including Oliver Ljustina, Marie-Anna Hohenfeld, Julia Ersan, Jennifer Symons, Ryan Willis, Becca Wier, Lauren Ross, Christian Krupke, P. Curtis Hoffman, and Caitlin Campbell. I am grateful to my committee members Evelyn Gaiser, Brian Halstead, John Kominoski and Joel Heinen, and for collaborations with Brian Halstead, Maureen Donnelly, and Justin Nowakowski on publications resulting from chapters of this dissertation.

My labmates, Michael Britton, Lilly Eluvathingal, Justin Nowakowski, Luke Linhoff, Kelsey Reider, and honorary lab mate, collaborator, and carpool buddy James Stroud, who although were dispersed across the globe, formed a tight-knight group of support. I am grateful to my parents, Elaine and Tom Thompson, family, and many friends who gave me emotional support and encouragement, especially Hailey Marshall, Jeremy Partch, and Nicki Hunt. Hailey's random messages of encouragement always came just at the right time.

This dissertation was completed with financial support from the following: FIU Dissertation Year and Doctoral Evidence Acquisition Fellowships, FIU Tinker Field 
Research Grant, Fulbright U.S. Student Research Award, Organization for Tropical

Studies (Foster and Dole fund) Fellowships, IDEA Wild Equipment Grant, International

Herpetological Symposium Grant in Herpetology, and American Society of

Ichthyologists and Herpetologists Gaige Award. 


\title{
ABSTRACT OF THE DISSERTATION \\ RECOVERY OF AMPHIBIAN AND REPTILE COMMUNITIES DURING TROPICAL SECONDARY FOREST SUCCESSION
}

\author{
by
}

Michelle Elaine Thompson

Florida International University, 2018

Miami, Florida

\section{Professor Maureen A. Donnelly, Major Professor}

The extensive clearing and modification of natural systems from anthropogenic activities is a pressing global concern. Forest habitats and animal communities within forests are among the most highly impacted, globally. Forest destruction has been repeatedly documented as a driver of biodiversity loss. However, little is known about how animal communities respond when altered landscapes are abandoned and left to regenerate into secondary forests. It is thought that the regrowth of secondary forests may help reverse biodiversity loss by restoring habitats to similar conditions as prior to land conversion. Of the forest cover that remains, over half is secondary forest, and in many countries secondary forest cover has been steadily increasing. Therefore, it is important to understand how and if faunal communities recover during secondary forest regeneration.

I combined meta-analytic, field-survey-based, and lab-based experimental techniques to determine how amphibians and reptiles respond to habitat change in general, and secondary forest regeneration on landscapes previously cleared for use as pasture. I addressed five specific questions: 1) what are the effects of habitat alteration on amphibians and reptiles?, 2) what are the effects of secondary forest succession on 
amphibians and reptiles?, 3) what is the relative importance of stochastic and deterministic effects on community assembly during secondary forest succession?, 4) how do amphibian and reptile species composition, probability of occurrence, and species richness change over the course of secondary forest succession?, and 5) is thermal quality of habitat an important mechanism of species response to secondary forest succession? I found that secondary forest has high conservation value for many amphibian and reptile species, environmental changes associated with secondary forest succession have a significant effect on shaping amphibian and reptile community composition, thermal quality is an important mechanism for species response and that strength of response is mediated by species-specific thermal biology. I also highlight the importance of riparian corridors in maintaining species diversity in modified habitats. 


\section{TABLE OF CONTENTS}

CHAPTER

PAGE

INTRODUCTION 1

CHAPTER 1: THE IMPORTANCE OF DEFINING FOCAL ASSEMBLAGES WHEN EVALUATING AMPHIBIAN AND REPTILE RESPONSES TO LAND USE ..............7

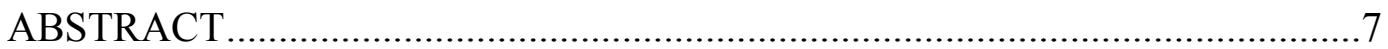

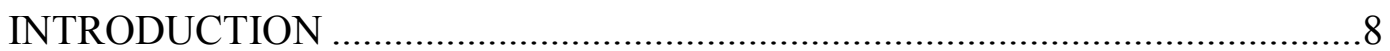

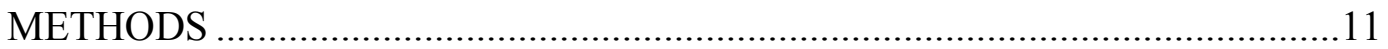

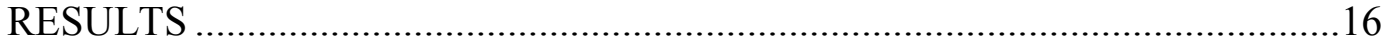

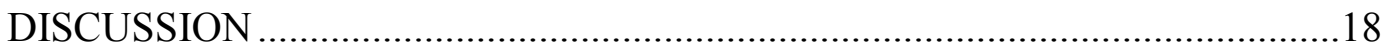

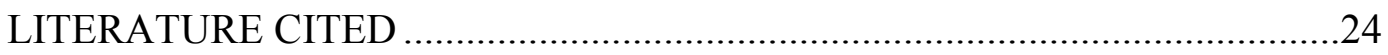

CHAPTER 2: EFFECTS OF SECONDARY FOREST SUCCESSION ON

AMPHIBIANS AND REPTILES: A REVIEW AND META-ANALYSIS ...................36

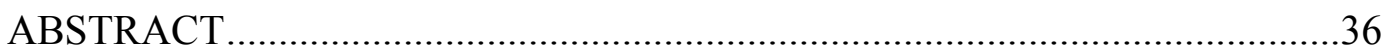

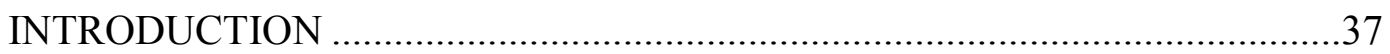

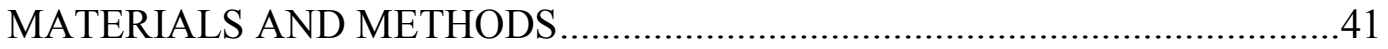

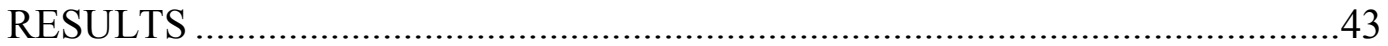

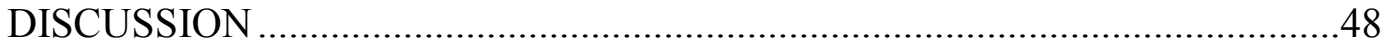

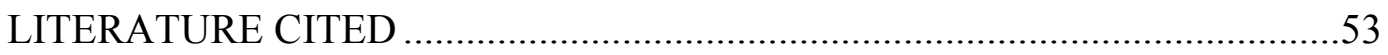

CHAPTER 3: BUILDING A NEW COMMUNITY: FACTORS AFFECTING

TROPICAL FOREST SUCCESSIONAL OUTCOMES FOR AMPHIBIANS AND

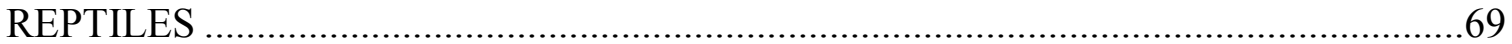

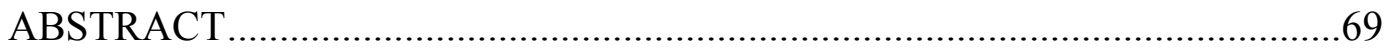

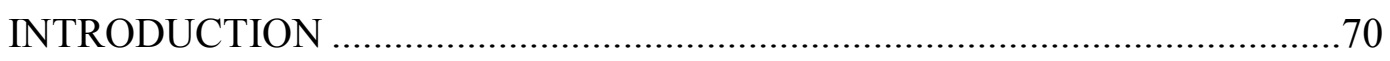

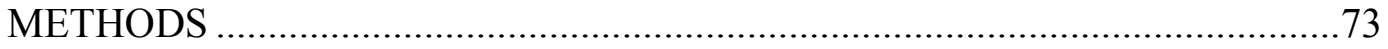

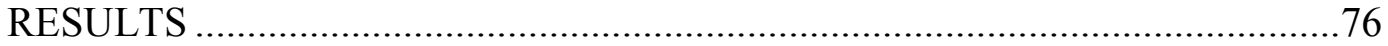

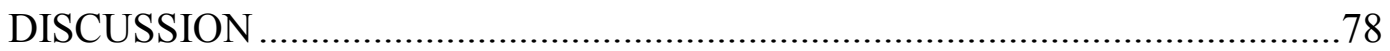

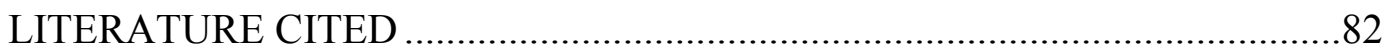

CHAPTER 4: RECOVERY OF AMPHIBIAN AND REPTILE COMMUNITIES

DURING TROPICAL SECONDARY FOREST SUCCESSION $\ldots \ldots \ldots \ldots \ldots \ldots \ldots \ldots . . . \ldots 91$

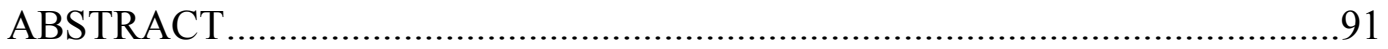

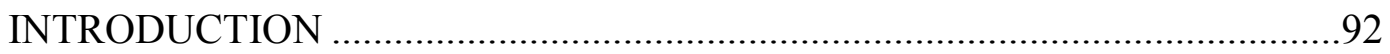

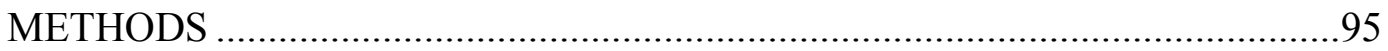

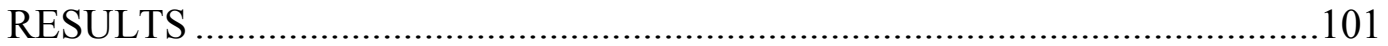

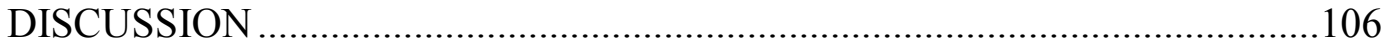

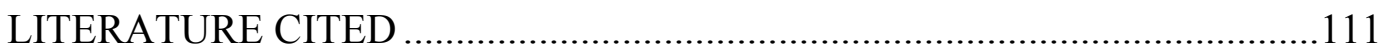

CHAPTER 5: THERMAL QUALITY INFLUENCES HABITAT USE OF TWO ANOLE SPECIES 


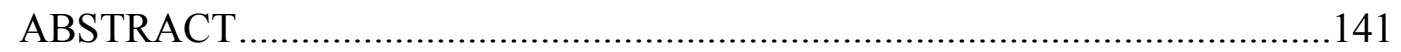

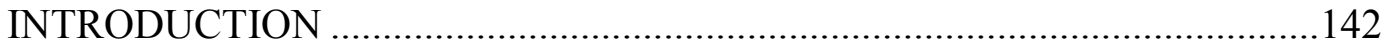

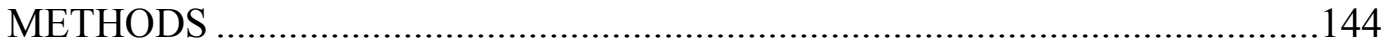

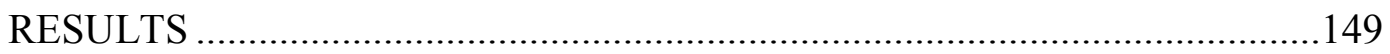

DISCUSSION ..................................................................................... 150

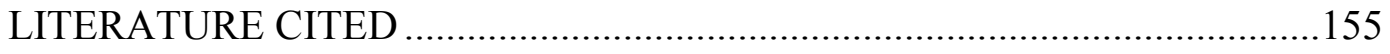

CONCLUSIONS

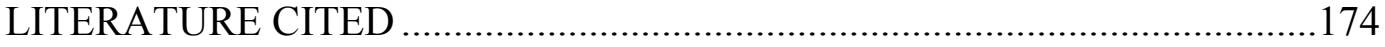

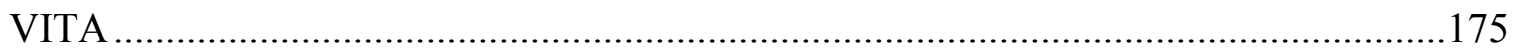




\section{LIST OF TABLES}

TABLE

PAGE

1.1. Linear model results for relationships between effect size of land use on total herpetofauna species richness and Jaccard index and proportion of generalists and disturbance specialists in the community....

3.1. Description of study sites in a) Sarapiquí and b) the Osa Peninsula, Costa Rica

3.2. Partial Mantel tests (Mantel $r$ and $p$-value) between species composition and environmental determinate (forest stage) and geographical distance for amphibians and reptiles in Sarapiquí and the Osa Peninsula using the Raup-Crick and Jaccard index.

4.1. Species presence absence matrix.

4.2. Anuran and lizard species detected during transects surveys and included in multi-species occupancy modeling with general habitat and breeding habitat categories

4.3. Anuran community and group parameter estimates (and $95 \%$ credible intervals) for covariates of probability of occurrence (psi) and probability of detection (p).

4.4. Lizard community and group parameter estimates (and $95 \%$ credible intervals) for covariates of probability of occurrence (psi) and probability of detection (p).

5.1. Mean percentage $( \pm \mathrm{SE})$ of deviations of operative temperatures above or below the preferred temperature range $\left(\mathrm{T}_{\mathrm{sel}}\right)$.

5.2. Results for model selection for occupancy of $N$. humilis and $N$. limifrons 162

5.3. Parameter estimates for probability of occurrence $(\psi)$. 


\section{LIST OF FIGURES}

FIGURE

PAGE

1.1. Three general scenarios of species composition and abundances in forest and matrix habitat when species richness is equal between habitat types (i.e., species richness effect size $=0$ )

1.2. Reported effects of different land-use types on amphibian and reptile (a) total species richness, (b) mean species richness, (c) total abundance (mean abundance for all species abundances pooled together), and (d) species-specific abundance.

1.3. Mean effect sizes (and 95\% CIs) for the effect of land use on amphibian and reptile total species richness.

1.4. Relationships between the effect size of land use on total amphibian and reptile species richness and (a) the Jaccard index and (b) the proportion of generalists and disturbance specialists in the assemblage

2.1. Map of percent of primary forest (black) and other naturally regenerated or planted forests (white) as defined by FAO (2015) by continent.

2.2. Map of study sites included in meta-analysis by country

2.3. The age distribution of forest included in 20 of the published articles included in the meta-analysis.

2.4. Published estimates of time to recovery of amphibian and reptile species richness ..66

2.5. Mean effect sizes (and 95\% CIs) for the comparison of amphibian and reptile mean species richness and mean abundance in secondary forest to old-growth forest (closed circles) and human-modified habitat (open circles).

3.1. Map of study sites in A) Sarapiquí and B) Osa Peninsula, Costa Rica..

3.2. Variance partitioning results from partial canonical correspondence analysis for amphibian and reptile community composition in Sarapiquí and the Osa Peninsula. analysis

3.3. Mean Raup-Crick dissimilarity index $( \pm 1 \mathrm{SE})$ by forest stage for amphibians and reptiles in Sarapiquí and the Osa Peninsula 
4.1. Rank abundance plots for anurans and lizards in pasture (P), secondary forest

$<16$ years old (S1), secondary forest $17-27$ years old (S2), secondary forest $>27$ years old (S3), and mature forest (MF).

4.2. Nonmetric multidimensional scaling (NMDS) ordination plots for communities of anurans and lizards..

4.3. Anuran and lizard observed (grey) and estimated (black) species richness from multispecies occupancy models at each transect in riparian and upland habitats (mean species richness $\pm 95 \%$ credible intervals).

4.4. Estimated and observed anuran species richness by transect 133

4.5. Anuran species-specific probability of occurrence in Sarapiquí

4.6. Anuran species-specific probability of occurrence in the Osa Peninsula.

4.7. Lizard species-specific probability of occurrence at sites in Sarapiquí

4.8. Lizard species-specific probability of occurrence at sites in the Osa Peninsula

4.9. Boxplots of leaf-litter measurements

4.10. Percent of vegetation structure counts at different height classes

4.11. Mean daytime (6:00 - 18:00) temperature and 95\% confidence intervals between $8-18$ October, 2014 in two pasture, secondary forest $>27$ years old, and mature forest sites in Sarapiquí......

5.1. Frequency distribution of operative temperatures in a) old growth forest, $b$ ) secondary forest, and c) pasture.

5.2. Mean $( \pm \mathrm{SE})$ thermal quality $\left(\mathrm{d}_{\mathrm{e}}\right)$ in different successional forest stages for $N$. humilis and $N$. limifrons.

5.3. Mean probability of occurrence $(\psi)$ in relation to thermal quality $\left(\mathrm{d}_{\mathrm{e}}{ }^{\circ} \mathrm{C}\right)$ for Norops humilis in (a) upland and (c) riparian habitat and Norops limifrons in (b) upland and (d) riparian habitat.

5.4. Mean probability of occurrence ( $\pm 95 \%$ credible intervals) in different successional forest stages for upland habitat (a) N. humilis and (b) N. limifrons, and riparian habitat (c) $N$. humilis and (d) N. limifrons. 


\section{INTRODUCTION}

Currently anthropogenic disturbances are unprecedented in intensity and spatial scale, affecting approximately $75 \%$ of the Earth's land surface. This humantransformation of landscapes is recognized as a primary contributing factor to the global biodiversity crisis and is expected to continue as a leading cause of biodiversity loss over the next century (Ellis and Ramankutty 2008). Within this biodiversity crisis, amphibians and reptiles are among the taxa most at risk of extinction (Vié et al. 2008). While it is known that there are multiple and synergistic causes for reported declines, habitat loss and degradation are considered primary threats to amphibians (Stuart et al. 2004, Gardner et al. 2007, Vié et al. 2008, Böhm et al. 2013).

One of most pervasive forms of habitat modification is deforestation. This complete clearing of a landscape is known to cause multiple adverse effects including disruption of nutrient and water cycles, increased erosion, and a reduction in biodiversity (Brook et al. 2003, Gibson et al. 2011). While deforestation continues to be a pressing problem, there is some hope that the negative effects caused by deforestation may be offset by secondary forests regenerating on abandoned human-altered landscapes. It is important to consider the conservation potential of secondary forests because they are currently the dominant global forest cover type, and are increasing in cover in many regions (Aide and Gau 2007, FAO 2015). It has been posed that these secondary forests may be a "safety net" for biodiversity loss (Wright and Muller-Landau 2006). However, very little is known about the conservation value of secondary forest to fauna.

The knowledge of the conservation value of secondary forest for biota has a broad and powerful application for land management and conservation. At present, 
understanding and communicating the conservation value of secondary forest is particularly pertinent in Costa Rica. Many areas are extremely fragmented as a consequence of clearing of land for pastoral and agricultural activities. The main mechanism to increase forest patch connectivity and increase forest cover is through the provisions set by the Costa Rican 1996 Forestry Law (no. 7575). Private landowners receive economic incentives to retain forest cover already present, or to reforest their land by either establishing a plantation (which then may be harvested and sold for lumber) or by allowing natural secondary forest to regrow through a payments for environmental services program (pago por servicios ambientales [PSA]). Studies that analyzed land use before and after the 1996 Forestry Law was established and that studied the law's influence on landholder decisions have shown that the Forestry Law and the payments for environmental services program were effective at promoting forest retention and forest cover gain where PSA efforts were targeted (Morse et al. 2009, Fagan et al. 2014). However, reforestation gains were mainly due to plantations. Plantation are temporary and intended for harvest, and are allowed to be converted back to other land-uses after harvest (such as agriculture), unlike natural regrowth of secondary forest which may not be cut or converted to another land use after the forest reaches a growth stage legally defined as "forest." As a consequence, there is an incentive for landholders to inhibit growth of secondary forest (Sierra and Russman 2006, Morse et al. 2009). Because of the temporal nature of plantations and permanent nature of secondary forests in providing connectivity and habitat for biota, secondary forests are thought to provide a higher value for restoration goals. However, the first question that must be answered to motivate change in policy is what is the conservation value of secondary forest? 
In this dissertation, I first use meta-analytic techniques to synthesize what is known about how amphibians and reptiles respond to habitat alteration. I then combine meta-analytic, field-survey-based, and lab-based experimental techniques to determine how amphibians and reptiles respond to secondary forest regeneration on landscapes previously cleared for use as pasture.

In Chapter 1, I conducted a review and meta-analysis on the effects of humanaltered habitat on amphibians and reptiles. I reviewed the effects of four prevalent types of habitat alteration (urbanization, agriculture, grazing, and silviculture) on amphibian and reptile species richness and abundance by summarizing reported responses in the literature and by estimating effect sizes across studies for species richness in each landuse type. I then examined variation in effect sizes for each land-use type according to habitat specialization categories (natural habitat specialists, generalists, and disturbed habitat specialists). This chapter is published in Conservation Biology.

In Chapter 2, I conducted a review and meta-analysis on the effects secondary forest succession on amphibians and reptiles. I summarized literature on mechanisms of community change during forest succession and conducted a meta-analysis to estimate effect sizes for species richness and abundance in human-modified landscapes (agriculture, pasture, and plantation) and old-growth forests compared to secondary forests. This chapter is published in Copeia.

In Chapter 3, I explore community assembly theory. The two major conceptual frameworks for community assembly are the neutral theory (stochastic viewpoint) and the niche-based theory (deterministic viewpoint). I determined the relative contribution of stochastic and deterministic processes on community assembly of amphibians and 
reptiles over the course of secondary forest succession and tested the hypothesis that harshness of environmental filter mediates the importance of stochastic and deterministic processes, using data collected in my two study regions in Costa Rica.

In Chapter 4, I analyze patterns of whole community, group-specific and speciesspecific amphibian and reptile responses to secondary forest succession. I determined differences in community measures such as evenness, composition, and species richness. I also determined the community, group-specific and species-specific responses to probability of occurrence to different forest stages along the course of secondary forest succession. I interpreted findings in relation to spatial scale, and compared trends across regions, forest stages, and habitat type (upland, riparian).

In Chapter 5, I tested for support of thermal quality as an important mechanism of species response to habitat change during forest succession using a case study of two common lizard species Norops humilis and Norops limifrons. I determined if thermal quality differs among successional forest stages and if occupancy and habitat use by lizards is associated with thermal quality. To achieve this, I combined field data and experimental approaches. I measured thermal quality as the difference between temperature available in the environment (measured with copper operative models in the field) and the preferred temperature of lizards exposed to a thermal gradient in shuttlebox experiments. I then tested to see if probability of occurrence of lizards (estimated with survey data from Chapter 4) is associated with thermal quality of habitat. 


\section{LITERATURE CITED}

Aide, T. M., and H. R.Grau. 2004. Globalization, migration, and Latin American ecosystems. Science 305:1915-1916.

Böhm M, et al. 2013. The conservation status of the world's reptiles. Biological Conservation 157:372-385.

Brook, B. W., N. S. Sodhi, and P. K. Nq. 2003. Catastrophic extinctions follow deforestation in Singapore. Nature 24:420-426.

Ellis, E. C. and N. Ramankutty .2008. Putting people in the map: anthropogenic biomes of the world. Frontiers in Ecology and the Environment 6: 439-447.

Fagan M. E., R. S. DeFries, S. E. Sesnie, J. P. Arroyo, W. Walker, C. Soto, R. L. Chazdon, A. Sanchun. 2013. Land cover dynamics following a deforestation ban in northern Costa Rica. Environmental Research Letters 8:1-9.

FAO (Food and Agriculture Organization). 2015. Global Forest Resources Assessment 2015: How are the world's forests changing? Second Edition.

Gardner TA, Barlow J, Peres CA. 2007. Paradox, presumption and pitfalls in conservation biology: The importance of habitat change for amphibians and reptiles. Biological Conservation 138:166-179.

Gibson, L., T. M. Lee, L. P. Koh, B. W. Brook, T. A. Gardner, J. Barlow, C. A. Peres, C. J. A. Bradshaw, W. F. Laurance, T. E. Lovejoy, N. S. and Sodhi. 2011. Primary forests are irreplaceable for sustaining tropical biodiversity. Nature 478:378-383.

Morse, W. C., J. L. Schedlbauer, S. E. Sesnie, B. Finegan, C. A. Harvey, S. J. Hollenhorst, K. L. Kavanagh, D. Stoian, and J. D. Wulfhorst. 2009. Consequences of environmental service payments for forest retention and recruitment in a Costa Rican biological corridor. Ecology and Society 14:23

Sierra, R., and E. Russman. 2006. On the efficiency of environmental service payments: a forest conservation assessment in the Osa Peninsula, Costa Rica. Ecological Economics 59:131-141.

Stuart SN, Chanson JS, Cox NA, Young BE, Rodrigues ASL, Fischman DL, Waller RW. 2004. Status and trends of amphibian declines and extinctions worldwide. Science 306:1783-1786. 
Vié J-C, Hilton-Taylor C, Stuart SN. (eds). 2008. The 2008 Review of The IUCN Red List of Threatened Species. IUCN Gland, Switzerland.

Wright, S. J. and H. C. Muller-Landau. 2006. The Future of Tropical Forest Species ${ }^{1}$. Biotropica, 38: 287-301. 
CHAPTER 1: THE IMPORTANCE OF DEFINING FOCAL ASSEMBLAGES WHEN EVALUATING AMPHIBIAN AND REPTILE RESPONSES TO LAND USE

\section{ABSTRACT}

Habitat loss and degradation are primary threats to amphibians and reptiles, but the relative effects of common land uses on assemblages and the mechanisms that underlie faunal responses are poorly studied. I reviewed the effects of four prevalent types of habitat alteration (urbanization, agriculture, livestock grazing, and silviculture) on amphibian and reptile species richness and abundance by summarizing reported responses in the literature and by estimating effect sizes across studies for species richness in each land-use type. I then used a multinomial model to classify species as natural habitat specialists, generalists, and disturbed habitat specialists and examined variation in effect sizes for each land-use type according to habitat specialization categories. There were mixed conclusions from individual studies, some reporting negative, neutral, or positive effects of land use on species richness and total abundance. A large proportion of studies reported species-specific effects of individual species abundance. However, in my analysis of effect sizes, I found a general trend of negative effects of land use on species richness. I also demonstrated that habitat associations of common species and species turnover can explain variation in the effect of land use on herpetofauna. My review highlights the pervasive negative effects of common land uses on amphibians and reptiles, the importance of identifying groups vulnerable to land-use change (e.g., forest-associated species) in conservation studies, and the potential influence of disturbance-associated species on whole assemblage analyses. 


\section{INTRODUCTION}

Humans have had a ubiquitous and adverse effect on Earth's biota (Ojima et al. 1994; Barnosky et al. 2012). All environments experience natural disturbances (Kaufman 1993); however, anthropogenic disturbances are unprecedented in intensity and spatial scale, affecting approximately 75\% of Earth's land surface (Cuaron 2000; Hobbs et al. 2009). Human-induced transformation of landscapes alters the Structure and function of ecosystems (Vitousek et al. 2008), is recognized as a primary contributing factor to the global biodiversity crisis (IUCN 2014), and is expected to continue as a leading cause of biodiversity loss over the next century (Sala et al. 2000; Newbold et al. 2015). However, recent literature also highlights the ability of some anthropogenic habitats to support moderate to highly diverse assemblages and suggests there are important conservation opportunities in altered landscapes (Daily et al. 2001; Bell \& Donnelly 2006; Kurz et al. 2014; Mendenhall et al. 2014). To define the circumstance under which land uses may provide some habitat value to species, it is necessary to synthesize species responses to common land uses across systems. Past studies on community response to land-use change often report complex, idiosyncratic results and weak effect sizes of species response to land-use change (this study and see reviews by Gardner et al. [2007], and Scheffers and Pazkowski [2012]). I focused on the importance of investigating species contributions to the assemblage-level response to understand and predict the conservation value of altered landscapes.

Amphibians are among the taxa most at risk of extinction; $41 \%$ of amphibian species are categorized as vulnerable, endangered, or critically endangered by the International Union for Conservation of Nature (IUCN) Red List (Wake \& Vredenburg 
2008; IUCN 2014). There is growing concern that reptiles may be declining (Gibbons et al. 2000; Böhm et al. 2013); however, a full global assessment on reptiles has yet to be completed (IUCN 2014). There are multiple and synergistic causes for reported declines (e.g., disease, climate change, habitat alteration, invasive species, pollutants, overexploitation and their interactions [reviewed by Beebee \& Griffiths 2005; Böhm et al. 2013]), but habitat loss and degradation are considered primary threats to both amphibians and reptiles (Stuart et al. 2004; Gardner et al. 2007; Vié et al. 2008; Böhm et al. 2013). The combination of recently documented declines and increasing pressure from anthropogenic habitat alteration make it imperative that existing information on faunal responses to modified habitats be synthesized to prioritize and guide conservation efforts.

The intensity of anthropogenic habitat change can range from relatively minor effects to replacement of natural systems with human-made infrastructure, such as dense urban settlements (Ellis \& Ramankutty 2008). Direct mortality of amphibians and reptiles from habitat disturbance can result from activities related to land modification and road use (Fahrig et al. 1995; Carr \& Fahrig 2001; Gibbs \& Shriver 2002; Row et al. 2007), conflict with humans [e.g., killing of venomous species for safety reasons (Speake \& Mount 1973; Shine \& Koenig 2006)], and pollutants (which can also affect animals indirectly [reviewed by Mann et al. 2009]). Habitat alteration can influence multiple facets of the environment inhabited by amphibians and reptiles through changes in vegetation structure (Lillywhite \& North 1974; Allen \& Bartolome 1989; Belsky \& Blumenthal 2002; Thompson et al. 2003) thermal environment (Hossack \& Corn 2007), food sources (Hellgren et al. 2010), and biotic interactions (Wilgers \& Horne 2007). Habitat alteration can also have genetic consequences such as change of selection 
pressures (Franssen 2011) and changing patterns of gene flow (Spear \& Storfer 2010; Nowakowski et al. 2015).

Previous reviews on the effects of habitat alteration on amphibians and reptiles commonly report highly inconsistent results among studies, indicating there are sources of variation that inhibit the ability to draw conclusions about the effects of habitat alteration (this study and reviews by Gardner et al. [2007] and Scheffers and Pazkowski [2012]). My overall objective was to identify common responses in species richness and abundance and to evaluate potential sources of variation in responses of species and assemblages to habitat alteration. I hypothesized that variable levels of habitat specialization of constituent species among assemblages is a major source of noise in assemblage-level analyses and contributes to species-specific responses to habitat alteration. I synthesized the literature by tallying results reported across individual studies that examined effects of four prevalent land-use types (urbanization, agriculture, grazing, and silviculture [selective logging, clearcut logging, plantations]) on abundance and species richness of amphibians and reptiles. I re-analyzed published data sets with metaanalytic summary statistics to determine mean responses of assemblages to land uses as well as the contributions of subsets of the assemblages to overall effect sizes (i.e., natural habitat specialists, generalists, and disturbed habitat specialists). I then re-analyzed case studies for which independent species abundance data were available for classifying species to determine whether the inclusion of disturbed-habitat specialists in analyses modifies overall effect sizes. Finally, I analyzed species-richness effect sizes to determine whether habitat associations of constituent species and species turnover explain interstudy variation in effect size. 
The last analysis allowed me to determine potential assemblage characteristics underlying species richness effects (Figure 1.1). For example, community composition can be described by three general scenarios when species richness is the same in forest and adjacent land use: there is spillover of forest specialists into adjacent land uses that results in little or no species turnover; there are forest specialists, Generalists, and disturbance associated species that occur in both habitats to varying degrees, or there is high species turnover between habitats from assemblages dominated by forest specialists to disturbance-associated species in altered habitats. To date, there is no published example of a consolidated, global synthesis of the literature on the effects of urbanization, pasture, agriculture, and silviculture (i.e., prevalent land-use types) on the abundance and species richness of amphibians and reptiles. My global data set of 132 studies includes research conducted across geographic locations (31 countries) and different land-cover types (from grassland to tropical rainforest). Therefore, trends identified in my analyses are robust and provide a valuable synthesis of the processes behind amphibian and reptile response to land-use change and the conservation value of these altered landscapes.

\section{METHODS}

\section{Literature Search}

I addressed both amphibian and reptile responses to land use because these taxonomic groups exhibit some physiological (e.g., ectothermy) similarities, frequently occupy similar niches (e.g., insectivores occurring in leaf litter microhabitat), and are commonly 
studied together. However, because of their distinct evolutionary histories and biological differences, I analyzed these groups separately unless otherwise indicated.

I searched the databases Thompson ISI Web of Knowledge and BIOSIS (all years through 2013) for keywords herpetofauna or amphibian* or reptile*, in combination with urbanization, urban, logging, silviculture, agriculture, crops, grazing, pasture, habitat disturbance, habitat alteration, habitat destruction, habitat fragmentation, plantation, or matrix. Additionally, I searched in the literature cited section of relevant papers found through the database search. All studies that compared altered habitat with a control (either unaltered reference habitat or a before plot) or that evaluated the effects of habitat alteration along a landscape gradient using richness or abundance were included in my quantitative summary. I excluded studies specifically focused on habitat fragmentation that did not report richness or abundance in altered habitats (i.e., the land-use matrix) and studies solely concentrated on secondary forest regeneration.

\section{Reported Responses to Land Use}

I tallied the results of 132 studies and focused on summarizing four commonly reported response variables: total richness, the total number of species summed across replicates of disturbed habitat (urbanization, agriculture, grazing, and silviculture) relative to natural habitat; mean richness, the mean number of species across replicates in the matrix relative to natural habitat; total abundance, the mean abundance across replicates of all amphibian or reptile species found in matrix relative to natural habitat; and individual species abundance, the mean abundance of individual species in matrix relative to natural habitat. I summarized data for amphibians and reptiles separately. 
On the basis of the analyses conducted by the original authors or by calculating parameters with data provided in publications, I categorized the results of each study as follows: decrease (parameter was lower in the matrix than in control), increase (parameter was higher in the matrix than in control), no effect (no difference between control and matrix), or mixed (results depended on categorization within the study). A study was categorized as mixed if the result depended on heterogeneity within a given land-use type (e.g., coffee cultivation categorized as shade-grown vs. nonshade grown) or if significant results were detected one year but not all years of the study and insufficient information was provided to determine an overall effect across years. For individual species abundance, the category species-specific indicated abundances of some species in a study significantly increased or decreased in the matrix, but not all species followed the same trend. For mean species richness, total abundance, and individual species abundance, I used a threshold of $p=0.05$ to determine significance.

\section{Species Habitat Preferences}

Because I was interested in the degree to which disturbance-associated and generalist species influence effect sizes for whole assemblages, I categorized species into four groups (natural habitat specialists, disturbed habitat specialists, generalists, and species too rare to classify). To classify species, I used the program CLAM, which employs a multinomial model to categorize species on the basis of their relative abundances in two habitat types. I used the recommended parameters for analyzing a community of species: a significance threshold of $p=0.005$ and a supermajority classification threshold of 0.667 (Chao \& Lin 2011; Chazdon et al. 2011). 


\section{Effect Sizes}

I calculated mean effect sizes for each comparison of species richness in natural habitat with that in a given land use for studies that provided data tables in the published article or in online appendices (39 studies). To estimate the effect size of matrix type on total species richness, I calculated the natural $\log$ of the response ratio, $R R=\ln$ (total species

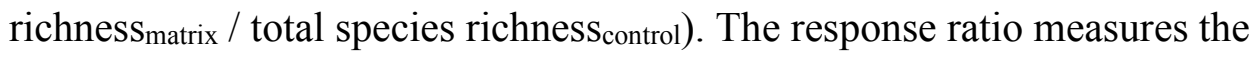
proportionate change in the experimental group relative to the control group and is a common measure of effect size in ecological studies and meta-analyses (Hedges et al. 1999). I report the mean and $95 \% \mathrm{CI}$ across studies to estimate overall effect sizes for the whole assemblage. I also estimated group-specific effect sizes in addition to the effect size for the whole fauna. A response ratio $<0$ can be interpreted as the matrix having a negative effect on total species richness, and a response ratio $>0$ can be interpreted as the matrix having a positive effect on total species richness relative to the control. Mean effect sizes were considered significant when the confidence interval did not include zero. I was unable to analyze effect sizes for studies on the effects of urbanization because of a lack of studies that provided adequate data for analysis. I used total richness for this analysis because that was the metric most consistently available that would allow calculation of both whole fauna and group-specific effect sizes. Because habitat preference was classified using relative abundance data in each habitat from the same study, there is potential for non-independence of abundance and species richness responses; however, my objective was to examine the contribution of different groups to the overall effect size rather than to make ecological inferences. 


\section{Case Studies}

A number of ecological studies support the contentions that species are not equally sensitive to environmental change and that ecological specialization contributes to extinction risk and sensitivity to change (Colles et al. 2009). Natural habitat specialists (i.e., forest specialists) are typically of greater conservation concern than disturbanceassociated species (Rubbo \& Kiesecker 2005; Gardner et al. 2007). Because I was interested in how generalist and disturbance-associated species affect whole assemblage analyses, I further analyzed the contribution of generalists and disturbed habitat specialists to whole-assemblage responses to land uses. I examined studies for which independent data were available for classifying species habitat preferences $(n=6)$. Independent data were obtained from studies conducted by different authors but in the same region or with overlapping suites of species. I calculated the difference in response ratios between the original data set and a data set where independently classified generalists and disturbed habitat specialists were excluded from the analysis.

\section{Variation in Effect Sizes}

I analyzed species richness effect sizes to determine whether species turnover and species-habitat associations could explain interstudy variation. I used linear models to analyze the effects of species turnover between natural and disturbed habitat (agriculture, pasture, and silviculture). I measured turnover with the Jaccard index, a widely used community similarity index that represents the proportion of the total number of observed species in a study present in both natural and altered habitats (Magurran 2004). I combined amphibians and reptiles in this analysis to obtain adequate sample sizes for 
linear models. I also fit models using the proportion of total species in a study classified as generalists and disturbance-associated as an explanatory variable. Because of the curvilinear relationship between effect sizes and turnover or habitat associations in pastures, I fit these models with a second-order polynomial. These analyses allowed me to evaluate the applicability of three general scenarios underlying differences in richness as effect sizes approach zero (Figure 1.1). All statistical analyses were performed using R statistical software (R Core Development Team 2013).

\section{RESULTS}

Of the 132 studies that analyzed amphibian or reptile species richness and abundance and were tallied in my review, 33 studies reported on effects of agriculture, 36 on effects of pasture, 24 on effects of urbanization, and 55 on effects of silviculture. I found almost twice as many studies for amphibians $(n=98)$ than reptiles $(n=50)$.

\section{Reported Response to Land Use}

Overall, studies reported a range of amphibian and reptile responses to habitat alteration. However, the majority of the studies reported either a decrease or no effect of habitat alteration on richness and abundance of amphibians and reptiles (Figure 1.2). Of the different types of response variables, I found the highest proportion of negative responses to habitat alteration when examining total species richness. With the exception of selective logging and clearcut studies, at least $50 \%$ of studies in each category reported a negative effect of change in land use on total species richness (Figure 1.2a). For the summary of reported results on mean species richness, the majority of studies did not find 
a statistically significant effect of habitat alteration (Figure 1.2b). A high proportion of studies that included multiple species reported species-specific effects of habitat alteration on individual species abundance (77\% of studies on amphibians, $96 \%$ of studies on reptiles). Of the land-use types examined, studies on urbanization most consistently reported negative effects of land use on species richness and abundance and studies on selective logging reported negative effects least frequently (Figure 1.2).

\section{Variation in Effect Sizes}

In general, habitat alteration had a negative effect on species richness of whole assemblages; results were significant for reptiles in agriculture and for amphibians in agriculture and pastures (Figure 2.2). I found that analyzing specific groups, defined by habitat preference, can alter the magnitude and direction of the effect of matrix habitat on species richness. Specifically, natural habitat specialists and species too rare to classify typically exhibited negative responses to matrix habitat, whereas disturbanceassociated species typically exhibited positive responses (Figure 2.2). For case studies, $67 \%$ of studies $(n=6)$ had a negative change in effect size calculated from abundance data. For species richness, 33\% of studies $(n=6)$ had a negative change in effect size when generalists and disturbed habitat specialists were removed from the analysis. However, the magnitude of change in effect size varied considerably among studies.

The relationship between effect size and both community similarity and proportion of species that were classified as generalists or disturbance associated depended on land-use type (Figure 1.4). For agriculture and pasture, the proportion of 
generalist and disturbance-associated species and the magnitude of the effect of land use on total species richness were negatively associated. Additionally, the magnitude of the effect size decreased as community similarity increased. However, I did not find similar trends for silviculture (Figure 1.4). Species turnover and habitat associations were significant predictors of effect size for pasture data sets $(p<0.001)$ (Table 1.1), but not for silviculture or agriculture.

\section{DISCUSSION}

Conversion of natural habitats to human land uses will continue to drive species declines and extinctions over the next century. Current reserve networks are not sufficient to protect many species (Rosenzweig 2003; Whitfield et al. 2007; Laurance et al. 2012), and there is a need to develop effective conservation strategies in the context of land use. Syntheses of existing literature can help identify generalized responses to Globally predominant land-use types (Newbold et al. 2015). A better understanding of the sources of variation in faunal responses to land-use effects and species contributions to assemblage-level responses is critical for the improvement of conservation strategies. Even when communities exhibit weak responses to habitat alteration, there may be notable group-level or species-specific responses (Figure 1.3). My results suggest that habitat specialization of constituent species can be an important factor modifying assemblage-level effects of altered habitats. 


\section{Reported Responses and Reanalysis of Effect Sizes}

In my summary of reported responses of amphibians and reptile to land use, I found overall mixed conclusions from individual studies, some showing negative, neutral, or positive effects of the matrix (Figure 1.2). Forty-one percent of studies that reported community-level mean richness responses found no significant effect. However, $88 \%$ of studies did report significant species-level abundance responses (at least one species in the study had significantly different abundance in control verses altered habitat). My review highlights that important underlying species-specific and group-specific responses can be overlooked when only the whole-assemblage response is considered. Therefore, caution should be used when concluding that a given land use can support high diversity when studies report no significant difference in richness between natural and altered habitats. Considerable species turnover and loss of phylogenetic diversity in altered habitats can underlie similar levels of observed species richness (Frishkoff et al. 2014).

By analyzing effect sizes calculated from published data, I found salient assemblage-level responses of amphibians and reptiles to human land use. I found significant losses of species in agricultural and pastoral systems and nonsignificant loss of species in silvicultural systems when summarized at the whole assemblage level across studies. My results for species richness are consistent with a recent meta-analysis of five studies of herpetofaunal abundances in that the effect size for the silvicultural category did not differ from zero (Newbold et al. 2015). The difference in magnitude of effect between agricultural and silvicultural land uses may be attributable to consistently weak effects of silviculture, which could in turn reflect greater similarity 
of logged forest and plantations to undisturbed forest in habitat structure than to cultivated fields. Alternatively, variation in sampling methods and silvicultural practices among studies could have contributed to a weaker grand effect size than observed for agricultural systems.

\section{Variation in Assemblage-Level Responses}

Studies that analyze whole assemblages may be subject to noise introduced when disturbance-associated species are included in the data set. Specialists of disturbed areas may dampen observed effects for whole assemblages (Figure 1.3). Because conservation actions will likely target rare species and natural-habitat-associated species such as forest specialists, I re-analyzed these data sets and examined effect sizes separately for forest and matrix specialists and habitat generalists (Figure 1.3). Specific groups, defined by habitat preference, altered the magnitude and direction of the effect of the matrix. Species that were too rare to classify in terms of their habitat preference exhibited the strongest negative response to agriculture and pastures in amphibians. This result suggests that relatively less common amphibian species are most sensitive to habitat modification. In my case study analysis, I observed changes in the magnitude of effect size when matrix specialists and generalists were removed from analysis of abundance and species richness for some studies. Although changes in effect size were not consistent across case studies, I recommend examining sensitivity of results to removal of generalists and matrix specialists, especially when the objective of the study is to draw inferences relevant to conservation of species dependent on natural habitats. 
Many studies that I reviewed (62\%) reported no significant effect of land use on mean species richness (Fig. 1). Similar species richness in altered and natural habitats can result from several scenarios. For example, observed richness can be equal when there is spillover of forest specialists that occasionally use the matrix, when both habitats support a mixture of forest specialists, generalists, and disturbance-associated species (little or no turnover may be observed in this scenario) or when there is considerable species turnover between habitats from forest specialist to disturbance-associated species (Figure 1.1). In my analysis of pasture and agriculture studies, the magnitude of effect size generally decreased as proportion of habitat generalist and disturbance-associated species increased and as community similarity between habitats increased (Figure 1.3). My results suggest that in studies with weak species richness effects, both natural and disturbed areas tended to support a mixture of generalist and specialist species that use each habitat type to varying degrees (Figure 1.3; Figure 1.1).

\section{Opportunities for Conservation in Human-Altered Systems}

My results corroborate existing literature that suggests certain land uses may be less detrimental to amphibians and reptiles than others (Kurz et al. 2014; Mendenhall et al. 2014). Land uses that generally support high levels of species richness in comparison with forest potentially present opportunities to increase connectivity and buffer existing habitat reserves through incentive programs in altered landscapes (e.g., Morse et al. 2009). According to my analysis of effect size, timber extraction and tree plantations did not significantly lower species richness in comparison with forest habitats. Programs, such as payments for environmental services, that promote conversion of pastures and 
other land uses to tree plantations can be effective in maintaining tree cover within proposed biological corridors, which are often composed of patchworks of reserve networks and human land uses (e.g., Fagan et al. 2013).

However, the potential to effectively rank and prioritize specific land uses for conservation planning according to their value as habitat for wildlife depends on filling several important deficiencies in the literature. First, many studies of assemblages in altered habitats (including those reviewed here) have examined relative abundances and species richness as the primary response types. However, metrics that account for the composition and phylogenetic distinctness of assemblages are used less often and may complement information on relative abundance and species richness (Frishkoff et al. 2014).

Second, high abundances and diversity of species in altered habitats does not necessarily indicate those habitats are capable of supporting stable communities into the future. Long-term studies are needed in altered habitats that evaluate population dynamics and trajectories. Populations in altered habitats can often be sinks that are in decline (i.e., experiencing extinction debt [Tilman et al. 1994]). Time since disturbance and timing and duration of assessment can affect results. For example, several silviculture studies conducted in stands of different ages show mixed results that depend on time since logging activities (Ash 1997; Herbeck \& Larsen 1999; Crawford \& Semlitsch 2008).

Third, my meta-analysis, constrained by data availability, focused on coarse landuse categories. Within each category, there exists variation in management practices and intensities. For example, I did not find strong support for a negative effect of silviculture 
on amphibian and reptile species richness. However, $38 \%$ of studies reported a negative effect of silviculture on species abundance, richness, or both (Fig. 1). The finding of weak support of a negative effect of silviculture on herpetofauna species richness may result from grouping studies that span a range of silvicultural practices (e.g., clearcut forestry and selective logging).

Finally, presence of remnant vegetation (e.g., individual trees or riparian strips) within a given land use can modify the ability of that land use to support biodiversity (Karp et al. 2013; Robinson et al. 2013). Describing the degree to which remnant vegetation modifies faunal responses across systems will prove important, but difficult, because these landscape elements are often missed with remote sensing (Mendenhall et al. 2014).

Human impacts on the environment are extensive, expanding (Ojima et al. 1994), and creating novel environments that modify the structure and composition of remnant assemblages at the landscape scale (Bell \& Donnelly 2006; Karp et al. 2013; Kurz et al. 2014; Mendenhall et al. 2014). Amphibians and reptiles are historically less well studied than other vertebrates (Gardner et al. 2007), and given the extent of human impacts, further research is needed on the generality and underlying mechanisms of habitat alteration effects on herpetofauna. Continued habitat loss and expansion of agricultural and urban land uses in the coming years will likely continue to shift species composition toward communities dominated by generalist and disturbance-associated species. I therefore urge conservation researchers and practitioners to carefully define and examine focal assemblages for conservation studies and planning. Analyzing whole assemblages can be useful in assessing broad effects of habitat alteration, but care should be taken in 
making sweeping conclusions about the ability of land uses to support biodiversity and maintain ecosystem services on the basis of combined results. My analyses show that differences in species richness between natural and disturbed habitats can be influenced by species turnover and the proportion of generalist and disturbance-associated species. My results suggest that similar levels of species richness often mask changes in species composition and relative abundances between natural and disturbed habitats.

Ideally, conservation resources will be targeted toward natural habitat-dependent species that are most threatened by land-use change.

\section{LITERATURE CITED}

Allen BH, Bartolome JW. 1989. Cattle grazing effects on understory cover and tree growth in mixed conifer clearcuts. Northwest Science 63:214-220.

Ash AN. 1997. Disappearance and return of Plethodontid salamanders to clearcut plots in the Southern Blue Ridge Mountains. Conservation Biology 11:983-989.

Barnosky AD, et al. 2012. Approaching a state shift in Earth's biosphere. Nature 486:5258.

Beebee TJC, Griffiths RA. 2005. The amphibian decline crisis: A watershed for conservation biology? Biological Conservation 125:271- 285.

Bell KE, Donnelly MA. 2006. Influence of forest on community structure of frogs and lizards in northeastern Costa Rica. Conservation Biology 20:1750-1760.

Belsky A, Blumenthal D. 2002. Effects of livestock grazing on stand dynamics and soils in upland forests of the Interior West. Conservation Biology 11:315-327.

Böhm M, et al. 2013. The conservation status of the world's reptiles. Biological Conservation 157:372-385.

Carr LW, Fahrig L. 2001. Effect of road traffic on two amphibian species of differing vagility. Conservation Biology 15:1071-1078.

Chao A, Lin SY. 2011. Program CLAM (Classification Method). Program and user's guide. Available from http://purl.oclc.org/clam (accessed February 2015). 
Chazdon RL, Chao A, Colwell RK, Lin S-Y, Norden N, Letcher SG, Clark DB, Finegan B, Arroyo JP. 2011. A novel statistical method for classifying habitat generalists and specialists. Ecology 92:1332-1343.

Colles A, Liow LH, Prinzing A. 2009. Are specialists at risk under environmental change? Neoecological, paleoecological and phylogenetic approaches. Ecology Letters 12:849-863.

Crawford JA, Semlitsch RD. 2008. Post-disturbance effects of even aged timber harvest on stream salamanders in southern Appalachian forests. Animal Conservation 11:369-376. Cuaron AD. 2000.

Global perspective on habitat disturbance and tropical rainforest mammals. Conservation Biology 14:1574-1579.

Daily GC, Ehrlich PR, Sanchez-Azofeifa A. 2001. Countryside biogeography: use of human-dominated habitats by the avifauna of southern. Costa Rica 11:1-13.

Ellis EC, Ramankutty N. 2008. Putting people in the map: anthropogenic biomes of the world. Frontiers in Ecology and the Environment 6:439-447.

Fagan ME, DeFries RS, Sesnie SE, Arroyo JP,WalkerW, Soto C, Chazdon RL, Sanchun A. 2013. Land cover dynamics following a deforestation ban in northern Costa Rica. Environmental Research Letters 8:1-9.

Fahrig L, Pedlar JH, Pope SE, Taylor PD, Wegner JF. 1995. Effect of road traffic on amphibian density. Biological Conservation 73:177-182.

Franssen NR. 2011. Anthropogenic habitat alteration induces rapid morphological divergence in a native stream fish. Evolutionary Applications 4:791-804.

Frishkoff LO, Karp DS, M'Gonigle LK, Mendenhall CD, Zook J, Kremen C, Hadly EA, Daily GC. 2014. Loss of avian phylogenetic diversity in neotropical agricultural systems. Science 345:1343-1346.

Gardner TA, Barlow J, Peres CA. 2007. Paradox, presumption and pitfalls in conservation biology: the importance of habitat change for amphibians and reptiles. Biological Conservation 138:166-179.

Gibbons JW, et al. 2000. The global decline of reptiles, déjà vu amphibians. BioScience 50:653-666. Gibbs JP, Shriver WG. 2002. Estimating the effects of road mortality on turtle populations. Conservation Biology 16:1647-1652. 
Hedges LV, Gurevitch J, Curtis PS. 1999. The meta-analysis of response ratios in experimental ecology. Ecology 80:1150-1156.

Hellgren EC, Burrow AL, Kazmaier RT, Ruthven DC. 2010. The effects of winter burning and grazing on resources and survival of Texas Horned Lizards in a thornscrub ecosystem. Journal of Wildlife Management 74:300-309.

Herbeck LA, Larsen DR. 1999. Plethodontid salamander response to silvicultural practices in Missouri Ozark Forests. Conservation Biology 13:623-632.

Hobbs RJ, Higgs E, Harris JA. 2009. Novel ecosystems: implications for conservation and restoration. Trends in Ecology \& Evolution 24:599-605.

Hossack BR, Corn PS. 2007. Responses of pond-breeding amphibians to wildfire: shortterm patterns in occupancy and colonization. Ecological Applications 17:14031410 .

IUCN (International Union for Conservation of Nature). 2014. The IUCN red list of threatened species. Version 2014.3. IUCN, Gland, Switzerland. Available from http://www.iucnredlist.org (accessed February 2015).

Karp DS, Mendenhall CD, Sand'1 RF, Ehrlich PR, Hadly EA, Daily GC. 2013. Forest bolsters bird abundance, pest control, and coffee yield. Ecology Letters 16:13391347.

Kaufman LS. 1993. Why the ark is sinking. Pages 1-46 in Kaufman LS, Mallory K, editors. The Last Extinction. 2nd edition. MIT Press, Cambridge, MA.

Kurz DJ, Nowakowski AJ, Tingly MW, Donnelly MA, Wilcove DS. 2014. Forest-land use complementarity modifies community structure of tropical: herpetofauna. Biological Conservation 170:246-255.

Laurance WF, et al. 2012. Averting biodiversity collapse in tropical forest protected areas. Nature 489:290-294. Lillywhite HB, North F. 1974. Perching behavior of Sceloporus occidentalis in recently burned chaparral. Copeia 256-257.

Magurran AE. 2004. Measuring biological diversity. Blackwell Publishing, Oxford, United Kingdom.

Mann RM, Hyne RV, Choung CB, Wilson SP. 2009. Amphibians and agricultural chemicals: review of the risks in a complex environment. Environmental Pollution 157:2903-2927. 
Mendenhall C, Frishkoff L, Santos-Barrera G, Pacheco J, Mesfun E, Mendoza-Quijano F, Ehrlich PR, Ceballos G, Daily G, Pringle RM. 2014. Countryside biogeography of neotropical reptiles and amphibians. Ecology 95:856-870.

Morse WC, Schedlbauer JL, Sesnie SE, Finegan B, Harvey CA, Hollenhorst SJ, Kavanagh KL, Stoian D, Wulfhorst JD. 2009. Consequences of environmental service payments for forest retention and recruitment in a Costa Rican biological corridor. Ecology and Society 14:23.

Newbold T, et al. 2015. Global effects of land use on local terrestrial biodiversity. Nature 520: $45-50$.

Nowakowski AJ, DeWoody JA, Fagan ME, Willoughby JR, Donnelly MA. 2015. Mechanistic insights into landscape genetic structure of two tropical amphibians using field-derived resistance surfaces. Molecular Ecology 24:580-595.

Ojima DS, Galvin KA, Turner BL II. 1994. The global impact of land-use change. BioScience 44:300-304.

R Core Development Team. 2013. R: a language and environment for statistical computing. R Foundation for Statistical Computing, Vienna.

Robinson D, Warmsley A, Nowakowski AJ, Reider KE, Donnelly MA. 2013. The value of remnant trees in pastures for a neotropical poison frog. Journal of Tropical Ecology 29:345-352.

Rosenzweig ML. 2003. Reconciliation ecology and the future of species diversity. Oryx 37:194-205.

Row JR, Blouin-Demers G,Weatherhead PJ. 2007. Demographic effects of road mortality in black ratsnakes (Elaphe obsoleta). Biological Conservation 137:117-124.

Rubbo MJ, Kiesecker JM. 2005. Amphibian breeding distribution in an urbanized landscape. Conservation Biology 19:504-511.

Sala OE, et al. 2000. Global biodiversity scenarios for the year 2100. Science 287:17701774 .

Scheffers BR, Paszowski CA. 2012. The effects of urbanization on North American amphibian species: identifying new directions for urban conservation. Urban Ecosystems 15:133-147.

Shine R, Koenig J. 2006. Snakes in the garden: an analysis of reptiles "rescued" by community-based wildlife carers. Biological Conservation 102:271-283. 
Speake D, Mount R. 1973. Some possible ecological effects of rattlesnake roundups in the southeastern coastal plain. Pages 267-277 in the Proceedings of the annual conference. Southeastern Association of Game and Fish Commissioners, Columbia, SC.

Stuart SN, Chanson JS, Cox NA, Young BE, Rodrigues ASL, Fischman DL, Waller RW. 2004. Status and trends of amphibian declines and extinctions worldwide. Science 306: $1783-1786$.

Spear SF, Storfer A. 2010. Anthropogenic and natural disturbance lead to differing patterns of gene flow in the Rocky Mountain tailed frog, Ascaphus montanus. Biological Conservation 143:778- 786.

Thompson ID, Baker JA, Ter-Mikaelian M. 2003. A review of the long-term effects of post-harvest silviculture on vertebrate wildlife, and predictive models, with an emphasis on boreal forests in Ontario, Canada. Forest Ecology and Management 177:441- 469 .

Tilman D, May RM, Lehman CL, Nowak MA. 1994. Habitat destruction and the extinction debt. Nature 371:65-66.

Vié J-C, Hilton-Taylor C, Stuart SN, editors. 2008. The 2008 review of the IUCN Red List of Threatened Species. IUCN, Gland, Switzerland. Vitousek PM, Mooney HA, Lubchen J, Melillo JM. 2008. Human domination of Earth's ecosystems 277:494-499.

Wake DB, Vredenburg VT. 2008. Are we in the midst of the sixth mass extinction? A view from the world of amphibians. Proceedings of the National Academy of Sciences 105:11466-11473.

Whitfield SM, Bell KE, Philippi T, Sasa M, Bola nos F, Chaves G, Savage JM, Donnelly MA. 2007. Amphibian and reptile declines over 35 years at La Selva, Costa Rica. Proceedings of the National Academy of Sciences 104:8352-8356.

Wilgers DJ, Horne EA. 2007. Spatial variation in predation attempts on artificial snakes in a fire-disturbed tallgrass prairie. The Southwestern Naturalist 52:263-270. 
Table 1.1 Linear model results for relationships between effect size of land use on total herpetofauna species richness and Jaccard index and proportion of generalists and disturbance specialists in the community

\begin{tabular}{|c|c|c|c|c|}
\hline Model & Estimate & SE & $\mathbf{R}^{2}$ & $\mathbf{P}$ \\
\hline \multicolumn{5}{|l|}{ Agriculture } \\
\hline Jaccard & 0.631 & 0.4703 & 0.141 & 0.2068 \\
\hline Proportion Gen+MS & 0.5375 & 0.4712 & 0.106 & 0.2782 \\
\hline \multicolumn{5}{|l|}{ Pasture } \\
\hline Jaccard & 4.8028 & 0.8983 & 0.764 & $0.0001 *$ \\
\hline Jaccard $^{2}$ & -3.1392 & 0.805 & - & $0.0016 *$ \\
\hline Proportion Gen+MS & 6.778 & 1.351 & 0.689 & $0.0002 *$ \\
\hline Proportion Gen+MS ${ }^{2}$ & -6.519 & 1.586 & - & $0.0011 *$ \\
\hline \multicolumn{5}{|l|}{ Silviculture } \\
\hline Jaccard & 0.0889 & 0.3548 & 0.004 & 0.806 \\
\hline Proportion Gen+MS & 0.1002 & 0.4173 & 0.004 & 0.813 \\
\hline
\end{tabular}




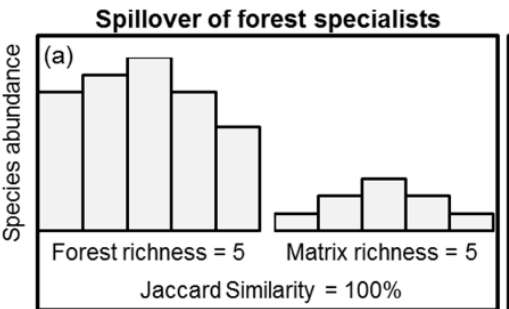

Shared generalists and specialists

Turnover from forest to matrix specialists
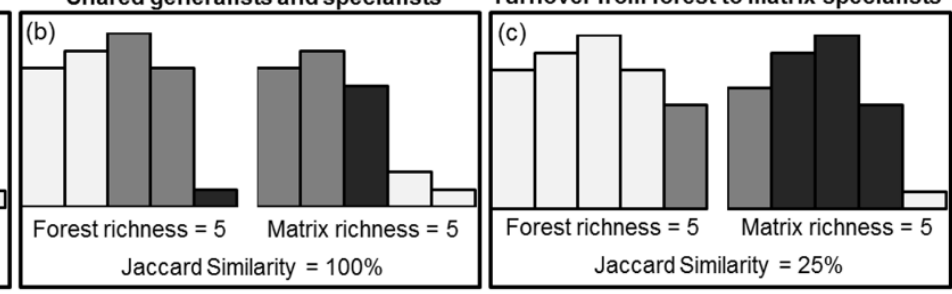

Figure 1.1. Three general scenarios of species composition and abundances in forest and matrix habitat when species richness is equal between habitat types (i.e., species richness effect size $=0$ ). a) Species richness may be equal when there is spillover of forest specialists that occasionally use matrix habitat; in this scenario there is no species turnover between habitats (i.e., Jaccard index $=100 \%$ ). b) Habitats may support a mixture of forest specialists (white), generalists (light grey), and disturbance-associated species (dark-grey) that use both habitats to varying degrees; little or no turnover may be observed in this scenario. c) Species richness can also be equal when there is considerable turnover between habitats from forest specialist to disturbance-associated species (i.e., Jaccard index $<100 \%$ ). 


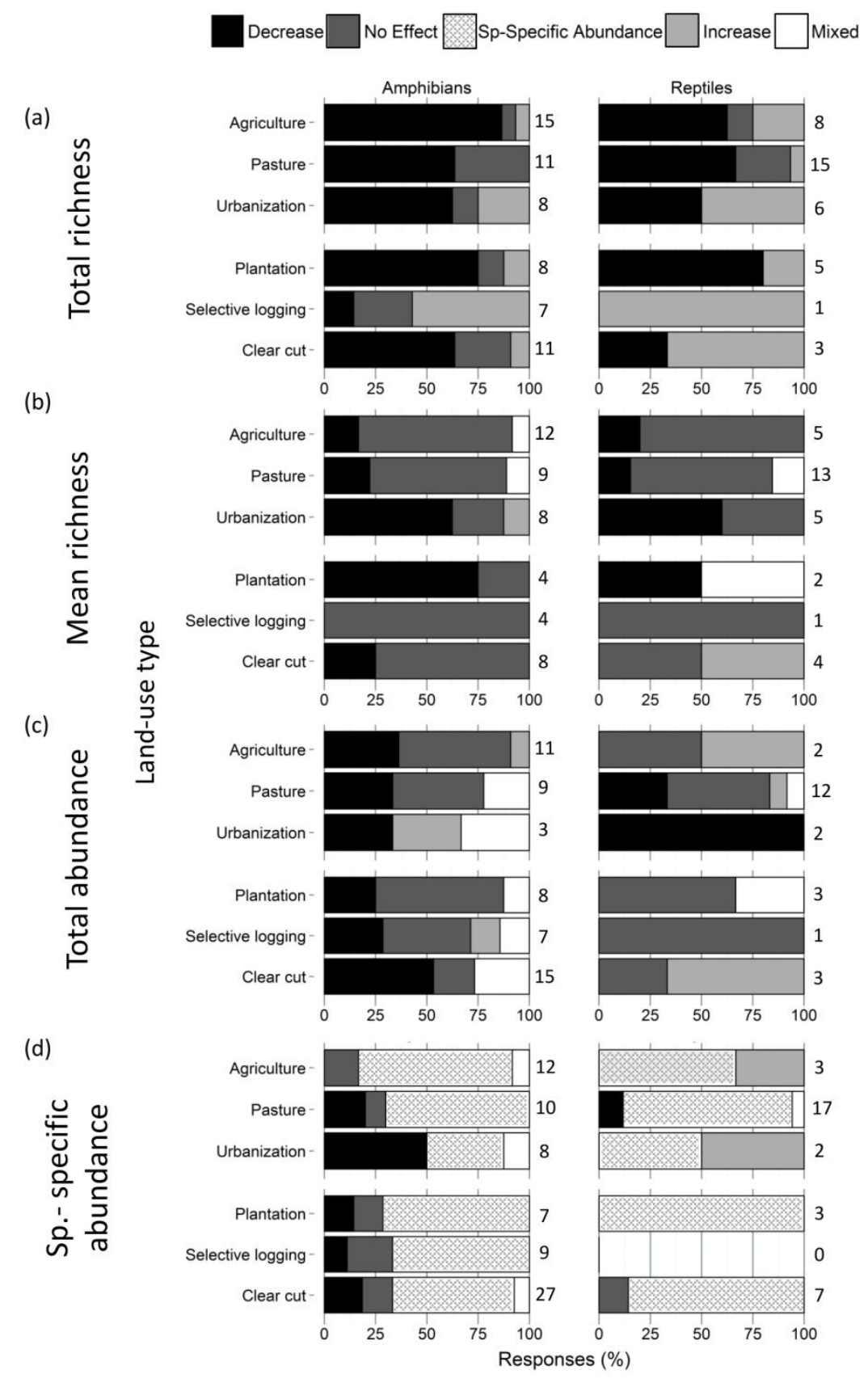

Figure 1.2. Reported effects of different land-use types on amphibian and reptile (a) total species richness, (b) mean species richness, (c) total abundance (mean abundance for all species abundances pooled together), and (d) species-specific abundance. Reported effects were decrease (parameter was lower in the matrix than in control), increase (parameter was higher in the matrix than in control), no effect (no difference between control and matrix), and mixed (results depended on categorization within the 
study). For individual species abundance, the category species-specific refers to cases in which some species significantly increased and some decreased or did not change in the matrix but not all species followed the same trend within the same study. For mean species richness, total abundance, and individual species abundance, I used a threshold of $p=0.05$ to determine significance. The number of studies summarized in each category is shown to the right of each percent bar. 


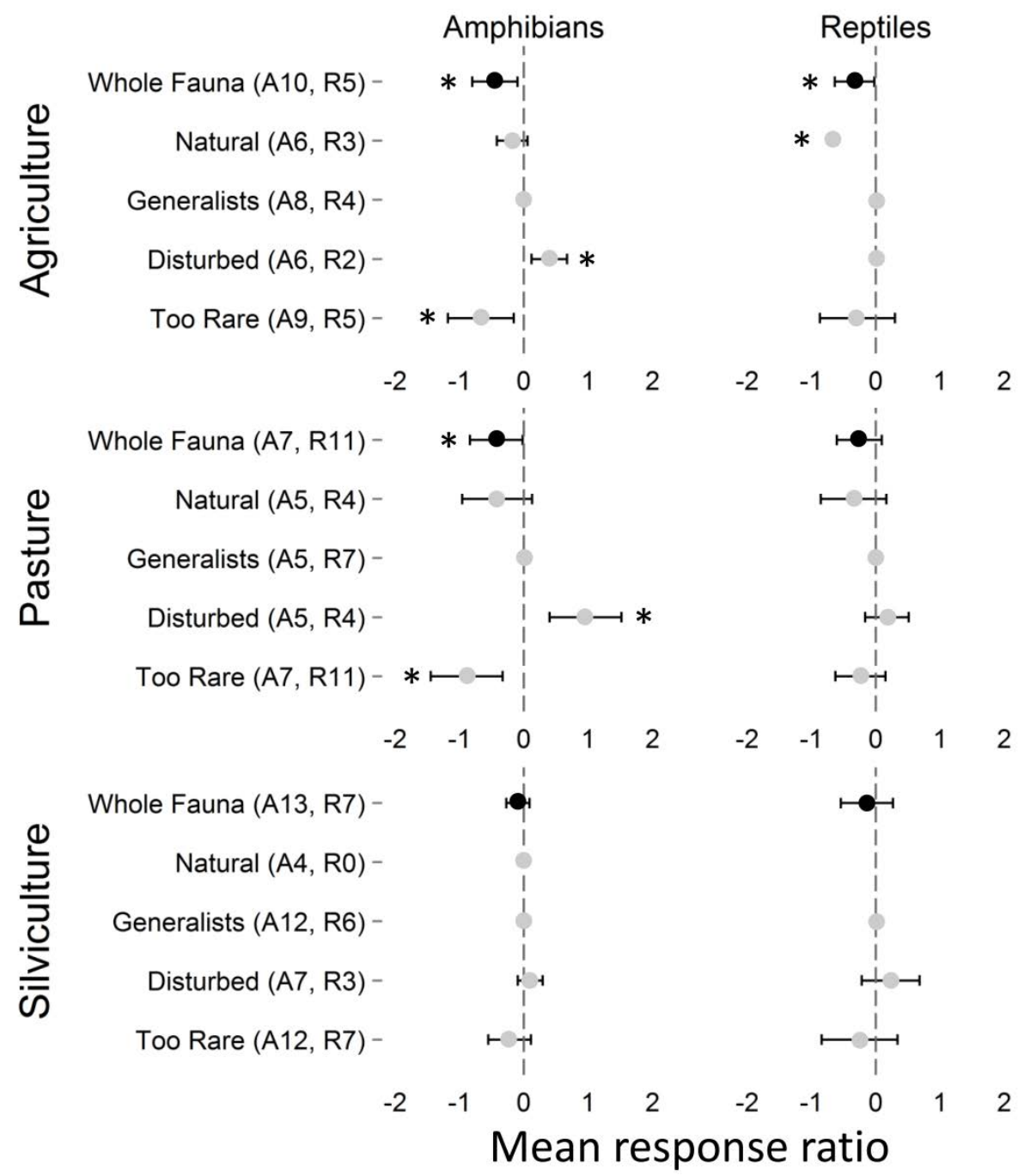

Figure 1.3. Mean effect sizes (and 95\% CIs) for the effect of land use on amphibian and reptile total species richness. Mean response ratios were calculated as the natural log of the ratio of species richness in a given land use to species richness in natural habitat (black, mean effect sizes for the whole assemblage in each category; gray, mean effect sizes for each habitat preference category). Negative values indicate species richness was lower in areas of land use than in natural areas. Number of studies used in analyses for amphibians (A) and reptiles (R) shown in parentheses. An asterisk signifies that $95 \%$ CIs do not overlap zero. The category too rare includes species that were too rare in studies to classify as habitat specialists or generalists by program CLAM. 
(a) Agriculture
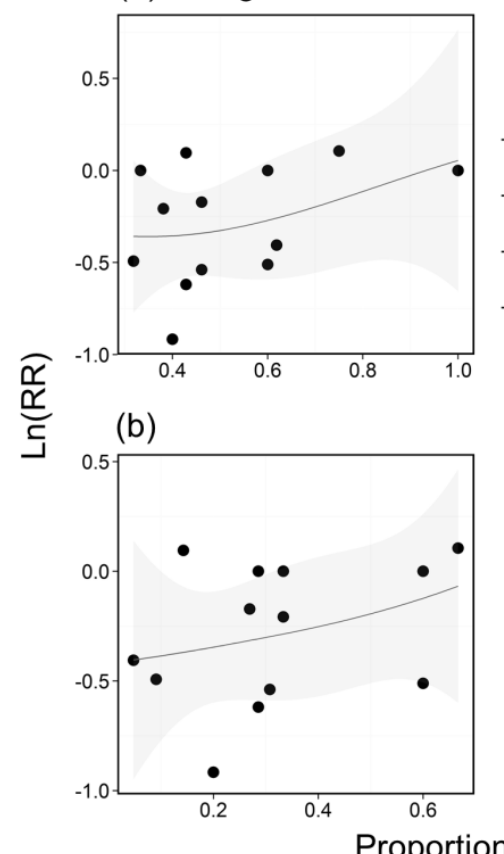
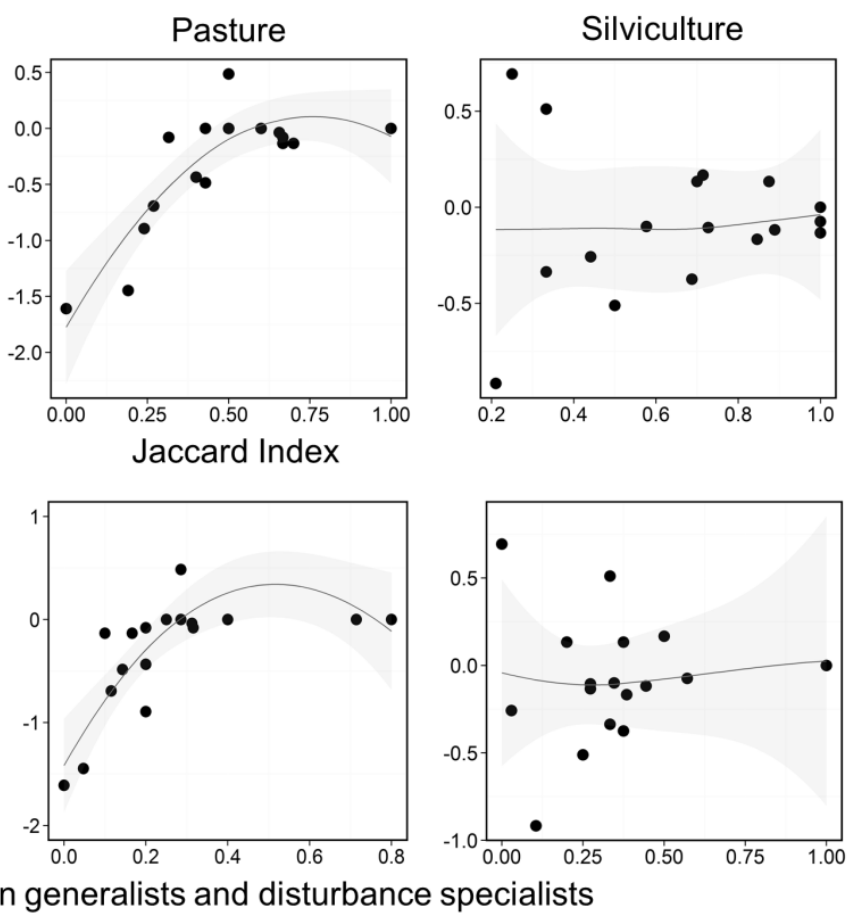

Figure 1.4. Relationships between the effect size of land use on total amphibian and reptile species richness and (a) the Jaccard index and (b) the proportion of generalists and disturbance specialists in the assemblage (point, a given study; fitted line, loess smoother; shaded area, 95\% CI). The effect size, $\ln (\mathrm{RR})$, was calculated as the natural log of the ratio of species richness in a given land use to species richness in natural habitat.

Negative values indicate species richness was lower in areas of land use than in natural habitat. The Jaccard index represents the proportion of species in the study found in both areas of land use and in natural habitats. 
Chapter 1 (in modified form) was published in Conservation Biology. This chapter is printed (with permission) by John Wiley and Sons.

\section{Reference:}

Thompson, M. E., A. J. Nowakowski, and M. A. Donnelly. 2016. The importance of defining focal assemblages when evaluating amphibian and reptile responses to land use. Conservation Biology 30:249-258. 


\title{
CHAPTER 2: EFFECTS OF SECONDARY FOREST SUCCESSION ON
}

\section{AMPHIBIANS AND REPTILES: A REVIEW AND META-ANALYSIS}

\begin{abstract}
Over the past century, humans have cleared the Earth's forests at an alarming rate and intensity. The majority of global forest cover is categorized as secondary forest, and it is becoming increasingly important to consider secondary forests in addition to old-growth forest in conservation planning for biota. I reviewed the literature to synthesize information on amphibian and reptile communities during secondary forest succession. I summarized literature on mechanisms of community change during forest succession and conducted a meta-analysis to estimate effect sizes for species richness and abundance in human-modified landscapes (agriculture, pasture, and plantation) and old-growth forests compared to regenerating secondary forests. Studies reported strong support for differences in species composition among human-modified landscapes, secondary forest, and old-growth forest as well as species-specific responses to successional forest change. Secondary forest generally had higher species richness and abundance than humanmodified landscapes, but lower species richness and abundance than old-growth forests. This result was more pronounced in amphibians than reptiles, and effect size of abundance was more variable than richness among studies. Secondary forests have better conservation value than altered habitats, but they do not necessarily hold the same conservation value for species as old-growth forest.
\end{abstract}




\section{INTRODUCTION}

The extensive degradation of natural systems caused by anthropogenic activities is a pressing global conservation concern (Raven and Wilson, 1992; Williams and Nowak, 1993; Sodhi et al., 2008). There is hope that some of the negative impacts caused by forest loss such as reduction of ecosystem services and loss of biodiversity may be offset by the regeneration of altered landscapes to secondary forests (Pearce, 2001). However, the value of secondary forests to fauna is poorly understood (Gardner et al., 2007a). Over $60 \%$ of the world's forests are degraded or are recovering from a major disturbance (FAO, 2015; Figure 2.1), and in some regions of the world, secondary forest cover is increasing (Aide and Grau, 2004). Thus, understanding the role, structure, and function of secondary forests in supporting biodiversity is critical for wildlife in the future.

For decades, there has been a consistent trend of loss in global forest cover. However, in many regions of the world, forest loss is partially mitigated by secondary forest regeneration (Keenan et al., 2015). Shifting social, political, and economic trends are driving reduction in forest cover loss and secondary forest gain. As a consequence of reduced deforestation and an increase in forest regeneration, the global rate of forest loss was reduced by over 50\% between the periods of 1990-2000 and 2010-2015 (FAO, 2015). Many countries are experiencing trends of rural to urban migration (Grau et al., 2003; Barbieri and Carr, 2005; McDonald, 2008), changes in forest and conservation policy (Southworth and Tucker, 2001; Kull et al., 2007), or are developing ecotourism (Kull et al., 2007), resulting in abandonment of agriculture and pasture land 
and promoting natural regeneration and formation of protected areas (Aide and Grau, 2004; Aide et al., 2012).

One of the main consequences of deforestation is biodiversity loss (Brook et al., 2003; Gibson et al., 2011). Worldwide declines have been reported for amphibians and reptiles (Houlahan et al., 2000; Wake and Vredenburg, 2008), and habitat destruction is one of the primary contributing factors to declines (Stuart et al., 2004; Reading et al., 2010; Böhm et al., 2013). Approximately one third of amphibian species are listed as threatened on the IUCN red list (IUCN et al., 2008). Although a full assessment for reptiles has not yet been completed, it is estimated that somewhere between $15 \%$ and $36 \%$ of reptiles qualify as threatened by IUCN standards (Böhm et al., 2013). The ecological requirements and physiological limitations of amphibians and reptiles make these animals sensitive to environmental changes such as altered vegetation structure and microclimates after deforestation.

In many animal taxa, species richness recovers asymptotically as forest matures, and recovery has been found to occur in approximately the same amount of time as recovery of tree species richness (Dunn, 2004). Thus, the ecological values of secondary forest to fauna may largely depend on the trajectory of vegetation regrowth. For plant species, overcoming the challenges of recolonization involves species overcoming biotic (e.g., competition with exotic species) and abiotic legacies (e.g., altered soil nutrient content, altered hydrology) of disturbance that can vary considerably as a result of disturbance type (e.g., large-scale hurricane, agriculture, pasture), disturbance intensity, and surrounding landscape matrix (e.g., proximity to patches of remnant forest; Lucas et al., 2002; Cramer et al., 2008). The factors that may contribute to recovery of amphibians 
and reptiles during secondary succession include dispersal to secondary forest, changes in forest structure, temperature and humidity, competition, and prey, predator, and parasite fluctuations over the course of forest succession, all of which are directly or indirectly affected by the course of regeneration of the vegetation.

Across animal taxa, there is support for lower diversity in secondary forests than in old-growth forests (Gibson et al., 2011). Often, species composition differs between secondary and old-growth forests. Subsets of old-growth specialist species are absent from secondary forests (Luja et al., 2008; Chazdon et al., 2009; Gibson et al., 2011; Hernandez- Ordonez et al., 2015) but begin to recover as the forest ages (Chazdon et al., 2009). In some cases, recovery can result in new forests with new combinations of species in comparison to historical sites (Lugo and Helmer, 2004). While secondary forests have been found to be a valuable habitat for a wide array of species, species' use of secondary forests is extremely variable among species and sites differing in land use history (Janzen, 2002; Bowen et al., 2007).

These highly variable species responses to forest succession are reflected in the literature on recovery of amphibian and reptile communities. For example, some authors have found similar species richness (Herrera-Montes and Brokaw, 2010; Hilje and Aide, 2012; Cortés-Gómez et al., 2013), while others have found higher species richness in oldgrowth forest compared to secondary forests (Petranka et al., 1993, 1994; Vallan, 2002; Pawar et al., 2004; Scott et al., 2006; Gardner et al., 2007a; Basham et al., 2016). For abundance, studies have reported similar (Corn and Bury, 1991; Gardner et al., 2007a), lower (Lieberman, 1986; Heinen, 1992), and higher total community abundance in oldgrowth forest compared to secondary forest (Petranka et al., 1993; Crawford and 
Semlitch, 2008; Luja et al., 2008). Measures of total abundance and species diversity tend to be variable, but there is an emerging consensus on changes in species composition and interspecific differences in abundance (Ernst and Rödel, 2006; Gardner et al., 2007a; Ficetola et al., 2008; Hawkes and Gregory, 2012; Beirne et al., 2013; Guerra and Aráoz, 2015; Hernández-Ordóñez et al., 2015). There is a distinct difference in amphibian and reptile composition between secondary forest and anthropogenic land use (Gardner et al., 2007a; Luja et al., 2008; Gillespie et al., 2012; Bruton et al., 2013; Cortés-Gómez et al., 2013; Guerra and Aráoz, 2015) and between secondary forest and old-growth forest (Luja et al., 2008; Cortés-Gómez et al., 2013; Hernández - Ordóñez et al., 2015).

The dominance of secondary forest cover is ubiquitous across continents (Figure 2.1). However, we currently have poor knowledge of patterns of and mechanisms of community assembly in secondary forests. To better understand general trends of amphibian and reptile communities in secondary forests, I conducted a review and metaanalysis of the literature. I summarized published literature on mechanisms that drive amphibian and reptile community change during secondary forest succession and conducted a meta-analysis of published studies on amphibian and reptile community recovery in secondary forests to determine the overall effect sizes of amphibian and reptile richness and total abundance in old-growth forest and human-modified landscapes (agriculture, pasture, and plantation) compared to secondary forests. I hypothesized that amphibian and reptile species richness and abundance would be higher in secondary forest than human-modified landscapes and lower in secondary forests than in old-growth forests. 


\section{MATERIALS AND METHODS}

Literature search.- - I searched the database Thompson ISI Web of Knowledge (all years through March 2017) for keywords "herpetofauna" or "amphibian*', or "reptile*', in combination with "secondary forest" or "secondary succession" or "forest regeneration" or "regenerating forest" or "'logging"'. In addition, I searched the literature cited sections of relevant papers found through the database search.

Literature summary of mechanisms. - As a consequence of the lack of research that explicitly tests mechanistic drivers to amphibian and reptile community change during forest regeneration, I was unable to conduct a formal meta-analysis. Instead, I summarized abiotic and biotic trends in secondary forest succession that have the potential to act as mechanisms for amphibian and reptile community change during secondary forest succession and discussed results of the few studies that have that have tested support for these mechanisms.

Meta-analysis._-The term 'secondary forest' encompasses many land use types ranging from forests regenerating from complete clearing of land for another use to moderate human use for selective logging and agriculture. For my meta-analysis, I defined secondary forest as forest that had been completely cut and was undergoing natural regeneration. I compiled data on estimated time to recovery for species richness for studies that conduced research in different age classes of secondary forest (at least two different replicated age classes of secondary forest) and reference sites (old-growth 
forest). I calculated "recovery time" as the age or age class reported by the literature where species richness in secondary forest was not significantly different from reference sites.

To calculate effect size of community parameters across studies (average species richness and average abundance of total community), I included studies that compared secondary forest with undisturbed reference sites or a human-modified land use (agriculture, pasture, and plantation) and that used standardized sampling techniques, replication, and reported values on species richness and abundance. I combined all human-modified habitats together in one category because I found too few studies to analyze each type of modified habitat separately. I used reported values of average species richness and average total abundance and standard deviation or I calculated values using data extracted from tables and figures. I calculated the effect sizes across studies by using the log-transformed ratio of means (Hedges et al., 1999). Because I was interested in how anthropogenic land use and reference sites compared to secondary forests, I calculated effect size as the natural $\log$ of the ratio of average species richness or average total community abundance in a given land use or undisturbed natural habitat to species richness or abundance in secondary forest. Negative values indicate average species richness or abundance was lower in old-growth forest or human-modified habitat than in secondary forest. I conducted analysis using the 'escalc' function and by using random-effects models with the restricted maximum likelihood estimator in package 'metafor' (Viechtbauer, 2010) in R v3.3.1 (R Core Team, 2016). 


\section{RESULTS}

\section{Literature summary of mechanisms}

Dispersal.-Before any other mechanisms driving community assembly in secondary forests can take place, species must first disperse to secondary forest sites. Compared to other taxa such as birds and mammals, amphibians and reptiles are generally more limited in dispersal capability (Hillman et al., 2014), and limited dispersal may limit their ability to colonize secondary forests. Dispersal is largely affected by geographic distance between patches (Brown and Kodric- Brown, 1977; Ficetola and De Bernardi, 2004), type of matrix between patches (Fahrig and Merriam, 1994; Gascon et al., 1999; Nowakowski et al., 2013), and species-specific behavior and physiology (Lees and Peres, 2009). Species that are highly mobile and resilient to matrix conditions will be more successful in colonizing isolated secondary forest patches. For amphibians and reptiles, differences in microclimates, predation rates, and movement through substrate type can affect dispersal through matrix habitat (Nowakowski et al., 2015; Kay et al., 2016). However, studies on amphibians and reptiles rarely explicitly incorporated matrix type or distance of secondary forest to old-growth forest in analyses (but see Hilje and Aide, 2012).

Forest structure. - Compared to old-growth stands, secondary forests have been found to differ in vegetation structure and leaf litter structure (Lebrija-Trejos et al., 2008; Letcher and Chazdon, 2009; Chazdon, 2014) which are thought to be important habitat components that regulate amphibian and reptile community composition and density (Lieberman, 1986; Heinen, 1992; Herrera-Montes and Brokaw, 2010; Whitfield et al., 
2014). The structure of forest vegetation provides species with microhabitats for perching, foraging, breeding, and fleeing predators. Additionally, forest structure and leaf litter structure mediate temperature and humidity on the forest floor; the leaf litter layer is an important habitat feature for amphibians and reptiles in forests. As secondary forest ages, and forest structure becomes more similar to that of old-growth forest, secondary forest may provide more suitable habitat for amphibian and reptile species that are dependent on the characteristics of old-growth forest. Early stages of secondary forests (i.e., 20 years after disturbance) tend to have low plant diversity (Letcher and Chazdon, 2009) and young trees, of similar age and size (Budowski, 1965), providing a uniform habitat of canopy height and perch diameter, and in some studies of herpetofauna in secondary forests, these vegetation characteristics have been linked to change in amphibian and reptile communities. For example, vegetation structure features such as canopy cover and abundance of woody plants (Cortés-Gómez et al., 2013; HernándezOrdóñez et al., 2015) have been linked to amphibian and reptile community composition. In young secondary forests, there is an absence of large, mature buttressed trees, and there is less course woody debris on the forest floor (Kissing and Powers, 2010) than in old-growth forests which are microhabitats that some amphibian and reptile species specialize on (e.g., Norops humilis in Central American tropical forest [Fitch, 1973] and Ensatina eschscholtzii in the Pacific Northwest of the United States [Jones and Aubry, 1985; Butts and McComb, 2000]). Additionally, absence of trees in riparian zones following clearing can also increase sedimentation in streams that may affect amphibian stream communities (Corn and Bury, 1989). Depth of leaf litter is known to affect densities of amphibians and reptiles (Whitfield et al., 2014), and therefore fluctuations in 
leaf litter among successional stages can also influence community composition. For example, Ash (1997) found that plethodontid salamander abundance returned in concurrence with return of the leaf litter layer. However, leaf litter fall and depth has been shown to recover rapidly during secondary forest succession (Oliviera, 2008; Ostertag et al., 2008), so leaf litter depth may have a greater effect on species composition and abundance in very early stages of regeneration than in later stages of succession.

Temperature and humidity. - As secondary forest ages, temperature decreases and humidity increases (Lebrija-Trejos et al., 2011). Response of ectothermic animals, such as amphibians and reptiles, to habitat change is thought to be influenced by changes in temperature (Tuff et al., 2016). Regulation of body temperature is important for amphibians and reptiles because temperature affects growth, reproduction (Hillman et al., 2009), ecological interactions, and disease susceptibility in ectotherms (Woodhams et al., 2003; Pounds et al., 2006). Additionally, for amphibians, humidity influences distribution because the highly permeable skin of amphibians increases their vulnerability of desiccation, particularly for species that oviposit terrestrially (Duellman, 1988; Hillman et al., 2009). The eggs, surrounded by a gelatinous coat, are also vulnerable to desiccation. Many studies that conducted amphibian and reptile surveys over the course of forest succession suggest that temperature and humidity likely play a large role in the described patterns of amphibians and reptiles they observed (Lieberman, 1986; Welsh, 1990; Heinen, 1992; Vallan, 2002; Rios-López and Aide, 2007; Herrera-Montes and Brokaw, 2010; Hernández- Ordóñez et al., 2015). One study found that forest 
structure explained the variability in microclimatic data and microclimate explained best the variation in herpetofaunal diversity (Herrera-Montes and Brokaw, 2010). Rittenhouse et al. (2008) found reduced juvenile anuran survival in recent clear-cut areas because of desiccation, but brush piles helped mitigate negative effects of logging by providing cool, humid microhabitats for amphibians. Despite the general consensus that microclimate likely plays a large role in community assembly, there is a lack of research that specifically tests for temperature and humidity as mechanisms for species response to forest succession.

Biotic factors. - Biotic factors such as the effect of prey and predator fluctuations, competition, and parasitism are known to affect species distributions at both local and broad spatial extents (Wisz et al., 2013). In studies in secondary forests, much less attention has been paid to biotic factors compared to abiotic factors. Competition between ecologically close species has been found to increase with increasing levels of human disturbance (Luiselli, 2006). However, Ernst and Rödel (2006) tested the importance of competition in community organization in secondary forests and did not find evidence for competition shaping species assemblage of anurans in regenerating forests. Arthropods, common prey for amphibians and reptiles, change in abundance and diversity during secondary forest succession, but communities are similar to those in old-growth forests after about 25-50 years (Floren and Linsenmair, 2001; Osorio-Pérez et al., 2007; Hopp et al., 2010). Changes in prey abundance may not only affect composition and abundance of species but can also affect behavior. For example, Greene et al. (2008) found that terrestrial prey abundance for salamanders was lower in late 
successional forests than early successional forests, causing salamanders to move farther from streams to forage in late successional sites. Predator assemblages change over the course of secondary forests regeneration (e.g., birds: Borges, 2007; Karthik et al., 2009). Therefore, it is likely that predation rates differ during forest regeneration. However, little is known about amphibian and reptile predation rates during forest succession.

\section{Meta-analysis}

A total of 24 studies met my requirements for meta-analysis of species richness and total abundance in land use, secondary forests, and old-growth forests. Sixteen studies included amphibians and 14 included reptiles. Studies were conducted across the globe but mostly clustered in North America, South America, and Australia (Figure 2.2). There was an even distribution of age classes of secondary forests included in studies, but $17 \%$ of studies did not include information on age of secondary forest (Figure 2.3). Estimates for time to recovery for species richness in secondary forest varied from 10 16 years to more than 80 years of regeneration (Figure 2.4).

The effect size across all studies for average amphibian species richness was significantly higher in undisturbed habitats compared to secondary forests. Sites with other types of land use had significantly lower species richness than secondary forests (Fig 2.5). However, there was no significant difference in abundance of amphibians between secondary forest and sites of anthropogenic land use. For reptiles, I did not find statistically significant trends in species richness. Results show only a suggestive trend of a positive effect of old-growth forest and negative effect of modified habitat on species richness compared to secondary forest (Figure 2.5). I did not find any trends in the 
comparison of average abundance among secondary forest and old-growth forest and human-modified land use sites for reptiles; there was substantial variation among studies (Figure 2.5).

\section{DISCUSSION}

With increasing reliance on secondary forest for conservation planning and maintaining biodiversity, it is imperative that we understand how animal communities assemble over the course of forest regeneration. Here, I report the state of knowledge on amphibian and reptile community response over the course of secondary forest succession and summarize information on potential mechanisms for observed patterns in the literature. I found that, in general, old-growth forest tends to have more species than secondary forest and human-modified habitat less species than secondary forest. Secondary forests have better conservation value than altered habitat, but they do not necessarily hold the same conservation value for species as old-growth forest. However, there was substantial variation among studies, especially for reptiles. My finding of significant differences in community response to secondary forest succession for amphibians but not reptiles suggests that amphibians and reptiles may be affected differently by environmental factors associated with secondary forest succession and supports why they should be considered separately in studies of communities, ecosystems, and landscapes.

Secondary forests provide suitable habitat for many amphibian and reptile species, but there is substantial variation in time to recovery of the animal community. Several studies reported that amphibian and reptile communities recover 
relatively rapidly. Others reported a period of at least 80 years to recovery (Figure 2.4). However, in these forests that are deemed "recovered," secondary forests may have similar species richness as old-growth forests but secondary forests may not provide suitable habitat for every species in the regional species pool. Some species appear to be unique only to old-growth forests (Barlow et al., 2007; Luja et al., 2008; Gibson et al., 2011). It is critical to identify the old-growth specialists in order to make appropriate conservation decisions for species most at risk. Additionally, it is unclear if amphibian and reptile populations in secondary forest patches are being maintained by internal recruitment, immigration from nearby mature forest, or a combination of the two processes. Although secondary forests do not provide suitable habitat to maintain populations of some species, they may still have other positive effects in comparison to matrix habitat such as increasing connectivity between older forest patches, providing less resistance to movement than matrix habitat, and acting as good corridors for dispersal (Nowakowski et al., 2013).

In some cases, land-use legacy and current surrounding landscape conditions may cause the trajectory of community assembly to vary from historic old-growth conditions. The variation in recovery trajectory has been recorded in plant communities (Janzen, 2002; Cramer et al., 2008). Time to recovery for a forest can also depend on the life zone. In the tropics, vegetation in dry forest recovers more rapidly than wet forest, and cloud forest recovers the slowest of the three forest types (Janzen, 2002). The variation in vegetation trajectory and recovery time is likely to affect amphibian and reptile communities. For example, a species may be less inclined to disperse through or populate a pasture or early stage secondary forest in lowland wet forest habitat than in lowland dry 
forest habitat because the microclimate conditions in the recently modified landscapes and old-growth forests sites are substantially more disparate in lowland wet forests than dry forests (i.e., hot, dry microclimates; Janzen, 2002). Not all species in a community respond the same over the course of secondary forest succession. There was a common trend across studies of species-specific effects. These species-specific effects are likely a contributing factor in why many studies found statistically nonsignificant effects between treatments and reference sites and why we found such variation in effect size across studies, especially for the measure of total abundance. Species that are disturbance specialists can weaken observed effects for whole community analysis (Thompson et al., 2016). Some trends in interspecific differences can be explained by particular ecological traits such as tolerance to harsh microclimates, breeding requirements, and other habitat associations. Species that are more resistant to desiccation (Ash, 1997) and species with high thermal tolerances and metabolic rates (Rios-López and Aide, 2007) can tolerate recently disturbed habitats that have high solar irradiation and warm, dry microclimatic conditions. Arboreal species of amphibians (Rios- López and Aide, 2007) and reptiles (Enge and Marion, 1986) increase in abundance and diversity with the return of woody vegetation. One of the most evident trends in the relationship between species traits and forest succession is effect of breeding habitat of anurans. Species with specific breeding habitats and with terrestrial breeding habits are more confined to old-growth forests (Vallan, 2002; Gardner et al., 2007b) whereas poolbreeding species are often able to exploit matrix habitat (Tocher et al., 2002). Terrestrial breeding anurans will likely be one of the groups most at risk in coming decades because of their adverse response to both habitat change (Nowakowski et al., 2017) and 
climate change (Donnelly and Crump, 1998). However, the presence of many terrestrial breeding anurans in later stages of secondary forest provides hope that secondary forest sites can eventually provide suitable habitat to maintain diversity of these species.

One of the main findings of my review is that there are enormous gaps in the understanding of amphibian and reptile community assembly over the course of secondary forest succession. In addition to calling attention to the dire need for more research, I suggest several recommendations for future studies. First, researchers should pay careful attention to study design. I found few studies that focused on amphibians and reptiles in secondary forest that had well-constructed experimental design, controls, and replication to adequately test hypotheses (and see review by Gardner et al., 2007b). Second, in future studies it is important to try to understand underlying causes of variation and explicitly test mechanisms driving trends in community change. Past studies characterize community patterns over the course of forest regeneration and suggest hypotheses to explain observed patterns. Future work should focus on the underlying processes generating the patterns and to evaluate the strength of mechanisms relative to one another. Success in planning conservation strategies not only depends on knowledge of patterns but the mechanisms driving the patterns (Cushman, 2006; Gardner et al., 2007a). Lastly, it is important to establish long-term research projects. Although several long-term studies on vegetation regeneration in secondary forest exist (Burslem et al., 2000; Sheil, 2001; Chazdon et al., 2007), I know of no long-term research on amphibians and reptiles along the course of secondary forest succession. Many studies stretch over one or two field seasons (one or two years) and substitute 
space for time by using chronosequences. While these methods are valid and provide valuable inference, ideally, long-term research programs should be established to tease out ecological trends from stochastic fluctuations, detect gradual changes, and detect small but biologically relevant effect sizes.

Future conservation management planning will have to use approaches that integrate the conservation of remaining patches of old-growth forest and surrounding secondary forests to preserve the greatest biodiversity possible. To integrate predictions of the value of secondary forest for a given conservation area, we first need to know for what species secondary forest can provide habitat that can maintain stable populations, and what the most important habitat features are to species at risk of decline. Secondary forest is the dominant global forest cover, is increasing in some regions, and it has been posed that secondary forest may mitigate for biodiversity loss from deforestation (Wright and Muller-Landau, 2006). However, the potential of secondary forests to serve as safety nets for biodiversity is the subject of formidable debate (Laurence, 2007). We still do not know to what extent secondary forest may mitigate for species loss, especially for relatively understudied taxa like amphibians and reptiles. It is urgent to evaluate the capability of secondary forests to host biodiversity comparable to old-growth forests and understand the mechanisms by which communities assemble in secondary forests, especially for taxa at high risk of extinction such as amphibians and reptiles. 


\section{LITERATURE CITED}

Aide, T. M, M. L. Clark, H. R. Grau, D. López-Carr, M. A. Levy, D. Redo, M. Bonilla-Moheno, G. Riner, M. J. Andrade-Núñez, and M. Muñiz. 2012. Deforestation and reforestation of Latin America and the Caribbean (2001 - 2010). Biotropica 45: 262-71.

Aide, T. M., and H. R.Grau. 2004. Globalization, migration, and Latin American ecosystems. Science 305:1915-1916.

Ash, A. 1997. Disappearance and return of plethodontid salamanders to clearcut plots in the southern Blue Ridge Mountains. Conservation Biology 11:983-989.

Barbieri, A. F., and D. L. Carr. 2005. Gender-specific out-migration, deforestation and urbanization in the Ecuadorian Amazon. Global and Planetary Change 47: 99-110.

Barlow, J. T. A. Gardner, I. S. Araujo, T.C. Ávila-Pires, A. B. Bonaldo, J. E. Costa, M. C. Esposito, L. V. Ferreira, J. Hawes, M. I. M. Hernandez, M. S. Hoogmoed, R. N. Leite, N. F. Lo-Man-Hung, J. R. Malcolm, M. B. Martins, L. A. M. Mestre, R. Miranda-Santos, A. L. Nunes-Gutjahr, W. L. Overal, L. Parry, S. L. Peters, M. A. Ribeiro-Junior, M. N. F. da Silva, C. da Silva Motta, and C. A. Peres. 2007. Quantifying the biodiversity value of tropical primary, secondary, and plantation forests. Proceedings of the National Academy of Sciences of the United States of America 104:18555-60.

Basham, E. W., P. González del Pliego, A. R. Acosta-Galvis, P. Woodcock, C. A. Medina Uribe, T. Haugaasen, J. J. Gilroy, and D. P. Edwards. 2016. Quantifying carbon and amphibian co-benefits from secondary forest regeneration in the Tropical Andes. Animal Conservation 19:548-560.

Beirne, C., O. Burdekin, and A. Whitworth. 2013. Herpetofaunal response to anthropogenic habitat change within a small forest reserve in Eastern Ecuador 23:209-219.

Böhm, M., B. Collen, J. E. M. Baillie ... G. Zug. 2013. The conservation status of the world's reptiles. Biological Conservation 157:372-385.

Borges, S. H. 2007. Assemblages in secondary forests developing after slash-and-burn agriculture in the Brazilian Amazon. Journal of Tropical Ecology 23:469-477.

Bowen, M. E., C. A. McAlpine, A. P. N. House, and G. C. Smith. 2007. Regrowth forests on abandoned agricultural land: A review of their habitat values for recovering forest fauna. Biological Conservation 140:273-296. 
Brook, B. W., N. S. Sodhi, and P. K. Nq. 2003. Catastrophic extinctions follow deforestation in Singapore. Nature 24:420-426.

Brown, J. H., and A. Kodric-Brown. 1977. Turnover rates in insular bio- geography: Effect of immigration on extinction. Ecology 58:445- 449.

Bruton, M. J., C. A. McAlpine, and M. Maron. 2013. Regrowth woodlands are valuable habitat for reptile communities. Biological Conservation 165:95-103.

Budowski, G. 1965. Distribution of Tropical American Rain Forest Species in the Light of Successional Processes. Turrialba 15:40-42.

Burslem, D. F. R. P., T. C. Whitmore, and G. C. Brown. 2000. Short-term effects of cyclone impact and long-term recovery of tropical rain forest on Kolombangara, Solomon Islands. Journal of Ecology 88:1063-1078.

Butts, S. R. and W. C. McComb. 2000. Associations of forest-floor vertebrates with coarse woody debris in managed forests of western Oregon. Journal of Wildlife Management 64:95-104.

Chazdon, R. L. 2014. Second Growth: The Promise of Tropical Forest Regeneration in an Age of Deforestation. University of Chicago Press, Chicago, IL.

Chazdon, R., S. Letcher, M. van Breugel, M. Martínez-Ramos, F. Bongers, and B. Finegan. 2007. Rates of changes in tree communities of secondary neotropical forests following major disturbances. Philosophical Transactions of the Royal Society B. 362: 273-289.

Chazdon, R. L., C. A. Peres, D. Dent, D. Sheil, A. E. Lugo, D. Lamb, N. E. Stork, and S. E. Miller. 2009. The potential for species conservation in tropical secondary forests. Conservation Biology 23:1406-1417.

Corn, P. S. and R. B. Bury. 1989. Logging in western Oregon: Rsponses of headwater habitats and stream amphibians. Forest Ecology and Management 29:39-57.

Corn, P. S. and R. B. Bury. 1991. Terrestrial amphibian communities in the Oregon Coast Range In L. F. Ruggiero, K. B. Aubry, A. B. Carey, and M. H. Huff (Eds.) Wildlife and Vegetation of Unmanaged Douglas-Fir Forests. Portland Oregon: USDA, Forest Service, Pacific Northwest Research Station, General Technical Report PNW-GTR-285 pp.241-254.

Cortés-Gómez, A. M., F. Castro-Herrera, and J. N. Urbina-Cardona. 2013. Small changes in vegetation structure create great changes in amphibian ensembles in the Colombian Pacific rainforest. Tropical Conservation Science 6:749-769. 
Cramer, V. A., R. J. Hobbs, and R. J. Standish. 2008. What's new about old fields? Land abandonment and ecosystem assembly. Trends in Ecology and Evolution 23:104-112.

Crawford, J. A., and R. D. Semlitsch. 2008. Post-disturbance effects of even-aged timber harvest on stream salamanders in southern Appalachian forests. Animal Conservation 11:369-376.

Cushman, S. A. 2006. Effects of habitat loss and fragmentation on amphibians: A review and prospectus. Biological Conservation 128:231-240.

Donnelly, M. A. and M. L. Crump. 1998. Potential effects of climate change on two neotropical amphibian assemblages. Climactic Change. 39:541-561.

Duellman, W. E. 1988. Patterns of species diversity in anuran amphibians in the American tropics. Annals of the Missouri Botanical Garden 75:79-104.

Dunn, R. R. 2004. Recovery of faunal communities during tropical forest regeneration. Conservation Biology 18:302-309.

Enge, K. M., and W. R. Marion. 1986. Effects of clearcutting and site preparation on herpetofauna of a North Florida flatwoods. Forest Ecology and Management $14: 177-192$.

Ernst, R., and M. O. Rödel. 2006. Community assembly and structure of tropical leaf litter anurans. Ecotropica 12:113-129.

FAO (Food and Agriculture Organization). 2015. Global Forest Resources Assessment 2015: How are the world's forests changing? Second Edition.

Fahrig, L., and G. Merriam. 1994. Conservation of fragmented populations. Conservation Biology 8:50-59.

Ficetola, F. G. and F. De Bernardi. 2004. Amphibians in a human-dominated landscape: the community structure is related to habitat features and isolation. Biological Conservation 119:219-230.

Ficetola, G. F., D. Furlani, G. Colombo, and F. De Bernardi. 2008. Assessing the value of secondary forest for amphibians: Eleutherodactylus frogs in a gradient of forest alteration. Biodiversity and Conservation 17:2185-2195.

Fitch, H. S. 1973. A field study of Costa Rican lizards. The University Of Kansas Science Bulletin 50:39-126. 
Floren, A., and K. E. Linsenmair. 2001. The influence of anthropogenic disturbances on the structure of arboreal arthropod communities. Plant Ecology 153:153-167.

Gardner, T. A., J. Barlow, and C. A. Peres. 2007a. Paradox, presumption and pitfalls in conservation biology: The importance of habitat change for amphibians and reptiles. Biological Conservation 138:166-179.

Gardner, T. A., M. A. Ribeiro-Júnior, J. Barlow, T. C. S. Ávila-Pires, M. S. Hoogmoed, and C. A. Peres. 2007b. The value of primary, secondary, and plantation forests for a neotropical herpetofauna. Conservation Biology 21:775-787.

Gascon, C., T. E. Lovejoy, R.O. Bierregaard, J. R. Malcolm, P. C. Stouffer, H. L. Vasconcelos,W. F. Laurance, B. Zimmerman, M. Tocher, and S. Borges. 1999. Matrix habitat and species richness in tropical forest remnants. Biological Conservation 91:223-229.

Gibson, L., T. M. Lee, L. P. Koh, B. W. Brook, T. A. Gardner, J. Barlow, C. A. Peres, C. J. A. Bradshaw, W. F. Laurance, T. E. Lovejoy, N. S. and Sodhi. 2011. Primary forests are irreplaceable for sustaining tropical biodiversity. Nature 478:378-383.

Gillespie, G. R., E. Ahmad, B. Elahan, A. Evans, M. Ancrenaz, B. Goossens, and M. P. Scroggie. 2012. Conservation of amphibians in Borneo: Relative value of secondary tropical forest and non-forest habitats. Biological Conservation 152:136144.

Grau, H. R. , T. M. Aide, J. K. Zimmerman, J. R. Thomlinson, E. Helmer, and X. M. Zou. 2003. The ecological consequences of socioeconomic and land-use changs in postagriculture Puerto Rico. BioScience 53:1159-1168.

Greene, B. T., W. H. Lowe, and G. E. Likens. 2008. Forest succession and prey availability influence the strength and scale of terrestrial-aquatic linkages in a headwater salamander system. Freshwater Biology 53:2234-2243.

Guerra, C. and E. Aráoz. 2015. Amphibian diversity increases in a heterogeneous agricultural landscape. Acta Oecologica 69:78-86.

Hawkes, V. C., and P. T. Gregory. 2012. Temporal changes in the relative abundance of amphibians relative to riparian buffer width in western Washington, USA. Forest Ecology and Management 274:67-80.

Hedges, L. V., J. Gurevitch, and P. S. Curtis. 1999. The meta-analysis of response ratios in experimental ecology. Ecology 80:1150-1156. 
Heinen, J. T. 1992. Comparisons of the leaf litter herpetofauna in abandoned cacao plantations and primary rain forest in Costa Rica: Some implications for faunal restoration. Biotropica 24:431-439.

Hernández-Ordóñez, O., N. Urbina-Cardona, and M. Martínez-Ramos. 2015. Recovery of amphibian and reptile assemblages during old-field succession of tropical rain forests. Biotropica 47:377-388.

Herrera-Montes, A., and N. Brokaw. 2010. Conservation value of tropical secondary forest: A herpetofaunal perspective. Biological Conservation 143:1414-1422.

Hilje, B., and T. M. Aide. 2012. Recovery of amphibian species richness and composition in a chronosequence of secondary forests, northeastern Costa Rica. Biological Conservation 146:170-176.

Hillman, S. S., P. C. Withers, R. C. Drewes, and S. D. Hillyard. 2009. Ecological and Environmental Physiology of Amphibians. Oxford University Press, Oxford.

Hillman, S. S. , R. C. Drews, M. S. Hedrick, and T. V. Hancock. 2014. Physiological vagility and its relationship to dispersal and neutral genetic heterogeneity in vertebrates. The Journal of Experimental Biology 217:3356-3364.

Hopp, P. W., R. Ottermanns, E. Caron, S Meyer, and M. Rob-Nickoll. 2010. Recovery of litter inhabiting beettle assemblages during forest regeneration in the Atlantic forest of Southern Brazil. Insect Conservation and Diversity 3:103-113.

Houlahan, J. E., C. S. Findlay, B. R. Schmidt, A. H. Meyer, and S. L. Kuzmin. 2000. Quantitative evidence for global amphibian population declines. Nature 404:752755.

IUCN, Conservation International, and NatureServe. 2008. An Analysis of Amphibians on the 2008 IUCN Red List <www.iucnredlist.org/amphibians>. Downloaded on 28 May 2014.

Janzen, D. H. 2002. Tropical dry forest: Area de Conservación Guanacaste, northwestern Costa Rica. In: M. R. Perrow, A. J. Davy (Eds.). Handbook of Ecological Restoration, Volume 2, Restoration in Practice Cambridge University Press, Cambridge, UK, pp. 559-583.

Jones, L. L. C. and K. B. Aubry. 1985. Natural history notes: Ensatina eschscholtzii oregonensis (Oregon ensatina). Reproduction. Herpetological Review 16:26

Karthik, T., G. G. Veeraswami, and P. K. Samal. 2009. Forest recovery following shifting cultivation: An overview of existing research. Tropical Conservation Science 2:374-387. 
Kay, G. M., D. A. Driscoll, D. B. Lindenmayer, S. A. Pulsford, and A. Mortelliti. 2016. Pasture height and crop direction influence reptile movement in an agricultural matrix. Agriculture, Ecosystems and Environment 235:164-171.

Keenan, R. J., G. A. Reams, F. Achard, J. V. de Freitas, A. Grainger, and E. Lindquist. 2015. Dynamics of global forest area: Results from the FAO global forest resources assessment 2015. Forest Ecology and Management 352:9-20.

Kissing, L. B., and J. S. Powers. 2010. Coarse woody debris stocks are a function of forest type and stand age in Costa Rica tropical dry forest: Long-lasting legacies of previous land use. Journal of Tropical Ecology 26:467-4714.

Kull, C. A., C. K. Ibrahim, and T. C. Meredith. 2007. Tropical forest transitions ad globalization: Neo-liberalism, migration, tourism, and international conservation agendas. Society and Natural Resources 20:723-737.

Laurence, W. F. 2007. Have we overstated the tropical biodiversity crisis? Trends in Ecology and Evolution 22:65-70.

Lebrija-Trejos, E., F. Bongers, E. A. P. Garcia, and J. A. Meave. 2008. Successional change and resilience of a very dry tropical deciduous forest following shifting agriculture. Biotropica 40:422-431.

Lebrija-Trejos, E., F. Bongers, E. A. P. Garcia, J. A. Meave, L. Poorter, and F. Bongers. 2011. Environmental changes during secondary succession in a tropical dry forest in Mexico. Journal of Tropical Ecology 27:477-489.

Lees, A. C. and C. Peres. 2009. Gap-crossing movements predict species occupancy in Amazonian forest fragments. Oikos 118:280-290.

Letcher, S. G., and R. L. Chazdon. 2009. Rapid recovery of biomass, species richness, and species composition in a forest chronosequence in northeastern Costa Rica. Biotropica 41:608-617.

Lieberman, S. S. 1986. The ecology of the leaf litter herpetofauna of a neotropical rain forest: La Selva, Costa Rica. Acta Zoológica Mexicana 15:1-72.

Lucas, R. M., M. Honzak, I. D. Amaral, P. J. Curran, and G. M. Foody. 2002. Forest regeneration on abandonded clearances in central Amazonia. International Journal of Remote Sensing 23:965-988.

Lugo, A. E., and E. Helmer. 2004. Emerging forests on abandoned land: Puerto Rico's new forests. Forest Ecology and Management 190:145-161. 
Luiselli, L. 2006. Food niche overlap between sympatric potential competitors increases with habitat alteration at different trophic levels in rain-forest reptiles (omnivorous tortoises and carnivorous vipers). Journal of Tropical Ecology 22:695-704.

Luja, V. H., S. Herrando-Pérez, D. González-Solis, and L. Luiselli 2008. Secondary rain forests are not havens for reptile species in tropical Mexico. Biotropica 40:747757.

McDonald, R. I. 2008 Global urbanization: Can ecologists identify a sustainable way forward? Frontiers in Ecology and the Environment 6: 99-104.

Nowakowski, A. J., B. Otero Jiménez, M. Allen, A, Diaz-Escobar, and M. A. Donnelly. 2013. Landscape resistance to movement of the poison frog, Oophaga pumilio, in the lowlands od northeaster Costa Rica. Animal Conservation 16:188197.

Nowakowski, A. J., M. Veiman-Echeverria, D. J. Kurz, and M.A. Donnelly. 2015. Evaluating connectivity for tropical amphibians using empirically, derived resistance surfaces. Ecological Applications 25:928-942.

Nowakowski, A. J., M. E. Thompson, M. A. Donnelly, and B. D. Todd. 2017. Amphibian sensitivity to habitat modification is associated with population trends and species traits. Global Ecology and Biogeography 26:700-712.

Oliviera, R. R. 2008. When the shifting agriculture is gone: Funcionality of Atlantic Coastal Forest in abandoned farming sites. Boletim do Museu Paraense Emílio Goeldi. Ciências Humanas 3:213-226.

Osorio-Pérez, K., M. F. Barberena-Arias, and T. M. Aide. 2007. Changes in ant species richness and comporition during secondary succession in Puerto Rico. Caribbean Journal of Science 43:244-253.

Ostertag, R., E. Marín-Spiotta, W. L. Silver, and J. Schulten. 2008. Litterfall and decomposition in relation to soil carbon pools along a secondary forest chronosequence in Puerto Rico. Ecosystems 11:701-714.

Pawar, S. S., G. S. Rawat, and B. C. Choudhury. 2004. Recovery of frog and lizard communities following primary habitat alteration in Mizoram, Northeast India. BMC ecology 4:1-18.

Pearce, D. 2001. The economic value of forest ecosystems. Ecosystem Health 7:284296. 
Petranka, J. W., M. E. Eldridge, and K. E. Haify. 1993. Effects of timber harvesting on Southern Appalachian salamanders. Conservation Biology 7:363-370.

Petranka J. W., M. P. Brannon, M. E. Hopey, and C. K. Smith. 1994. Effects of timber harvesting on low elevation populations of southern Appalachian salamanders. Forest Ecology and Management 67:135-147.

Pounds, J. A. M. R. Bustamante, L. A. Coloma, J. A. Consuegra, M. P. L. Fogden, P. N. Foster, E. La Marca, K. L. Masters, A. Merino-Viteri, R. Puschendorf, S. R. Ron, G. A.Sánchez-Azofeifa, C. J. Still, and B. E. Young. 2006. Widespread amphibian extinctions from epidemic disease driven by global warming. Nature 439:161-167.

R Core Team. 2016. R: A language and environment for statistical computing. R Foundation for Statistical Computing, Vienna, Austria. URL:https://www.Rproject.org/.

Raven, P. H., and E. O. Wilson. 1992. A fifty-year plan for biodiversity surveys. Science 258:1099-1100.

Reading, C. J., L. M. Luiselli, G. C. Akani, X. Bonnet, G. Amori, J. M. Ballouard, E. Filippi, G. Naulleau, D. Pearson, and L. Rugiero. 2010. Are snake populations in widespread decline? Biology Letters 6:777-780.

Rios-López, N., and T. M. Aide. 2007. Herpetofaunal dynamics during secondary succession. Herpetologica 63:35-50.

Rittenhouse, T. A. G., E. B. Harper, L. R. Rehard, and R. D. Semlitsch. 2008. The role of microhabitats in the desiccation and survival of anurans in recently harvested oak-hickory forest. Copeia 4:807-814.

Scott, D. M., D. Brown, S. Mahood, B. Denton, A. Silburn, and F. Rakotondraparany. 2006. The impacts of forest clearance on lizard, small mammal and bird communities in the arid spiny forest, southern Madagascar. Biological Conservation 127:72-87.

Sheil, D. 2001 Long-term observations of rain forest succession, tree diversity and responses to disturbance. Plant Ecology 155:183-199.

Sodhi, N. S., D. Bickford, A. C. Diesmos, T. M. Lee, L. P. Koh, B. W. Brook, C. H. Sekercioglu, and C. J. Bradshaw. 2008. Measuring the meltdown: drivers of global amphibian extinction and decline. PloS One 3:1-8. 
Southworth, J. and C. Tucker. 2001. The influence of accessibility, local institutions, and socioeconomic factors on forest cover change in the mountains of western Honduras. Mountain Research and Development 21:276-283.

Stuart, S. N., J. S. Chanson, N. A Cox, B. E. Young, A. S. L. Rodrigues, D. L. Fischman, and R. W. Waller. 2004. Status and trends of amphibian declines and extinctions worldwide. Science 306:1783-1786.

Thompson, M. E., A. J. Nowakowski, and M. A. Donnelly. 2016. The importance of defining focal assemblages when evaluating amphibian and reptile response to land use. Conservation Biology 30:249-258.

Tocher, M., Gascon, C., Meyer, J.R. 2002. Community composition and breeding success of Amazonian frogs in continuous forest and matrix aquatic sites. In: Bierregaard, R.O., C. Gascon, T. E. Lovejoy, and R Mesquita, (Eds.), Lessons from Amazonia: The Ecology and Conservation of a Fragmented Forest. Yale University Press, New Haven, pp. 235-247.

Tuff, K. T., T. Tuff, and K. F. Davies. 2016. A framework for integrating thermal biology into fragmentation research. Ecology Letters 19:361-374.

Vallan, D. 2002. Effects of anthropogenic environmental changes on amphibian diversity in the rain forests of eastern Madagascar. Journal of Tropical Ecology 18:725-742.

Viechtbauer, W. 2010. Conducting meta-analyses in R with the metafor package. Journal of Statistical Software, 36:1-48. URL: http://www.jstatsoft.org/v36/i03/

Wake, D. B., and V. T. Vredenburg. 2008. Are we in the midst of the sixth mass extinction? A view from the world of amphibians. Proceedings of the National Academy of Sciences of the United States of America 105:11466-11473.

Welsh, H. H. Jr. 1990. Relictual amphibians and old-growth forests. Conservation Biology 4:309-319.

Whitfield, S. M., K. Reider, S. Greenspan and M. A. Donnelly. 2014. Litter dynamics regulate population densities in a declinging terrestrial herpetofauna. Copeia 3:454461.

Williams, J. D., and R. M. Nowak. 1993. Vanishing species in our own backyard: Extinct fish and wildlife of the United States and Canada. In L. Kaufman and K. Mallory (Eds.) The Last Extinction. MIT Press, Cambridge, MA. 
Wisz, M. S., J. Pottier, W. D. Kissling, L. Pellissier, J. Lenoir, C. F. Damgaard, C. F. Dormann, M. C. Forchhammer, J. Grytnes, A. Guisan, R. K. Heikkinen, T. T. Høye, I. Kühn, M. Luoto, L. Maiorano, M. Nilsson, S. Normand, E. Öckinger, N. M. Schmidt, M. Termansen, A. Tiimmermann, D. A. Wardle, P. Aastrup, and J. Svenning. 2013. The role of biotic interactions in shaping distributions and realised assemblages of species: implications for species distribution modelling. Biological Reviews Cambridge Philosophical Sociey 88:15-30.

Woodhams D. C., R. A. Alford, and G. Marantelli. 2003. Emerging disease of amphibians cured by elevated body temperature. Diseases of aquatic organisms $55: 65-67$.

Wright, S. J. and H. C. Muller-Landau. 2006. The Future of Tropical Forest Species. Biotropica 38:287-301 


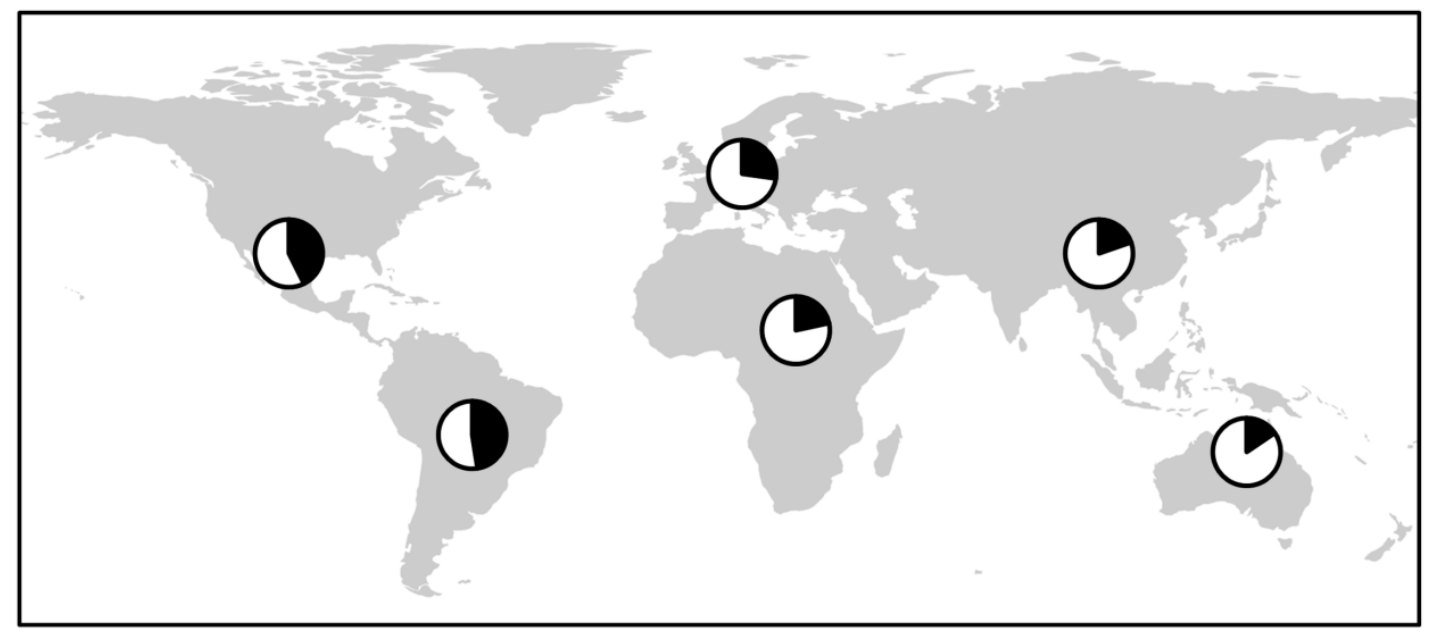

Figure 2.1. Map of percent of primary forest (black) and other naturally regenerated or planted forests (white) as defined by FAO (2015) by continent. 


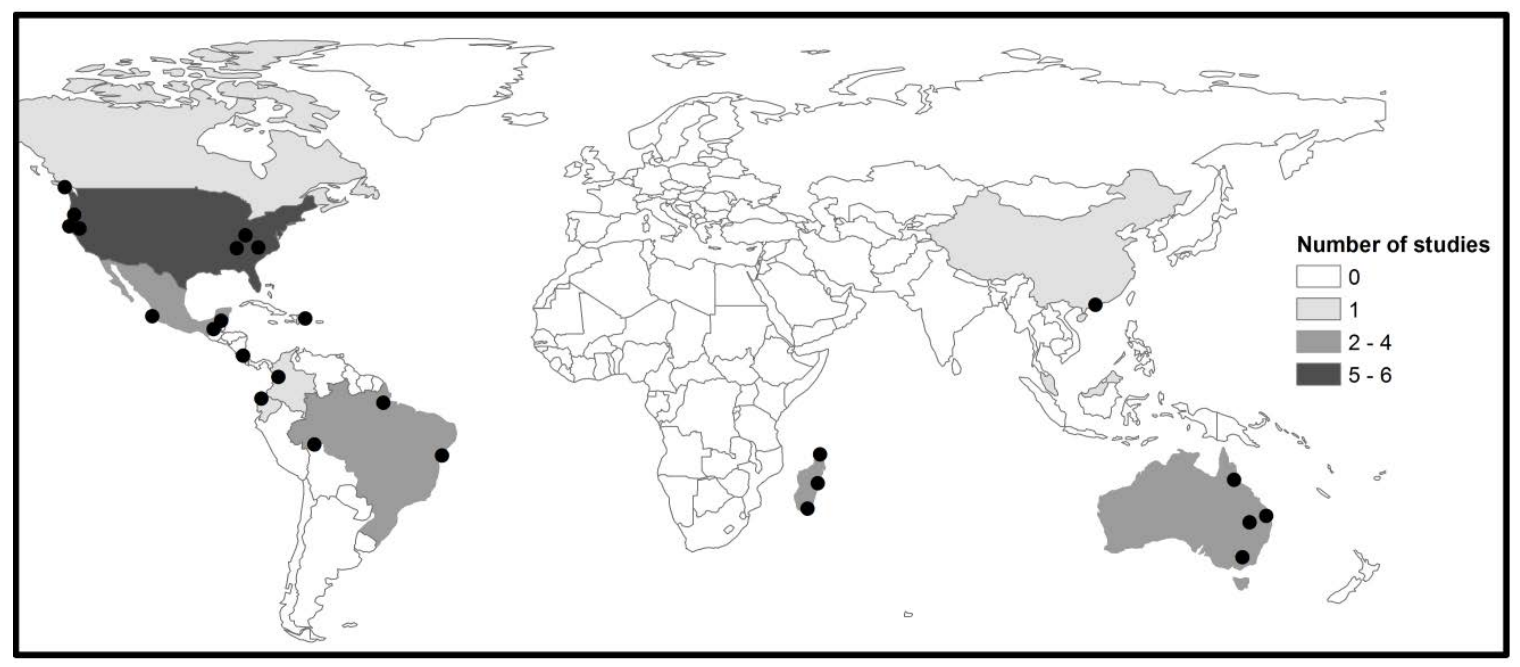

Figure 2.2. Map of study sites included in meta-analysis by country. Black dots indicate the study locations. Points jittered in the northwestern United States to show overlapping locations. 


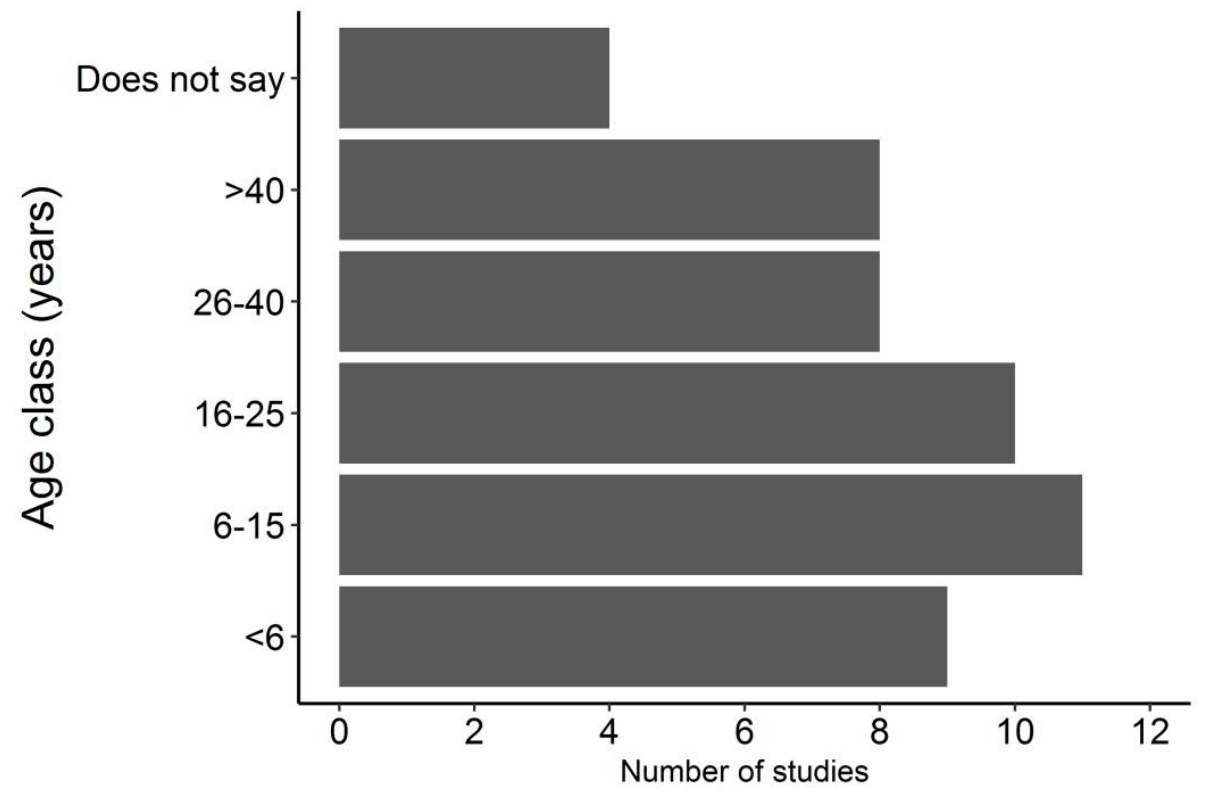

Figure 2.3. The age distribution of forest included in 20 of the published articles included in the meta-analysis. Four studies did not provide information on secondary forest age. 


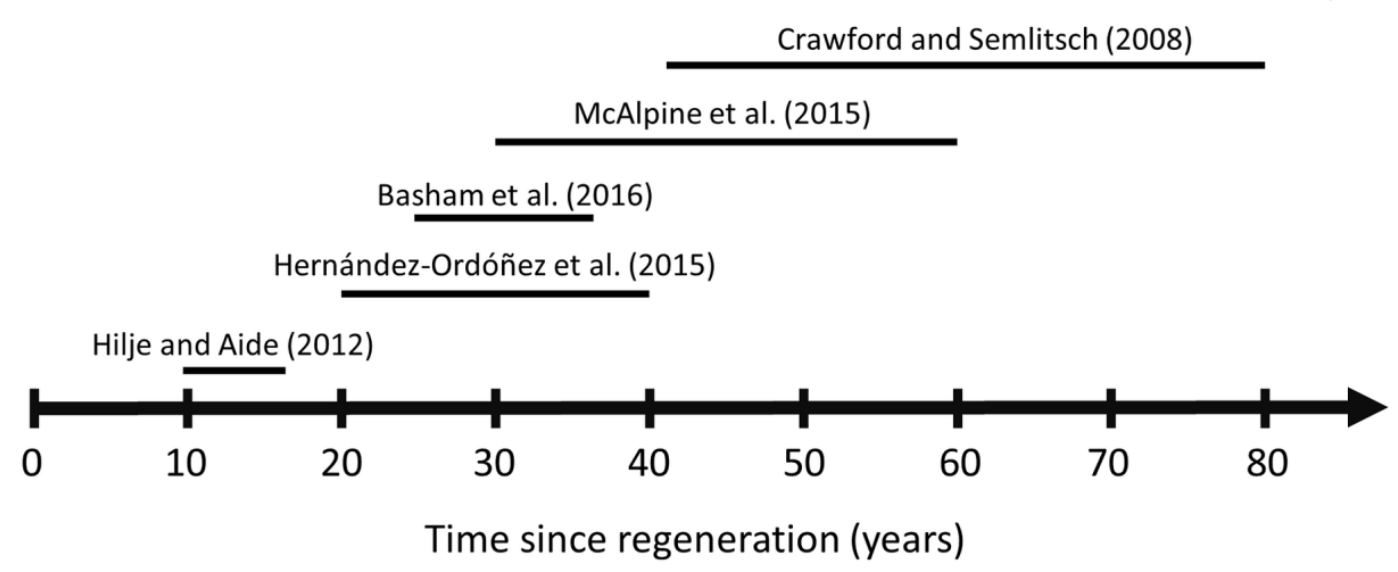

Figure 2.4. Published estimates of time to recovery of amphibian and reptile species richness. Arrow under Petranka et al. (1994) indicates that more than 80 years were required for species richness to recover. 


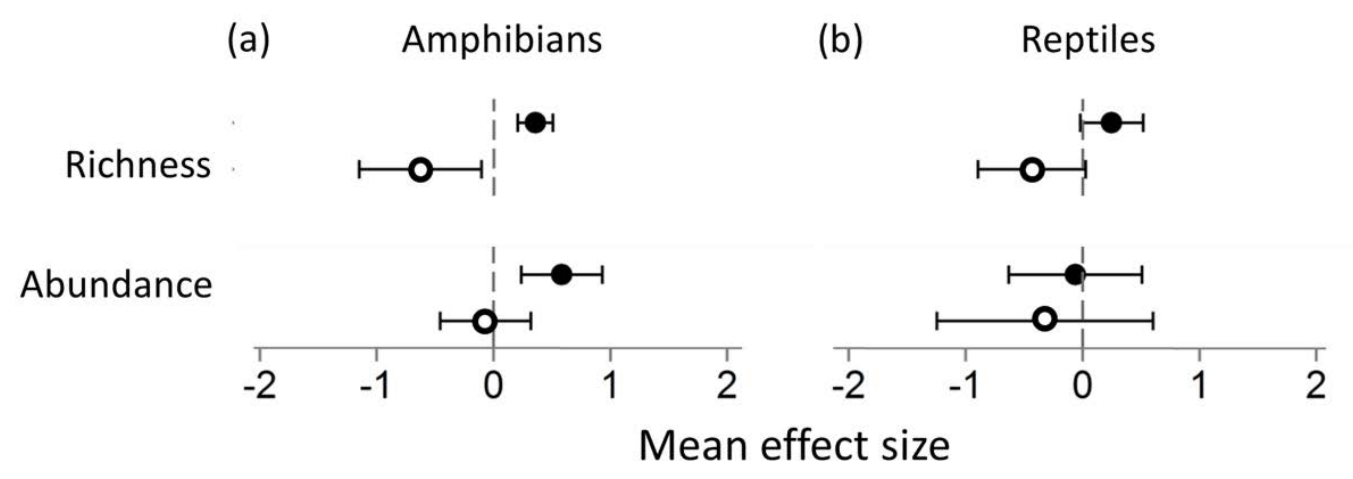

Figure 2.5. Mean effect sizes (and 95\% CIs) for the comparison of amphibian and reptile mean species richness and mean abundance in secondary forest to old-growth forest (closed circles) and human-modified habitat (open circles). Response ratios were calculated as the natural log of the ratio of average species richness or average abundance in a given human-modified land use or old-growth forest habitat to species richness or abundance in secondary forest. Negative values indicate average species richness or abundance was lower in areas of old-growth forest or human-modified habitat than in secondary forest. For amphibian richness: Nold-growth $=10, \mathrm{~N}_{\text {land use }}=5$, and for reptile richness: $\mathrm{N}_{\text {old-growth }}=11, \mathrm{~N}_{\text {land use }}=7$. For amphibian abundance: $\mathrm{N}_{\text {old-growth }}=10, \mathrm{~N}_{\text {land use }}=$ 6 , and for reptile abundance: $\mathrm{N}_{\text {old-growth }}=9, \mathrm{~N}_{\text {land use }}=7$. 
Chapter 2 (in modified form) was published in Copiea and as such the copyright is not owned by M. E. Thompson as is the rest of the dissertation. This chapter is printed (with permission) by the American Society of Ichthyologists and Herpetologists.

\section{Reference:}

Thompson, M. E. and M. A. Donnelly. 2018. Recovery of amphibian and reptile communities during tropical secondary forest succession. Copiea 106:10-19. 


\title{
CHAPTER 3: BUILDING A NEW COMMUNITY: FACTORS AFFECTING TROPICAL FOREST SUCCESSIONAL OUTCOMES FOR AMPHIBIANS AND REPTILES
}

\begin{abstract}
As habitats are increasingly dominated by human-induced land-use change and varying states of regeneration from human alteration of the natural habitat, understanding the drivers of community assembly and resulting patterns of biodiversity after major disturbance is critical for success in conservation and land management. My objective was to determine the relative contribution of stochastic and deterministic processes on community assembly of amphibians and reptiles over the course of secondary forest succession and to test the hypothesis that harshness of environmental filter mediates the importance of stochastic and deterministic processes, in two regions of Costa Rica. For amphibians and reptiles, I found that successional forest stage more often explained a significant and higher portion of variation in species composition (range: $23.3 \%-40.1$ ) than geographic distance (range: $4.3 \%-13.5 \%$ ). However, the strength of influence and type of deterministic process was mediated by forest stage, habitat type (upland, riparian), and taxon. My results indicate that changes associated with secondary forest succession have a substantial effect on shaping amphibian and reptile communities that inhabit regenerating forests and support the importance of examining processes of community assembly at different spatial scales.
\end{abstract}




\section{INTRODUCTION}

One of the most sought after challenges in ecology is to understand the mechanisms that drive observed patterns of communities across space and time. While there continues to be debate on which mechanisms are most important in structuring communities, many studies on variation in community composition have advanced our understanding stochastic and deterministic drivers such as neutral theory, mass effect, species sorting, and patch dynamics (Cottenie 2005, Weiher et al. 2011, Lohbeck et al. 2014). However, it remains to be determined what factors drive the relative strength of stochastic and deterministic drivers, comparatively, among ecosystems and communities. In an era dominated by human transformation of landscapes, understanding the factors that influence biodiversity patterns and community assembly during successional change and recovery is critical for success in conservation, habitat restoration, and land management.

The two major conceptual frameworks for community assembly are the neutral theory (stochastic viewpoint) and the niche-based theory (deterministic viewpoint). The deterministic or niche-based framework proposes that observed patterns in communities are a result of environmental filtering (similar species are sorted into similar habitats because of similar niche requirements) or through competitive interactions (species communities are not similar because similar species tend to exclude each other, Weiher and Keddy 1995). In contrast, neutral theory states that stochastic processes (dispersal limitation and random colonization and extinction events) drive community assembly and that community assembly is not influenced by differences in species traits (Hubbell 2001). The neutral theory is especially useful as a null-model framework with which to 
test alternative hypotheses because the neutral and niche-based frameworks predict different patterns of beta diversity along environmental and spatial gradients (Chase and Myers 2011). Stochastically-assembled communities are predicted to have high variation (unpredictability) in community composition among sites, even if the sites are very similar in environmental characteristics (Condit et al. 2002, Chave and Leigh 2002), whereas a community formed under niche-based processes would have more similar or predictable community composition among environmentally similar sites (Tuomisto et al. 2003, Dornelas et al. 2006).

Secondary forests are valuable study systems for exploring ecological theory and for insight into land-management and conservation of biodiversity because the earth is dominated by disturbed forests (Cramer et al. 2008). Secondary forests are ideal for studying community assembly because these habitats offer the opportunity to study community dynamics in relation to environmental change from a known starting point, which provides valuable insight into how communities assemble, change, and are structured over time (Lebrija-Trejos et al. 2010, Lohbeck et al. 2014, Meiners et al. 2015). Secondary forest succession involves a multitude of processes of interest in community assembly, such as dispersal, colonization, site modification, competition, facilitation, and extinction (Chang and HilleRisLambers 2016).

From a conservation perspective, the study of community assembly during secondary forest succession can help us gain insight as to whether anthropogenic disturbances lead to alterations in structure and predictability of forest communities (Didham et al. 1996, Wardle 1999, Ernst and Rödel 2005). The extent to which, and under what conditions, the recovery of secondary forest communities follow a predictable 
trajectory and converge on community composition to undisturbed reference sites is unclear (Ewel 1980, Cramer et al. 2008). Community composition may become more homogenous after disturbance (Solar et al. 2015, Nowakowski et al. 2017). If habitat specialists are less successful at colonizing or maintaining populations in regenerating forests, secondary forests could contribute to biological homogenization (Vellend et al. 2007). Over half the world's forests are categorized as secondary forests (FAO 2010). Therefore, understanding the recovery dynamics of communities in secondary forests is crucial to make sense of current and future patterns of biodiversity.

The importance of drivers of community assembly of flora during secondary forest succession has been shown to shift from early to late stages of forest regeneration. A multitude of studies have shown that environmental filtering is especially important in early stages of forest regeneration, whereas later stages of forest succession have been shown to be influenced by biotic interactions (Letcher et al. 2012, Lohbeck et al 2014, Chang and HilleRisLambers 2016). There is a clear lack of research focused on the drivers of community assembly of fauna during secondary forest succession. There is evidence that species composition recovers more slowly than richness and secondary forest stages tend to be more similar in composition to each other than mature forests (Dunn 2004, Ernst and Rödel 2005). However, what drives faunal community assembly over secondary forest succession is largely unknown (Ernst and Rödel 2005).

Here, I study community assembly during forest succession across different spatial scales. Specifically, I ask 1) what is the relative contribution of stochastic and deterministic drivers of community assembly of amphibians and reptiles along a gradient of successional forest that all originated from pasture, and 2) if there is evidence for 
environmental filtering, is the strength of environmental filtering dependent on the harshness of the habitat? I expected to find strength of support for deterministic processes to be dependent on harshness of the environmental filter (Chase 2007). I define 'harshness' by forest stage. I expected pasture to represent the harshest environmental filter because abiotic conditions contrast sharply with those in naturally occurring forest habitat in the region (e.g., pasture has hot, dry, highly variable abiotic conditions and large differences in vegetation structure compared to mature forest). I also expected that this trend would be dependent on habitat (stronger support for environmental filtering in upland habitat than riparian habitat, which changes much more dramatically than riparian habitat during secondary forest succession).

\section{METHODS}

Study sites: I conducted surveys in two regions of Costa Rica, in Sarapiquí (northeastern Costa Rica) and the Osa Peninsula (southwestern Costa Rica). Both regions are covered by tropical lowland wet forest (Holdridge 1971). Each of these locations is characterized by one fairly contiguous plot of continuous forest surrounded by forest fragments of varying size and age embedded in a matrix of agriculture and pasture land. My field sites included three replicates of each of five forest stages (years represent time since beginning of forest regeneration): pasture ( 0 years); $10-15$ years; $16-27$ years; > 27 years; mature forest (forest with minimum human disturbance) in each of the two study regions for a total of 30 sites (Table 3.1). I controlled for previous land use by only including secondary forest sites regenerating from pasture. 
Surveys: I conducted amphibian and reptile surveys using nocturnal and diurnal visual encounter surveys along transects (Crump and Scott 1994). I sampled six randomly placed $50 \times 2 \mathrm{~m}$ transects at each site. Three transects were in riparian habitat and three in forest habitat at least $30 \mathrm{~m}$ from riparian habitat. I visited each transect at each site on three occasions annually for two years, with surveys occurring in both the wet, dry and transition seasons, for a total of six sampling occasions (but see Table 3.1 for description of logistical sampling constraints at two of the Osa Peninsula sites). I conducted a total of 2,132 transect surveys. I recorded both visual (amphibians and reptiles) and auditory (amphibians) observations. The majority of my observations were composed on anurans and lizards. Therefore, these were the two groups of species I used for analysis.

Analysis: To determine if amphibian and reptile communities were dissimilar between upland and riparian habits in both study regions I used non-metric multidimensional scaling (NMDS) ordination and ANOSIM permutation tests (Clarke 1993) using the package vegan (Oksanen et al. 2017). I determined the significance and relative contribution of environmental and geographical distance on community composition of amphibians and reptiles using a complementary approach of partial Mantel tests and partial Canonical Correspondence Analysis (CCA) (Borcard et al. 1992, Legendre et. al. 2005). I used partial Mantel tests to test for statistical significance between matrices of species composition and environmental variable, forest stage, with geographic distance partialled out, and species composition and geographic distance with environmental variable, forest stage, partialled out. Partial Mantel tests provide significance tests but do not provide information on what percent of variation in the species matrix is explained by the spatial and environmental variables. I used partial CCA 
to preform variance partitioning analysis. Variation was partitioned into four groups, nonspatial environmental variation, spatially-structured environmental variation, spatial variation, and unexplained variation (Borcard et al. 1992).

I conducted partial Mantel tests using both the Jaccard index of dissimilarity and the Raup-Crick dissimilarity index (Raup and Crick 1979), with presence-absence matrices of species. The Jaccard index can be influenced by alpha and gamma diversity. The Raup-Crick index can be interpreted as the probability that two sample communities units have non-identical species composition, given differences in richness Therefore, the use of Raup-Crick index in addition to Jaccard allowed me to determine if observed dissimilarity was influenced by differences in alpha and gamma diversity components between sites and regions (Chase and Myers 2011). For partial Mantel tests, geographical distance was calculated as the Euclidean distances between latitude and longitude between each pair of sites. Because my main goal was to test how amphibian and reptile communities assemble over the course of secondary forest succession, I used forest stage as the environmental variable. I calculated the environmental distance matrix for forest stage as the distance of ranks between any two stages, which ranged between 0 and 4 , where 0 was the distance between two sites of the same stage and 4 was the greatest distance possible (the distance between the pasture stage and mature forest). For partial CCA analysis, I modeled spatial patterns with a third degree polynomial of latitude and longitude (Legendre 1993), and I created dummy variables for the environmental variable, forest stage (ter Braak 1987, Borcard et al. 1992). I used the best canonical correspondence model for spatial terms using a forward stepwise procedure with the 'ordistep' function in package vegan (Oksanen et al. 2017). 
To test the hypothesis that environmental filtering depends on harshness of habitat, I calculated the mean pairwise Raup-Crick dissimilarity index for each forest stage (Chase 2007, Vellend et al. 2007, Chase and Meyers 2011). The Raup-Crick index, calculated using the 'raupcrick' function in package vegan, varies from 0 to 1 (Oksanen et al. 2017). If community assembly is largely driven by stochastic processes, the mean Raup-Crick index would not significantly differ from 0.5 . Values that significantly deviate from 0.5 indicate that communities are affected by deterministic processes. If community assembly is driven by deterministic process such as environmental filtering, this would be represented by a Raup-Crick value of less than 0.5 (communities are more similar than expected at random). If community assembly is driven by deterministic process such as competition, this would be represented by a Raup-Crick value greater than 0.5 (communities are less similar than expected at random).

\section{RESULTS}

In Sarapiquí, I observed 38 species of amphibians and 16 species of reptiles; I detected 32 species of amphibians and 12 species of reptiles in upland habitats and 31 species of amphibians and 13 species of reptiles in riparian habitat. In the Osa Peninsula, I observed 32 species of amphibians and 16 species of reptiles; I detected 25 species of amphibians and 14 species of reptiles in upland habitats and 29 species of amphibians and 13 species of reptiles in riparian habitat. In both regions, amphibian and reptile communities were distinct between upland and riparian habitats (Sarapiquí amphibians: $\mathrm{R}$ $=0.196, \mathrm{p}=0.001$; Sarapiquí reptiles: $\mathrm{R}=0.443, \mathrm{p}=0.001$; Osa amphibians: $\mathrm{R}=0.075$, $\mathrm{p}=0.045$; Osa reptiles: $\mathrm{R}=0.165, \mathrm{p}=0.001$ ). 
Mantel correlations between species similarity and environmental factor, forest stage, with geographic distance partialled out were significant for amphibians in both study regions when riparian and upland communities were combined for analysis (Table 3.2). Mantel correlations between species similarity and environmental factor, forest stage, with geographic distance partialled out were significant for reptiles in the Osa Peninsula when the upland and riparian sites were analyzed all together (Table 3.2). When only analyzing upland habitat communities, partial Mantel correlations for environment were significant for amphibians and reptiles in both study regions. In riparian habitat communities, partial Mantel correlations for environment were only significant for amphibians in the Sarapiquí region (Table 3.2). Mantel correlations between species similarity and geographic distance with environmental factor, forest stage, partialled out were not significant for any of the cases using the Raup-Crick index and only in two cases using the Jaccard index of dissimilarity (Sarapiquí anurans, whole community and Sarapiquí anurans, upland habitat, Table 3.2). The environment accounted for a higher percentage of variation than geographic distance for all cases analyzed. Environment contributed $23.3 \%-40.1 \%$ of variation in species composition for amphibians and $29.3 \%-40.0 \%$ for reptiles, compared to geographic distance, which accounted for $5.8 \%-9.8 \%$ of species variation for amphibians and $4.3 \%-13.5 \%$ for reptiles (Figure 3.2).

I did not find consistent support for the hypothesis that environmental filtering depended on the harshness, forest age, or secondary forest stage. Amphibians followed the expected pattern in upland habitat in both study regions and when the community was analyzed as a whole in Sarapiquí. Support for environmental filtering was stronger in 
early successional stages and lower in older forest stages and mature forests. Pasture and early secondary forests had significantly more similar community composition than expected at random, and older secondary forests and mature forests had less predictable assemblages when compared among like sites (Figure 3.3). For reptiles in upland habitats in both regions I did not find a similar expected trend. Upland habitat reptile communities in pastures and early secondary forests had less similar community composition than expected at random and older secondary forests and mature forests had low predictability of species composition among like sites (Figure 3.3). For other categories analyzed there were no distinct patterns along the course of the choronosequence.

\section{DISCUSSION}

Amphibians and reptiles showed higher support for deterministic processes than stochastic processes driving community assembly in both the Sarapiquí and Osa Peninsula regions. However, the strength of deterministic influence on community structure was mediated by forest stage and habitat type. The environmental filtering hypothesis was more strongly supported in communities in upland habitats than riparian habitats. I found low support for a relationship between species composition and geographic distance. My results highlight the importance of recognizing that sub communities within a given forest patch may assemble under the influence of different (or different strengths of) mechanistic drivers.

My study suggests that there are different mechanisms of assembly operating on amphibian and reptile communities as a function of spatial scale. I hypothesized that the harsh environmental conditions in pasture and early secondary forest sites would increase 
community similarity because only a small pool of species would be able to tolerate the abiotic conditions present in early successional stages (Chase 2007). For amphibians, at the level of forest patch, the strength of the relationship between environmental filtering and forest stage, in general, decreased in a linear fashion. However, the strength of this trend was mediated by habitat type. In upland habitat, forest stage was most important in structuring communities of pasture and early successional forest and decreasingly less important as secondary forest approached the mature forest stage. Riparian habitat communities of amphibians and reptiles did not show decreasing support for deterministic processes along the course of succession; communities showed idiosyncratic trends. Reptiles in upland habitats showed support for deterministic, biotic processes driving community assembly in pasture and early secondary forest and either stochastic or environmental factors driving community assembly in later stages. At the regional scale, I found similar trends. Previous studies have found substantial variation in patterns of community composition among regions (Ernst et al. 2012, Chust et al. 2013). In my study, I controlled for previous land use and habitat type suggesting that regional variation found in other studies may be a result of differences in previous land use or habitat.

Within-site abiotic heterogeneity can determine the ability of community members to persist at a site (Kraft et al. 2015). Riparian habitats often harbor distinct communities from surrounding upland habitat (see review by Sabo et al. 2006, this study). However, there is general lack of understanding of how differences in diversity and composition between riparian and upland habitats shape regional community dynamics (Sabo et al. 2005). Communities in riparian habitats may respond differently to 
forest succession as a consequence of experiencing different abiotic conditions than communities in upland habitats and/or hosting a suite of different traits and requirements than communities in upland habitats. My study suggests that to fully understand community assembly within an ecosystem, future research should address community assembly at multiple spatial scales, especially when distinct sub-habitats are present within the focal study patch.

Differences in physiology and thermal biology in amphibians and reptiles may account for some of the variation I found between amphibian and reptilian taxa. Amphibian communities responded as predicted -environmental filtering was the strongest in what I considered to be the harshest abiotic environment, upland pasture and early secondary forests. However, reptile communities did not follow any particular pattern in relation to forest stage. I predicted that early stages of succession and upland habitats would pose the harshest environmental filter on communities because these stages have hot, dry conditions, compared to natural forest habitat of these communities as a result of reduced canopy cover and changes in forest structure (Pringle et al. 2003, Nowakowski et al. 2018). Amphibian communities may be more sensitive to these changes. For example, in amphibian and reptile communities living in the same habitat in the Colombian tropics, amphibians showed a trend of lower and smaller range of $\mathrm{CT}_{\max }$ values, a lower thermal safety margin and higher thermal instability than reptiles, all indicators of higher sensitivity to habitat modification than reptiles (Nowakowski et al. 2018).

Forest stage alone accounted for a substantial amount of variation in community composition of amphibians and reptiles. Forest stage explained at least 23.3\% (range 23.3 
$-40.1 \%$ ) of the variation in community composition in my study communities, suggesting that changes associated with secondary forest succession have a substantial effect on shaping amphibian and reptile communities that inhabit these regenerating forests. Compared to other studies focused on community assembly, the environmental variable, forest stage, had fairly high explanatory power (phytoplankton: 5-25\% [Chust et al. 2013], mycorrhizal fungi: 3.9-6.1\% [Gao et al. 2015], oribatid mites: $13.7 \%$ [Borcard and Legendre 1992], trees: 10.8\% [Borcard and Legendre 1992]). A substantial amount of variation was unaccounted for by the variables included in my study, but this level of unexplained variation in community composition is a common phenomenon (Borcard and Legendre 1992, Chust et al. 2013, Gao et al. 2015). Unmeasured environmental variables certainly account for some of the unexplained variation I obtained. My results support previous studies that show community assembly can be substantially influenced by anthropogenic or natural disturbance, (Ernst and Rödel 2005, Chase 2007). Beta diversity generally decreases after disturbance (Ernst and Rödel 2005, Chase 2007, this study). Even if beta diversity is restored through secondary forest succession, the trend of an increasing ratio of highly disturbed habitats to natural undisturbed habitats still may result in compromising regional diversity (Chase 2007). Furthermore, the restoration of beta diversity in regenerating habitats will be contingent on the presence of intact habitats in the region.

As the Earth is increasingly dominated by disturbed habitats and habitats regenerating from disturbance, it is essential for ecologists to understand drivers of community assembly in modified landscapes and also identify how disturbance may influence biodiversity patterns at different spatial scales (Chase 2007). Secondary forests 
offer key opportunities to understanding mechanisms that drive community assembly. In addition to the potential for advancement to the theoretical framework of community assembly, knowledge of how communities are structured over the course of secondary forest succession is critical for conservation and to inform restoration decisions (Chang and HilleRisLambers 2016).

\section{LITERATURE CITED}

Borcard, D., P. Legendre, and P. Drapeau. 1992. Partialling out the Spatial Component of Ecological Variation. Ecology 73:1045-1055.

Chang, C., and J. HilleRisLambers. 2016. Integrating succession and community assembly perspectives [version 1; referees: 2 approved] F1000Research 5: (F1000 Faculty Rev):2294.

Chase, J. M. 2007. Drought mediates the importance of stochastic community assembly. Proceedings of the National Academy of Sciences of the United States of America 104:17430-17434.

Chase, J. M., and J. A. Myers. 2011. Disentangling the importance of ecological niches from stochastic processes across scales. Philosophical Transactions of the Royal Society of London. Series B, Biological sciences 366:2351-2363.

Chave J, E. G. Leigh Jr. 2002.A spatially explicit neutral model of beta-diversity in tropical forests. Theor Popul Biol 62:153-168.

Chust, G., X. Irigoien, J. Chave, and R. P. Harris. 2013. Latitudinal phytoplankton distribution and the neutral theory of biodiversity. Global Ecology and Biogeography 22:531-543.

Clarke, K. R. 1993. Non-parametric multivariate analysis of changes in community structure. Australian Journal of Ecology 18:117-143.

Cottenie, K. 2005. Integrating environmental and spatial processes in ecological community dynamics. Ecology Letters 8:1175-1182.

Cramer, V. A., R. J. Hobbs, and R. J. Standish. 2008. What's new about old fields? Land abandonment and ecosystem assembly. Trends in ecology and evolution 23:104-12. 
Crump, M. L., and N. J. Scott. 1994. Visual Encounter Surveys. In W. R. Heyer, M. A. Donnelly, R W. McDiarmid, L. C. Hayek, and M. S. Foster (Eds.) Measuring and Monitoring Biological Diversity: Standard Methods for Amphibians (pp. 84-92). Smithsoniain Institution Press, Washington DC.

Condit R, N. Pitman, E. G. Leigh Jr., J. Chave, J.Terborgh, R. B.Foster, P. Núñez, S. Aguilar, R. Valencia, G. Villa, H. C. Muller-Landau, E. Losos, and S. P. Hubell. 2002. Science 295:666-669.

Didham, R. K., J. Ghazoul, N. E. Stork, and A. J. Davis. 1996. Insects in fragmented forests: a functional approach. Trends in Ecology and Evolution 11:255-260.

Dornelas M., S. R. Connolly, T. P. Hughes. 2006. Coral reef diversity refutes the neutral theory of biodiversity. Nature 440:80-82.

Dunn, R. R. 2004. Recovery of faunal communities during tropical forest regeneration. Conservation Biology 18:302-309.

Ernst, R., M. Rödel. 2005. Anthropogenically induced changes of predictability in tropical anuran assemblages. Ecology 86:3111-3118.

Ernst, R., A. Keller, G. Landburg, T. U. Grafe, K. E. Linsenmair, M.-O. Rödel, and F. Dziock. 2012. Common ancestry or environmental trait filters: cross-continental comparisons of trait-habitat relationships in tropical anuran amphibian assemblages. Global Ecology and Biogeography 21:704-715.

Ewel, J. 1980. Tropical succession: manifold routes to maturity. Biotropica 12(Suppl.):27.

FAO. 2010. Global Forest Resources Assessment Key Findings 12pp.

Gao, C., Y. Zhang, N. Shi, Y. Zheng, L. Chen, T. Wubet, H. Bruelheide, K. Nadrowski, and S. Both. 2015. Community assembly of ectomycorrhizal fungi along a subtropical secondary forest succession 205:771-785.

Holdridge, L. R. 1971. Forest Environments in Tropical Life Zone: A Pilot Study. Page 747.

Hubbell, S. P. 2001. The unified neutral theory of biodiversity and biogeography. Princeton University Press, New Jersey.

Kraft, N. J. B., P. B. Adler, O. Godoy, E. C. James, S. Fuller, and J. M. Levine. 2015. Community assembly, coexistence and the environmental filtering metaphor. Functional Ecology 29:592-599. 
Lebrija-Trejos, E., E. A. Perez-Garcia, J. A. Meave, and F. Bongers. 2010. Functional traits and environmental filtering drive community assembly in a species-rich tropical system. Ecology 91:386-398.

Legendre, P. 1993. Spatial autocorrelation: trouble or new paradigm? Ecology74: 16591673.

Legendre, P., Borcard, D. and Peres-Neto, P.R. 2005. Analyzing beta diversity: partitioning the spatial variation of community composition data. Ecological Monographs 75:435-450.

Letcher, S.G., R. L. Chazdon, A. C. S. Andrade, F.Bongers, M. van Breugel, B. Finegan et al. 2012. Phylogenetic community structure during succession: evidence from three Neotropical forest sites. Perspectives in Plant Ecology, Evolution and Systematics 14:79-87.

Lohbeck, M., L. Poorter, M. Martínez-Ramos, J. Rodriguez-Velázquez, M. van Breugel, and F. Bongers. 2014. Changing drivers of species dominance during tropical forest succession. Functional Ecology 28:1052-1058.

Meiners, S. J., Cadotte, M. W., Fridley, J. D., Pickett, S. T. A. \& Walker, L. R. 2015. Is successional research nearing its climax? New approaches forunderstanding dynamic communities.Functional Ecology29:154-164.

Nowakowski, A. J, M. E. Thompson, M. A. Donnelly, and B. D. Todd. 2017. Amphibian sensitivity to habitat modification is associated with population trends and species traits.26:700-712.

Oksanen J., F. Guillaume Blanchet, M. Friendly, R. Kindt, P. Legendre, D. McGlinn, P. R. Minchin, R. B. O'Hara, G. L. Simpson, P. Solymos, M. H. H. Stevens, E. Szoecs and H. Wagner 2017. vegan: Community Ecology Package. R package version 2.44.

Raup, D.M. \& Crick, R.E. 1979.Measurement of faunal similarity in paleontology. J. Paleontol. 53:1213-1227.

ter Braak. C. J. F. 1987. The analysis of vegetation-environment relationships by canonical correspondence analysis. Vegetation 69:69-77.

Sabo, J. S. 2006. Riparian zones increase regional species richness by harboring different, not more, species. Ecology 86:56-62.

Solar, R. R., Barlow, J., Ferreira, J., Berenguer, E., Lees, A. C., Thomson, J. R., . . .Gardner, T. A. 2015. How pervasive is biotic homogenization in human-modified tropical forest landscapes? Ecology Letters 18:1108-1118. 
Tuomisto H, K. Ruokolainen, M. Yli-Halla. 2003. Dispersal, environment, and floristic variation of western Amazonian forests. Science 299:241-244.

Vellend, M. et al. 2007. Homogenization of forest plant communities and weakening of species - environment relationships via agricultural land use. Journal of. Ecology 95:565-573.

Wardle, D. A. 1999. Biodiversity, ecosystems and interactions that transcend the interface. Trends in Ecology and Evolution 14:125-127.

Weiher, E. and P. Keddy. 1995. The assembly of experimental wetland plant communities. Oikos 73:323-335.

Weiher, E., D. Freund, T. Bunton, A. Stefanski, T. Lee, and S. Bentivenga. 2011. Advances, challenges, and a developing synthesis of ecological community assembly theory. Phil. Trans. Soc. B 366:2403-2413. 
Table 3.1. Description of study sites in a) Sarapiquí and b) the Osa Peninsula, Costa Rica

\begin{tabular}{|c|c|c|c|c|c|}
\hline Region & Site ID & Type & $\begin{array}{c}\text { Distance to } \\
\text { mature forest }(\mathrm{m})\end{array}$ & Matrix between site and closest mature forest & Notes \\
\hline \multirow[t]{15}{*}{ a) } & $\mathrm{P} 1$ & S3 & 0 & - & \\
\hline & P5 & MF & - & - & \\
\hline & TIR & MF & - & - & Has history of selective logging \\
\hline & P4 & S3 & 700 & Secondary forest & Nearest mature forest has history of Selective logging \\
\hline & P3 & S3 & 0 & - & \\
\hline & P7 & S2 & 1200 & Secondary forest & \\
\hline & P8 & MF & - & - & \\
\hline & P10 & S2 & 450 & Secondary forest & \\
\hline & P11 & S1 & & Secondary forest & \\
\hline & P13 & S1 & 800 & Secondary forest, selectively logged forest & \\
\hline & P14 & S2 & 600 & Secondary forest & \\
\hline & P15 & S1 & $500-1000$ & Secondary forest, residential, pasture & Partial reforestation of plot \\
\hline & POTLS & $\mathrm{P}$ & 0 & - & Nearest mature forest has history of selective logging \\
\hline & POT4 & $\mathrm{P}$ & 0 & - & Nearest mature forest has history of selective logging \\
\hline & POT8 & $\mathrm{P}$ & 0 & - & \\
\hline \multirow[t]{15}{*}{ b) } & OOG1 & MF & - & - & \\
\hline & OOG2 & MF & - & - & \\
\hline & OOG3 & MF & - & - & \\
\hline & OPOT1 & $P$ & 0 & - & \\
\hline & OPOT2 & $P$ & $500-1000$ & Secondary forest & \\
\hline & OPOT3 & $\mathrm{P}$ & 0 & - & \\
\hline & OS1 & S3 & 0 & - & \\
\hline & OS2 & S2 & 0 & - & \\
\hline & OS3 & S2 & 0 & - & \\
\hline & OS4 & S2 & 0 & - & $\begin{array}{l}\text { Prior to last survey two (ulpand) transects disappeared in a } \\
\text { landslide and therefore not able to be surveyed }\end{array}$ \\
\hline & OS5 & S3 & 0 & - & \\
\hline & OS6 & S3 & 0 & - & \\
\hline & OS7 & S1 & 0 & - & \\
\hline & OS8 & S1 & 0 & - & \\
\hline & OS9 & S1 & 200 & Secondary forest & $\begin{array}{l}\text { Only } 4 \text { transects ( } 2 \text { riparian } 2 \text { upland) fit with required buffers } \\
\text { (upland transects at least } 30 \mathrm{~m} \text { from riparian and all transects at } \\
\text { least } 10 \mathrm{~m} \text { from patch edge) due to size and shape of forest parcel } \\
\end{array}$ \\
\hline
\end{tabular}


Table 3.2. Partial Mantel tests (Mantel $r$ and $p$-value) between species composition and environmental determinate (forest stage) and geographical distance for amphibians and reptiles in Sarapiquí and the Osa Peninsula using the Raup-Crick and Jaccard index.

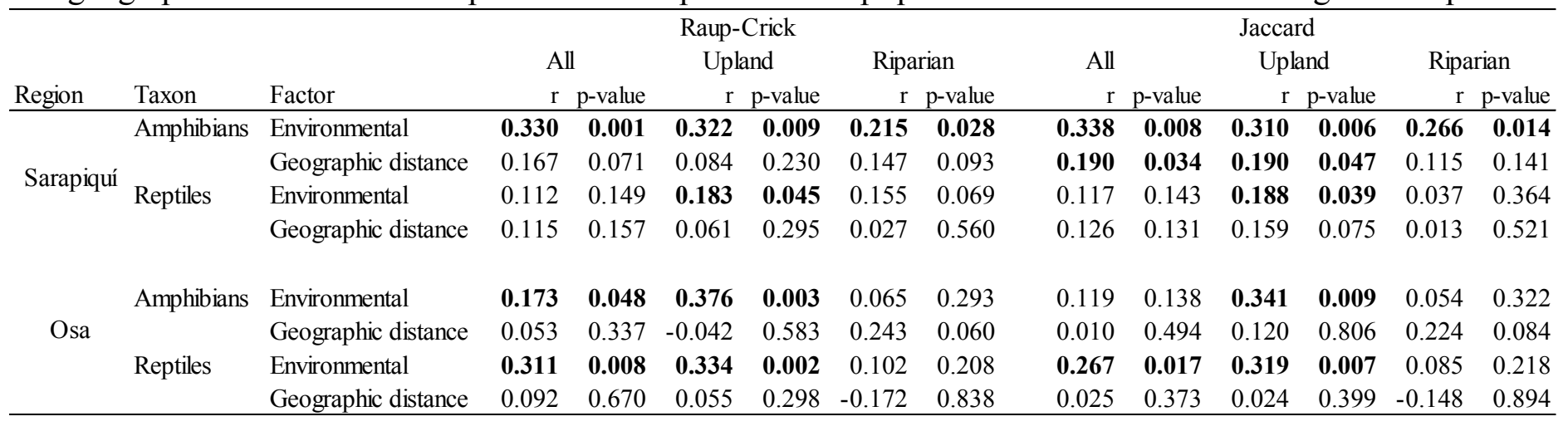




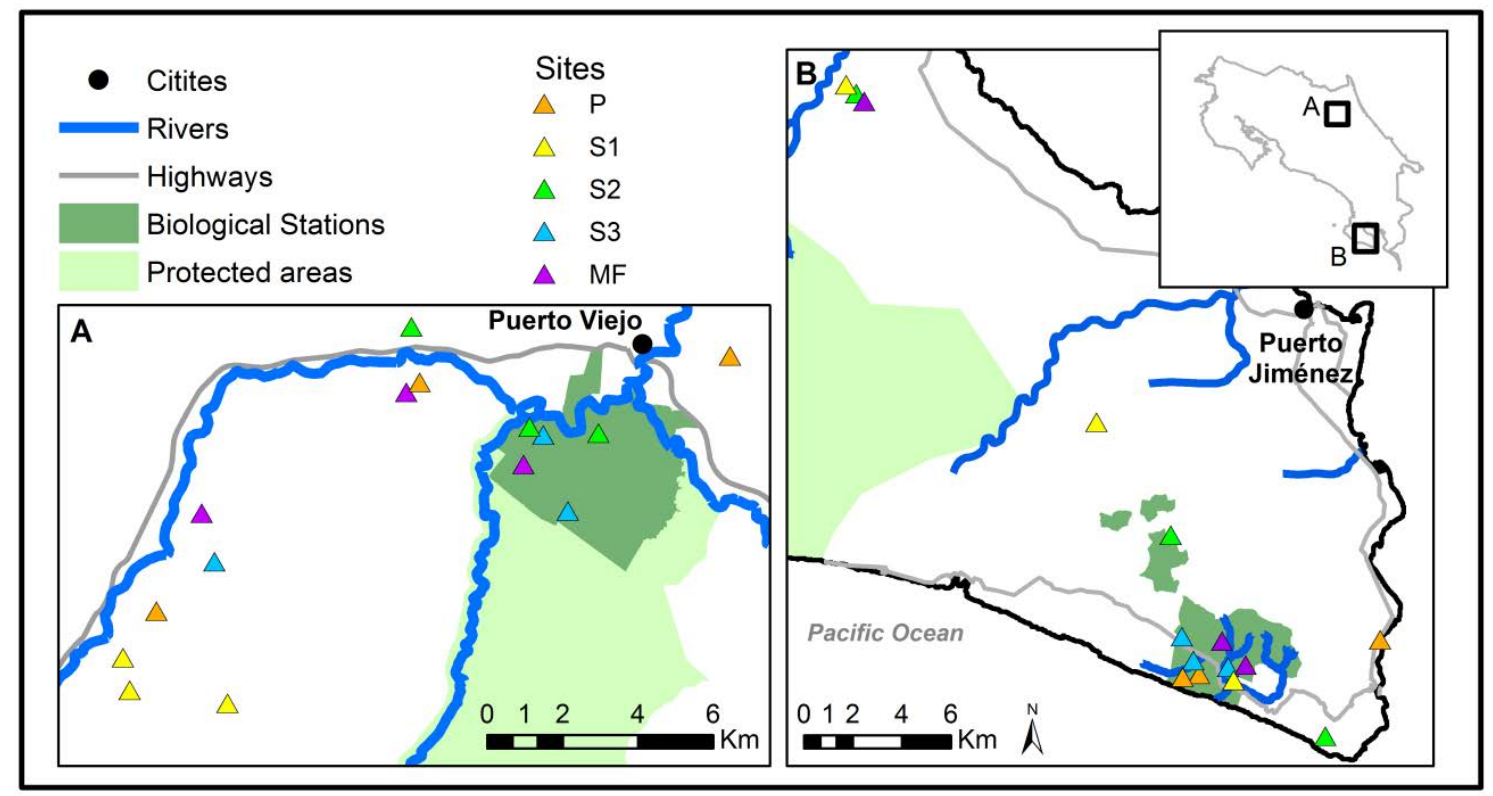

Figure 3.1. Map of study sites in A) Sarapiquí and B) Osa Peninsula, Costa Rica. $P=$ Pasture, $\mathrm{S} 1=$ secondary forest $<16$ years old, $\mathrm{S} 2=$ secondary forest $16-27$ years old, $\mathrm{S} 3=$ Secondary forest $>27$ years old, $\mathrm{MF}=$ mature forest. 


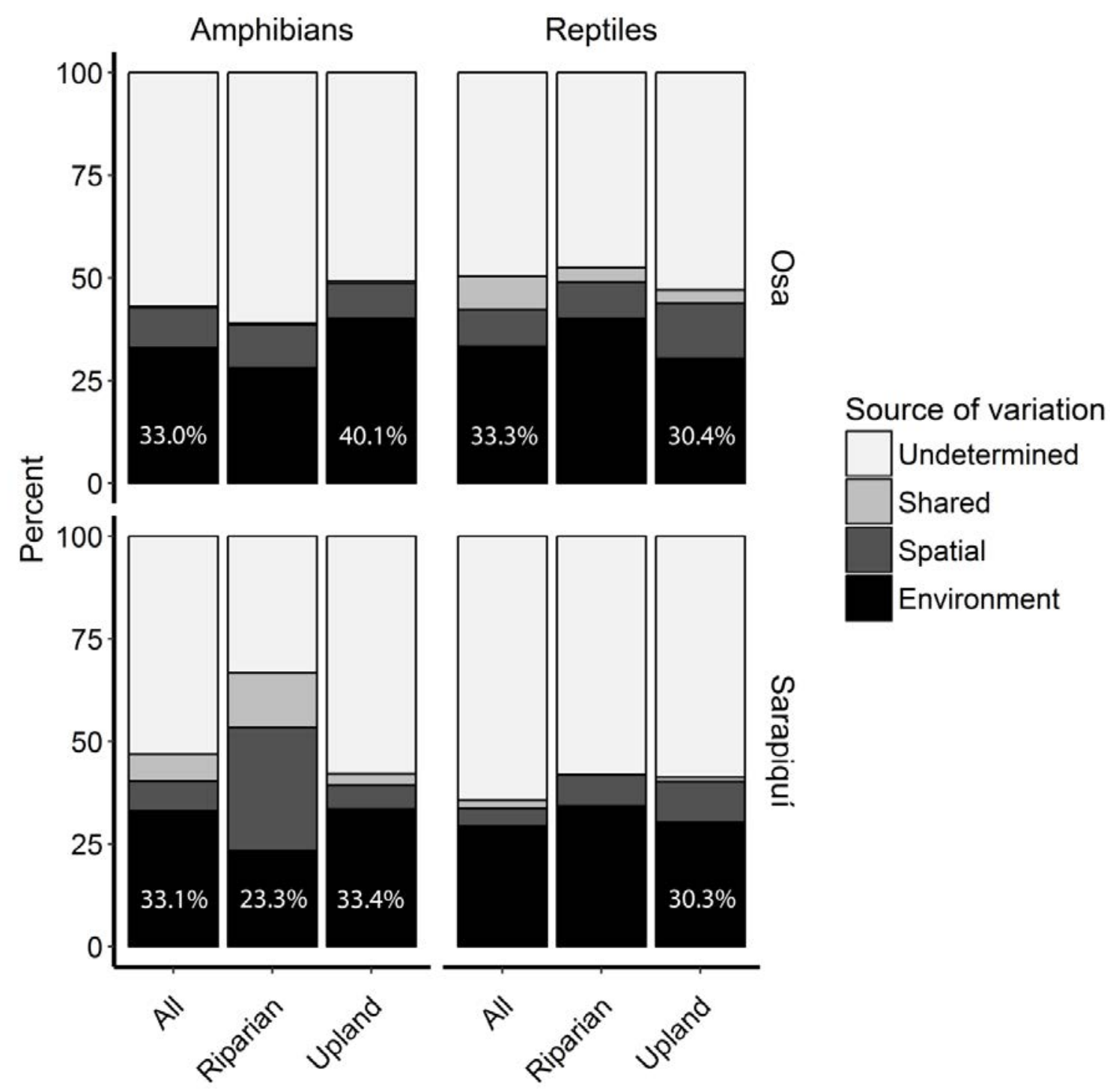

Figure 3.2. Variance partitioning results from partial canonical correspondence analysis for amphibian and reptile community composition in Sarapiquí and the Osa Peninsula. Bars labeled with percentages represent categories that were significant in partial Mantel tests. 


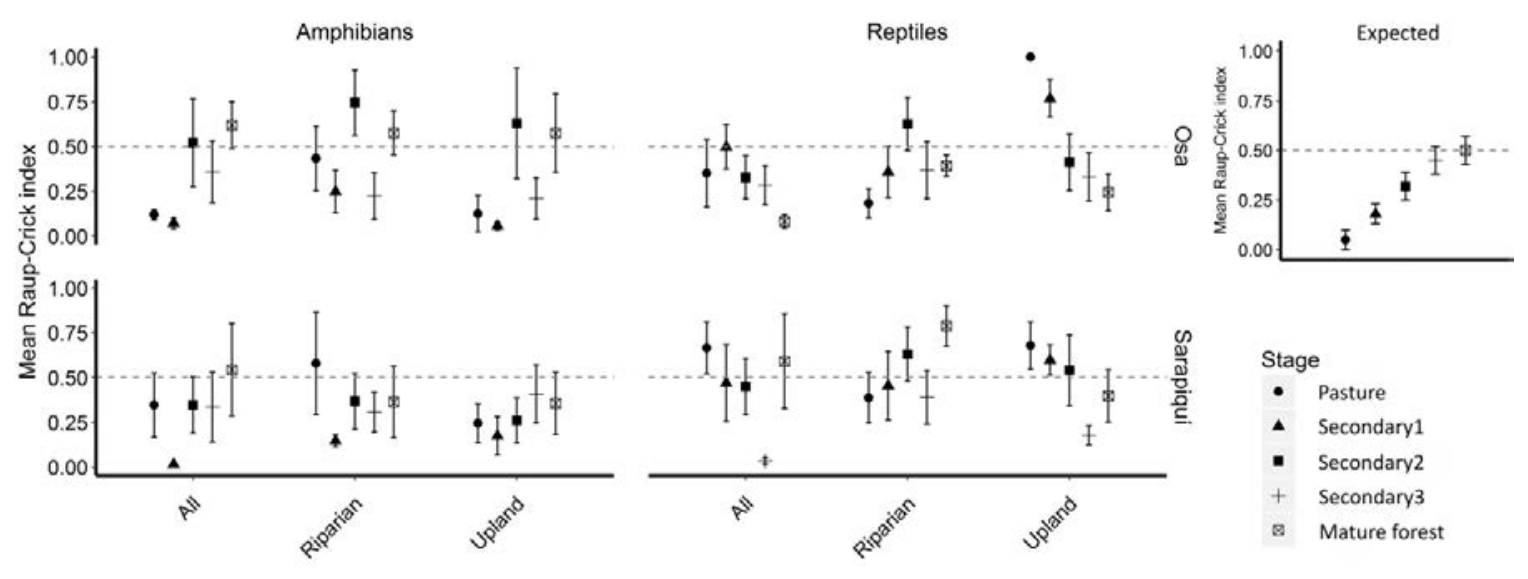

Figure 3.3. Mean Raup-Crick dissimilarity index ( $\pm 1 \mathrm{SE})$ by forest stage for amphibians and reptiles in Sarapiquí and the Osa Peninsula. Stochastically structured communities do not deviate from a Raup-Crick value of 0.5. Communities that are more similar than expected at random (communities structured by environmental filtering) have a RaupCrick index of less than 0.5.Communities that are less similar than expected at random (communities structured by biotic processes) have a Raup-Crick index of more than 0.5. The expected trend is shown in top right hand corner (deviation from 0.5 to be largest in pasture habitats, with mean Raup-Crick index converging on 0.5 as forest matures). 


\title{
CHAPTER 4: RECOVERY OF AMPHIBIAN AND REPTILE COMMUNITIES DURING TROPICAL SECONDARY FOREST SUCCESSION
}

\begin{abstract}
Intense deforestation and human transformation of landscapes is a main driver of biodiversity loss. There is potential for the regeneration of secondary forests on degraded lands to reverse some of the negative impacts caused by deforestation. However, there is a lack of understanding of the conservation value of secondary forest for wildlife. I evaluated the recovery of amphibian and reptile communities in tropical lowland wet forest in two regions of Costa Rica by determining whole community, group-specific (arboreal/terrestrial, lotic/lentic/terrestrial breeders) and species-specific responses to forest succession by measuring evenness, composition, community and species-specific probability of occurrence, and species richness. Mean occupancy response of anurans to forest stage was positively related to stage; mean occupancy was the lowest in pasture habitat. However, there was substantial variation in species-specific responses to successional change. I found that riparian habitats consistently maintain high species richness, and in upland habitats probability of occurrence of terrestrial breeding anurans was the most affected by structural changes as a result of forest succession. Terrestrial breeding anurans had a strong negative occupancy response to pasture, but increased in mean occupancy response as forest aged. My results suggest that secondary forests have high conservation value for many species of amphibians and reptiles and that in harsh
\end{abstract}


landscapes, such as those generated by land-use change, riparian corridors and other refuge habitats may be especially important in maintaining amphibian and reptile species diversity.

\section{INTRODUCTION}

Over the past century, high deforestation rates have transformed expanses of forest into landscapes consisting of a mosaic of remnant old-growth forest and secondary forest patches embedded in a matrix of human-altered land use such as agriculture, pastures, and urban living spaces (Tabarelli et al. 2010). In light of the global trend of a decrease in old-growth forest cover, and an increase of matrix (FAO 2015), secondary forests have high potential value as landscape elements that may mitigate for the loss of biodiversity and ecosystem services lost during deforestation (Brown and Lugo 1990). Currently, secondary forest is the dominant global forest cover type (FAO 2015) and in some countries, secondary forest may soon become the only forest type that remains (Dunn 2004). Despite the possibility of secondary forests to be considered as key elements in conservation management, there is a lack of understanding of the process of secondary forest succession and an even poorer understanding of the recovery of faunal communities during forest regeneration.

Two of the most important and still largely unanswered questions in research on forest succession are 1) how closely do the species in secondary forest resemble the assemblages of the original forest or nearby reference sites? and 2) what factors determine the rate and trajectory of recovery of communities during forest succession (Dunn 2004)? Across taxa, species richness and diversity decrease with increasing levels 
of degradation (Gibson et al. 2011). As forest regenerates, species richness and composition of some taxa have been shown to increase with forest age (e.g., birds, plants, see Dunn 2004) but secondary forests does not always provide suitable habitat for all species, especially specialists associated with a particular microhabitat (Dunn 2004). The trajectory of recovery of secondary forest communities may be species or group-specific, depend on presence or absence of specific habitat features such as breeding sites, and the interpretation of recovery dynamics may largely depend on the scale at which succession is studied and how communities are defined. Therefore, it is important to consider not only whole community responses but also group and species- specific responses, across different spatial scales.

In deforested landscapes, species assemblages at local sites tend to become taxonomically and functionally impoverished (Oliveira et al. 2004, Girãoet al. 2007) and at the landscape scale, communities of species tend to become taxonomically and functionally more similar, resulting in biotic homogenization (McKinney and Lockwood 1999, Olden and Rooney 2006). If secondary forests maintain high species richness, high dissimilarity of species composition among sites (as is typical of old-growth forest, e.g., Vázquez-Reyes 2017), and faunal communities recover in a short time span, then secondary forest will have high conservation value. In addition to potentially providing habitat suitable to maintain populations of species, secondary forests can also act as corridors between forests fragments (Faria 2006, Pardini et al. 2005). However, if secondary forests that regenerate from human-transformed land use have low species richness and species composition that more closely resembles that of degraded landscape 
than reference sites, then secondary forests might contribute to biological homogenization and be of low conservation value.

The physiological limitations, ecological requirements and small home range size relative to other fauna (Semlitsch et al. 2009) uniquely tie amphibians and reptiles to their abiotic environment. Additionally, amphibians and reptiles are known to comprise a high biomass in ecosystems (e.g., Burton and Likens 1975, Gibbons et al. 2006), have high value as prey items, and are important in nutrient cycling, which makes it imperative to understand how amphibian and reptile communities reassemble as forest regenerates and how these species may in turn contribute to ecological feedback during forest succession (Hocking and Babbitt 2014). These ecological characteristics make amphibian and reptile communities ideal to study the relationship between abiotic changes during forest succession and recovery of faunal communities. Compared to old growth forest, secondary forest have been found to differ in leaf litter structure, vegetation structure, and thermal and moisture microhabitat (Lieberman 1986, Chazdon 2014), all of which are thought to be important in regulating amphibian and reptile community composition and density (Lieberman 1986, Heinen 1992, Herrera-Montes and Brokaw 2010, Whitfield 2011). However, little is known about how amphibian and reptile communities recover over the course of secondary forest succession.

In this study, I evaluated the recovery of amphibian and reptile communities over the course of secondary forest succession in two tropical lowland forest sites of Costa Rica. I determined differences in community measures such as evenness, composition, and species richness. I also determined the community, group-specific and speciesspecific responses of probability of occurrence to different forest stages along the course 
of secondary forest succession. I interpreted findings in relation to spatial scale, and compare trends across regions, forest stages, and habitat type (upland, riparian). I expected to find similar trends between the two study regions which are similar in forest type (tropical lowland wet forest), regional species pools, and previous land use. I predicted that there would be distinct responses between communities associated with riparian and upland habitats and that strength of response to forest succession would be associated with ecological traits (general habitat use and breeding habitat).

\section{METHODS}

\section{Field methods}

Study sites: Generalizations of trends of faunal community recovery during forest succession have been hampered in past studies by lack of replication, lack of control for previous land-use, and because of difficulties with comparisons among regions with large differences in general habitat type and regional species pool. In this study, sites were selected to control for these variables (habitat type, altitude, previous land use, distance of secondary forests to reference sites, and regional species pools). I conducted amphibian and reptile surveys in two regions of Costa Rica, Sarapiquí (northeastern Costa Rica, $10^{\circ} 25^{\prime} 51.1^{\prime \prime} \mathrm{N} 84^{\circ} 00^{\prime} 53.1$ ”W) and the Osa Peninsula (southwestern Costa Rica, $8^{\circ} 25^{\prime} 29.0^{\prime \prime} \mathrm{N} 83^{\circ} 21^{\prime} 23.7^{\prime \prime} \mathrm{W}$ ) (Table 3.1, Figure 3.1). Both regions are dominated by tropical lowland wet forest (Holdridge 1971). Sarapiquí has an average annual precipitation of $4000 \mathrm{~mm}$ (Sanford et al. 1994) and the average for the Osa Peninsula is estimated to be $4000 \mathrm{~mm}-5500 \mathrm{~mm}$ (Sanchez-Azofeifa et al. 2002; McDiarmid and Savage 2005). Each of these regions is characterized by one contiguous plot of forest 
surrounded by forest fragments of varying size and age embedded in a matrix of agriculture and pasture land. Regional species pools have substantial overlap (McDiarmid and Savage 2005) and in many cases where there is not exact taxonomic overlap, species in one region were represented in the second region by their closest relative that is highly ecologically similar (e.g. Incilius melanochlorus in Sarapiquí and Incilius aucoinae in the Osa Peninsula). In each region, I surveyed a chronosequence of secondary forest sites regenerating from pasture ranging from $0-50$ years since abandonment as well as mature forest. I surveyed three replicates of each of five forest stages (abbreviations for each forest stage used throughout text shown in parentheses): pasture (P), secondary forest $<16$ years old (S1), secondary forest 17-27 years old (S2), secondary forest $>27$ years old (S3), and mature forest (MF, forest with a history of no or little human disturbance) in each of the two study regions (Table 3.1). Sites were all located less than $300 \mathrm{~m}$ in elevation.

Surveys: I conducted amphibian and reptile surveys using nocturnal and diurnal visual encounter surveys along transects (Crump and Scott 1994). Transect surveys are effective at sampling richness of tropical amphibians and reptiles (Pearman et al. 1995; Rödel and Ernst 2004) and allow for comparison across all land-use types. To increase detection of species that vary in seasonal activity patterns, I sampled on three occasions annually for two plus years (September 2014 - December 2016), with surveys occurring in both the wet and dry season, for a total seven sampling occasions per site. Each site was surveyed on at least six occasions. Data for sites that were surveyed an additional (seventh occasion) were only used in occupancy modeling analysis. All other analysis were conducted using six sampling occasions for each site. I surveyed six randomly 
placed $50 \times 2 \mathrm{~m}$ transects at each site. Three transects were in riparian habitat and three in upland habitat at least $30 \mathrm{~m}$ from any water features. Transects were located at least $30 \mathrm{~m}$ from edges and from another transects. The same transects were sampled repeatedly during the study. Species found during surveys are listed in Table 4.1.

Environmental characteristics: To determine how environmental variables vary over the course of secondary succession, I measured vegetation, leaf litter, and temperature, as these characteristics have been reported to change with forest stage (Chazdon 2014). I measured understory vegetation structure by tallying the number of times vegetation contacted a $2 \mathrm{~m}$ pole held vertically every $5 \mathrm{~m}$ along each upland transect at 5 height classes, $0,0.5,1.0,1.5$, and $2 \mathrm{~m}$. I measured leaf litter characteristics using two different metrics measured every $10 \mathrm{~m}$ along upland habitat transits at each site. I measured leaf litter depth (distance between the top of the soil and the top of the leaf litter measured with calipers), and leaf count (number of leaves pierced by spearing a random point). To measure differences in microclimate of different forest stages, habitat types, and substrate types, I placed iButton Thermochron dataloggers (DS1922L) in two randomly selected sites of pasture, secondary forest ( $>27$ years old), and mature forest sites in both upland and riparian habitats in leaf litter and attached to vegetation at $1 \mathrm{~m}$. Temperature was recorded by the dataloggers every half hour for a 10-day period 8 to 18 October, 2014.

$\underline{\text { Analysis }}$

Evenness: To compare species-abundance relationships among forest stages, I created rank-abundance plots (Whittaker plots) by plotting the log of the proportional 
abundance of species against species rank using package BiodiversityR (Kindt and Coe 2005). I compared assemblage evenness among stages by testing for a difference in slopes of rank-abundance curves (indicated by a significant interaction between species rank and forest stage in a two-way ANOVA) (Magurran 2004).

Composition: To determine if there is a difference amphibian and reptile community composition among forest stages, I used non-metric multidimensional scaling (NMDS) ordination and ANOSIM permutation tests (Clarke 1993) with species presenceabsence matrices using the $\mathrm{R}$ package vegan (Oksanen et al. 2017).

Occupancy: I used Bayesian hierarchical multi-species occupancy models (Dorazio and Royle, 2005, Zipkin et al., 2009) to estimate community and speciesspecific probability of occurrence and probability of detection parameters in relation to variables of interest. Hierarchical multi-species occupancy models account for imperfect detection (Dorazio and Royle 2005, Dorazio et al. 2006, Kery et al 2009) and improve individual parameter estimates, especially for rare species, (higher precision, less bias) by considering them as part of the larger community (Sauer and Link 2002, Zipkin et al. 2009). In addition to probability of occurrence and detection, other community measures of interest (e.g., species richness) can also be estimated, accounting for unobserved species during sampling (Dorazio et al. 2006, Zipkin et al. 2009).

For models used in analysis, occurrence, $z_{i j}$, is a binary variable where $z_{i j}=1$ if a species $i$ was present at site $j$, and $z_{i j}=0$ if a species was absent. I specified the occurrence state as the outcome of a Bernoulli random variable specified as $z_{i j}=$ $\sim \operatorname{Bern}\left(\Psi_{i j}\right)$, where $\Psi_{i j}$ is the probability that species $i$ occurs at site $j$. Repeated presenceabsence survey data at each site resulted in a data matrix $x_{i j k}$ for species $i$ at site $j$ at the 
$k$ th survey occasion. The detection model was specified as $x_{i j k} \sim \operatorname{Bern}\left(\Theta_{i j k} z_{i j}\right)$ where $\Theta_{i j k}$ is the probability of detection of species $i$ at site $j$ at the $k$ th survey. The detection model fulfills the condition that detection is zero when species $i$ is not present because $z_{i j}$ would be zero in that case.

I estimated community and species-specific responses to site-specific covariates forest stage and habitat (upland, riparian) and survey-specific covariates effort (person transect hours, z-transformed) and season (wet, dry). Effort was only included in models analyzing the Sarapiquí region datasets because effort was consistent in the Osa Peninsula surveys. I converted categorical variables to dummy variables (forest stage [mature forest used as the reference group], habitat [upland 0, riparian 1], and season [wet 0 , dry 1]. Site was included as a random effect to account for multiple transects surveyed at each site. I ran separate models for the Sarapiquí and Osa Peninsula and separate models for anurans and lizards. I first analyzed whole communities and then groups of species that share similar ecological traits that I predicted would affect response to forest succession: breeding strategy and general habitat use. For anurans, species were grouped into three main breeding habitat categories, terrestrial, lotic, and lentic. Anuran species were assigned to a category depending on where eggs and/or larvae develop. For both anurans and lizards, species were categorized as primarily terrestrial or primarily arboreal. I did not analyze lizard species by breeding habitat group because there is not much variation in breeding habitat of species (most lay eggs terrestrially or in leaf litter). Species used in occupancy analysis (i.e., detected during transect surveys) and categorical assignments are listed in Table 4.2. Species were assigned to categories following natural history accounts in (Savage 2002). 
The following equations represent the hierarchical models described above:

$$
\begin{aligned}
& \operatorname{logit}\left(\Psi_{i j}\right)=u_{i}+\alpha 1_{i} P_{j}+\alpha 2_{i} S 1_{j}+\alpha 3_{i} S 2_{j}+\alpha 4_{i} S 3_{j}+\alpha 5_{i} \text { habitat }_{j}+\alpha 6_{i} P * \text { habitat }_{j} \\
& +\alpha 7_{i} S 1 * \text { habitat }_{j}+\alpha 8_{i} S 2 * \text { habitat }_{j}+\alpha 9_{i} S 3 * \text { habitat }_{j} \\
& \operatorname{logit}\left(\Theta_{i j k}\right)=v_{i}+\beta 1_{i} \text { Season }_{j k}+\beta 2_{i} \text { effort }_{j k}
\end{aligned}
$$

Parameters $u_{i}$ and $v_{i}$ are the species-specific occurrence and detection probabilities (on the logit scale) that follow a joint normal distribution where $\left[u_{i}, v_{i} \mid \Sigma\right] \sim \mathrm{N}(0, \Sigma)$ (Dorazio et al. 2006). The variable $\sum$ represents a $2 \times 2$ symmetric matrix with variances $(\sigma)$ of $u_{i}$ and $v_{i}$ as the diagonal elements and covariances of $u_{i}$ and $v_{i}$ as the off-diagonal elements (Dorazio and Royle 2005). The community-level hierarchical component assumes that species-specific parameters were random effects governed by a communitylevel hyper-parameter. For example, $\alpha 1_{i} \sim N\left(u_{\alpha l}, \sigma_{\alpha l}\right)$, where $u_{\alpha l}$ is the mean communitylevel response to the covariate habitat and $\sigma_{\alpha l}$ is the standard deviation across all species. I specified mean and standard deviation for each of the 10 species-specific occurrence parameters $\left(u_{i}, \alpha 1_{i}, \alpha 2_{i}, \alpha 3_{i}, \alpha 4_{i}, \alpha 5_{i}, \alpha 6_{i}, \alpha 7_{i}, \alpha 8_{i}\right.$, and $\left.\alpha 9_{i}\right)$ and two detection parameters in Sarapiquí $\left(v_{i}, \beta 1_{i}\right.$,and $\left.\beta 2_{i}\right)$ as in the aforementioned example.

For each model, I ran 90,000 iterations of three chains after discarding 8,000 iterations and thinning by 20 , resulting in 12,300 draws for posterior estimates for each model. I used uninformative priors for all hyper-parameters (coefficients $\sim$ normal[ $[0$ $, 0.368]$, standard deviations $\sim$ half-Cauchy[1]). I evaluated convergence using the Gelman and Rubin statistic $(<1.01$ for all monitored parameters; Gelman and Rubin 
1992). I ran models by calling program JAGS (Plummer 2003) from R (R Core Team 2017) using package jagsUI (Kellner 2014).

Environmental variables: I compared leaf litter measurements (square root transformed to meet assumptions of normality) among forest stages using linear mixed effects models with site as a random effect in package nlme (Pinheiro et al. 2017). To test if stratification of vegetation structure was independent of forest stage, I used a Chisquare test for independence and pairwise post-hoc tests with a Bonferroni correction using function 'chisq.post.hoc' in package fifer (Fife 2017).

All analyses were conducted in R v3.4.3(R Core Team 2017).

\section{RESULTS}

I observed a total of 96 species during surveys in Sarapiquí; 42 species of amphibians and 54 species of reptiles. I observed a total of 71 species during surveys in the Osa Peninsula; 35 species of amphibians and 36 species of reptiles (Table 4.1).

Evenness: For anurans, there were similar species-abundance relationships among forest stages in upland habitat (Sarapiquí: $\mathrm{F}_{4,80}=0.278, \mathrm{p}=0.891 ;$ Osa: $\mathrm{F}_{4,57}=1.501, \mathrm{p}=$ 0.214; Figure 4.1). In riparian habitat, I found that pasture sites tend to support a more even assemblage of anurans than other forest stage categories (Sarapiquí: $\mathrm{F}_{4,90}=3.634, \mathrm{p}$ $=0.009$; Osa: $F_{4,75}=4.29, p=0.003$; Figure 4.1). Visual inspection of the rankabundance plots indicates that, in general, older stages of secondary forest and mature forest had more rare species than younger stages of secondary forest and pasture. The most common anuran species in both upland and riparian habitats of the Osa Peninsula were Craugastor bransfordii, Craugastor fitzingeri, and Diasporus diastema. In pasture 
habitats Rhinella marina, and Lebptodactylus bolivianus were also common. The most common anuran species in both upland and riparian habitats of Sarapquí were Oophgaha pumilio, Craugastor fitzingeri, and Diasporus diastema and in only upland habitats, Craugastor bransfordii.

For reptiles, there were similar species-abundance relationships among forest stages in upland habitat (Sarapiquí: $\mathrm{F}_{4,24}=1.181, \mathrm{p}=0.344$; Osa: $\mathrm{F}_{4,22}=2.705, \mathrm{p}=$ 0.057; Figure 4.1). In riparian habitat, I found that pasture sites tend to support a more even assemblage of reptiles than other forest stage categories in Sarapiquí but not in the Osa Peninsula (Sarapiquí: $\mathrm{F}_{4,25}=3.930, \mathrm{p}=0.013$; Osa: $\mathrm{F}_{4,25}=0.434, \mathrm{p}=0.783$ ). The most common lizard species in both upland and riparian habitats in the Osa Peninsula, were Norops polylepis, and Leptosoma southi, and only in riparian habitat, Basiliscus, basiliscus. The most common lizard species in riparian habitats in the Sarapiquí were Norops oxylophus and Basiliscus plumifrons.

Composition: I found stronger evidence for distinct amphibian and reptile communities among forest stages in upland habitat (Sarapiquí anurans: $\mathrm{R}=0.511, \mathrm{p}=$ 0.008; Osa anurans: $\mathrm{R}=0.550, \mathrm{p}=0.010$; Sarapiquí lizards: $\mathrm{R}=0.410 \mathrm{p}=0.072$; Osa lizards: $\mathrm{R} 0.576, \mathrm{p}=0.007$ ) than in in riparian habitat (Sarapiquí anurans: $\mathrm{R}=0.392, \mathrm{p}=$ 0.072, Osa anurans: $R=0.322 p=0.261$; Sarapiquí reptiles: $R=0.421 p=0.078$ Osa reptiles: $\mathrm{R}=0.375, \mathrm{p}=0.166$ ). Pastures tended to host the most distinct communities across all forest stages (Figure 4.2).

Occupancy models: For Sarapiquí anurans, I made 2,406 observations of 38 species, for Osa anurans I made 1,799 observations of 33 species, for Sarapiquí lizards, I 
encountered 685 individuals of 17 species, and for Osa lizards I made 766 observations of 17 species for analysis.

Community-level response: The occupancy models estimated a total species richness across sites to be 43.18 (95\% CI 39.00-50.00) for Sarapiquí anurans, 34.59 (95\% CI 33.00 - 38.00) for Osa anurans, 21.04 (95\% CI 17.00 - 28.00) for Sarapiquí lizards and 23.95 (95\% CI $18.00-36.00)$ for Osa lizards. Mean probability of occurrence was $0.174(95 \%$ CI $0.011-0.553)$ for Sarapiquí anurans, 0.104 (95\% CI $0.114-0.420)$ for Osa anurans, 0.232 (95\% CI 0.009 - 0.75) for Sarapiquí lizards and 0.201 (95\% CI $0.006-0.636$ ) for Osa lizards. Community mean probabilities of detection were low 0.106 (95\% CI 0.049-0.176) for Sarapiquí anurans, 0.135 (95\% CI 0.067 - 0.237) for Osa anurans, 0.060 (95\% CI 0.013 - 3.696) for Sarapiquí lizards and 0.029 (95\% CI $0.023-0.092)$ for Osa lizards.

Community level responses to the occupancy covariates reveal a positive relationship between forest stage and probability of occurrence for anurans in upland habitat. Anurans showed strong negative mean responses to pasture and this negative response weakened in a fairly linear fashion as forest stage progressed (Table 4.3). The positive response was reflected in the relationship between estimates of species richness and forest stage in Sarapiquí (Figure 4.4). The dry season had a negative effect on probability of detection of anurans (Table 4.3).

Group-level response: Group probability of occupancy of terrestrial breeding anurans was positively associated with forest stage in both Sarapiquí and the Osa Peninsula. Terrestrial breeding anurans had a strong negative response to pasture habitat. However, the negative response to occupancy covariate waned in a linear fashion as 
forest stage aged (the coefficient became less negative in response to stage S1, and negligible or positive for stages S2 and S3 (Table 4.3). Lotic and lentic breeding anurans tended to be more associated with riparian habitat and terrestrial breeding anurans with upland habitat but this trend was only significant for lotic breeders (Table 4.4, Figure 4.5). There was no difference in response for groupings of arboreal or terrestrial anurans or lizards. Probability of detection was significantly lower in the dry season for anurans that breed in lotic habitats (Table 4.4).

Species-specific response: Species-specific mean probability of occurrence among forest stages was variable (Figures 4.5-4.8). In Sarapiquí, anuran species-specific mean probability of occurrence ranged from 0.0009 (95\% CI $0.0003-0.006$, Sachatamia ilex) to 0.999 (95\% CI 0.995 - 1.000, Diasporus diastema) and lizard species-specific mean probability of occurrence ranged from $0.0002(95 \%$ CI $0.00004-0.003$, Gonatodes albogularis) to 0.980 (95\% CI 0.945 - 0.996, Norops oxylophus). In the Osa Peninsula, anuran species-specific mean probability of occurrence ranged from 0.0009 (95\% CI $0.003-0.181$, Phyllobates vittatus) to 0.995 (95\% CI $0.431-0.562$, Craugastor stejnegerianus) and lizard species-specific mean probability of occurrence ranged from 0.002 (95\% CI $0.0002-0.062$, Ctenosaura similis) to 0.967 (95\% CI $0.876-0.992$, Basiliscus basiliscus).

Species-specific responses to forest stage, in comparison to reference mature forest sites, was more variable in pasture and early secondary forest compared to older stages of secondary forest (Figures 4.5-4.8). Many anuran species showed significant positive relationships in probability of occurrence and forest stage (Allobates talamancae, Boana rufitela, Craugastor bransfordii, Crangastor megacephalus, Craugastor mimus, 
Craugastor stejnegerianus, Espadarana prosoblepon, Oophaga pumilio, Pristimantis cerasinus, Pristimantis ridens, and Teratohyla spinosa) and other species showed significant negative responses (Dendropsophus ebraccatus, Dendropsophus microcephalus, Leptodactylus bolivianus, Leptodactylus poecilochilus, Rhinella marina, and Scinax elaeochrous) (Figures 4.5, 4.6).

Lizard species-specific response to occupancy covariates was not as variable as anuran response (Figures 4.7, 4.8). Corytophanes cristatus and Norops humilis had the most negative response to pasture and early successional forest stage (Figures 4.7, 4.8)

The anurans most associated with riparian habitats were glass frogs in the family Centrolenidae, Craugastor fitzingeri, Lithobates vaillanti, Rhinella marina, and Smilisca sordida. The lizards most associated with riparian habitats were Basiliscus basiliscus, Basiliscus plumifrons, and Norops oxylophus. Norops humilis, Norops limifrons, and Sphenomorphus cherriei were negatively associated with riparian habitat (Figures 4.5-4.8).

Environmental variables: Leaf litter count in upland mature forest and all secondary forest stages was significantly higher than in pasture (Sarapiquí: MF-P est = $1.42, \mathrm{t}=4.50, \mathrm{p}=0.001 \mathrm{~S} 3-\mathrm{P}$ est $=1.36, \mathrm{t}=4.30, \mathrm{p}=0.002 ; \mathrm{S} 2-\mathrm{P}$ est $=1.49, \mathrm{t}=4.70, \mathrm{p}=$ $0.001 ; \mathrm{S} 1-\mathrm{Pest}=1.64, \mathrm{t}=5.16, \mathrm{p}<0.001 ;$ Osa:MF-P est $=1.92, \mathrm{t}=12.17, \mathrm{p}<0.001$; $\mathrm{S} 3-\mathrm{P}$ est $=1.79, \mathrm{t}=11.36, \mathrm{p}<0.001 ; \mathrm{S} 2-\mathrm{P}$ est $=1.74, \mathrm{t}=10.31, \mathrm{p}<0.001 ; \mathrm{S} 1-\mathrm{Pest}=$ $1.61, t=9.90, p<0.001 ;$ Figure 4.9). Leaf litter depth in upland mature forest and all secondary forest stages was significantly higher than in pasture site in the Osa Peninsula (Osa: $\mathrm{MF}-\mathrm{P}$ est $=1.49, \mathrm{t}=5.87, \mathrm{p}<0.001 ; \mathrm{S} 3-\mathrm{P}$ est $=1.30, \mathrm{t}=5.14, \mathrm{p}<0.001 ; \mathrm{S} 2-\mathrm{P}$ est $=1.30, \mathrm{t}=4.99, \mathrm{p}<0.001 ; \mathrm{S} 1-\mathrm{Pest}=1.12, \mathrm{t}=4.39, \mathrm{p}<0.001 ;$ Figure 4.9). No other 
paired comparisons between forest stages were significantly different for leaf litter measurements.

Vegetation structure was not independent of forest stage $\left(\mathrm{Osa}: \chi^{2}=188.84, \mathrm{df}=\right.$ 16, $\mathrm{p}<0.001$; Figure 4.10). Significant pairwise differences were found between pasture and all other forest stages, and between S1 and S3 (Osa: MF-P $\mathrm{p}_{\mathrm{adj}}<0.001 ; \mathrm{S} 3-\mathrm{Pp} \mathrm{padj}_{\mathrm{j}}<$ $\left.0.001 ; \mathrm{S} 2-\mathrm{P} \mathrm{p}_{\mathrm{adj}}<0.001 ; \mathrm{S} 1-\mathrm{P} \mathrm{p}_{\mathrm{adj}}<0.001 ; \mathrm{S} 1-\mathrm{S} 3 \mathrm{p}_{\mathrm{adj}}=0.500\right)$.

Visual inspection of the temperature plots suggests that day time temperature varied by land-use type, habitat (upland or riparian), and by microhabitat type (Figure 4.11). Pasture had higher average temperature and a higher variation in temperatures compared to secondary forest and mature forest. In pastures, riparian habitat had lower average temperatures through most of the day and lower variation of temperature throughout the day compared to pasture upland habitat. Temperature of dataloggers on vegetation at $1 \mathrm{~m}$ recorded higher temperatures and higher variation of temperature than leaf litter microhabitat; this trend was most striking in pasture sites (Figure 4.11).

\section{DISCUSSION}

The comparison of whole community, group, and species-specific parameters across spatial scales during tropical forest succession resulted in novel insights into the trends and sources of variation in response of amphibian and reptile species to forest regeneration. I found that, in general, secondary forest has a high conservation value for amphibians and reptiles and species assemblages are similar to reference sites in richness and composition after only two to three decades of regeneration. I also found that response and/or strength of response depended on level of community analyzed (whole 
community, group and species-specific) and scale of patch analyzed (whole forest patch or upland and riparian communities considered separately).

Whole-community level responses to occupancy parameters had a fair level of uncertainty (many posterior estimates contained both positive and negative values). The uncertainty in parameter estimates I found for whole-community level responses is expected for large communities of amphibians and reptiles with such diverse ecological requirements, even among closely related species (Irwin et al. 2010). Different group or species-specific responses can result in an overall no significant effect when the community is considered as a whole (Thompson et al. 2016). However, even with uncertainty in parameter estimates for occupancy, there is a clear trend of decreasing difference in probability of occurrence of forest stage and mature forest as forest ages; community probability of occurrence approaches similar values as mature forest about 20-30 years of regeneration.

Diversity of microhabitats (Suarzo-Ortuño 2008) and breeding habitats (Crump 1982) and habitat structural complexity may be important factors in determining species richness of herpetofauna as forest regenerates. Additionally, thermal microhabitat can be a critical determinate for the presence of ectothermic species (Kearney et al. 2009, Sinervo et al. 2010). I found the largest changes in species composition and trends in probability of occurrence in the transition from pasture to early secondary forest. The early transition from pasture to young secondary forest was also the most dramatic in changes of environmental variables. I found the strongest positive relationship between forest stage and probability of occurrence for anurans that breed in terrestrial habitat. Other studies have also found that terrestrial breeders, such as direct developers, are 
sensitive to human-modified habitats (Nowakowski et al. 2017). Many tropical terrestrial breeders may require moist leaf litter layer for successful development of their embryos (Wells 2007). Tropical anuran terrestrial breeders also have been found to have lower upper thermal tolerances, in comparison to aquatic breeding anurans (Nowakowski et al. 2016). The lack of leaf litter in pastures and some early secondary forests, and higher temperatures in these early forest stages are likely important factors that contributed to the negative response of terrestrial breeders in my study. The negative occupancy response to pasture habitat and linear increase in probability of occurrence as forest stage increased in age was stronger in the Sarapiquí region than in the Osa Peninsula. There was a lower species richness of terrestrial breeding anurans, in general, in the Osa, which may have contributed to the differences in strength of support found among the regions. It is possible that the lower species richness of this group in the Osa resulted in more subtle changes requiring more power to detect the response.

I found a positive mean occupancy response of lentic (still water) breeding amphibians to pasture habitat in the Osa Peninsula. Although there was uncertainty in the mean group response of lentic breeders in the Osa (credible interval for covariate pasture contained both positive and negative values) the positive mean estimate suggests that a number of lentic breeders are associated with pasture habitat and a look at the speciesspecific responses confirms the presence of positive responses of a selection of both arboreal and terrestrial lentic breeding anurans (e.g., D. ebraccatus and L. bolivianus). Pond breeders may be successful in human modified habitats such as pastures or clearcuts because in naturally forested habitats these species often gather to breed in open swampy areas which are similar to flooded pasture habitats after rain, and lentic breeding 
anurans respond more strongly to rainfall patterns than habitat type (Neckel-Oliveira and Gascon 2006). Breeding sites such as swamps are often have greater distances between them in forest patches than the multiple low points that become swamp-like breeding sites in a pasture site. An increase in breeding sites may increase density and species richness of lentic breeding anurans (Neckel-Oliveira and Gascon 2006).

I found no strong response of probability of occurrence of lizards to secondary forest succession when data were analyzed by whole community or by habitat-use group. Past studies have found that arboreal lizards are more sensitive to habitat modification (Theisinger and Ratianarivo 2015); however my results do not support higher sensitivity of arboreal lizards compared to species that are not aboreal. Instead, I found several species-specific negative occupancy responses to pasture (C. cristatus [arboreal], $N$. humilis [terrestrial], and N. oxylophus [arboreal]) that suggest that pasture habitat is not suitable for all lizard species and that response is irrespective of general habitat-use group. Many lizard species observed during pasture surveys ( $>90 \%)$ were located in refuge habitats, within $10 \mathrm{~m}$ of remnant trees or in riparian habitat. Even though I did not find a trend in probability of occurrence of many lizard species to forest stage, there may be large portions of pasture habitat that are uninhabitable to lizards species found in pasture habitat, likely limiting populations of lizards at these sites. In forested habitats, heliothermic lizards prefer gaps and edges to achieve optimal body temperature. Therefore I predicted that gap-specialists may be able to take advantage of pasture and early secondary forest habitats. I did not find support for an increase in the probability of occurrence of common heliothermic lizards (such as lizards in the genus Holcosus and Iguana iguana) in pasture habitats. Even though Holcosus species and I. iguana have 
high thermal tolerances that would allow them to persist in the high temperatures of pasture habitat, other habitat characteristics such as food availability may be missing from pasture sites. Although I did not find a difference in species richness among forest stages, species composition of lizards in pasture was different from species composition in forest habitat.

Regarding the questions 1) how closely do the species in secondary forest resemble the assemblages of the original forest or reference sites? and 2) what factors determine the rate and trajectory of recovery of communities during forest succession?, My results support other chronosequence studies in tropical forests that amphibian and reptile species richness recovers rapidly, approaching similar values as reference sites within about 20 - 30 years (Hilje and Aide 2010, Hernández-Ordóñez et al. 2015). However, it is important to note that secondary forest and pasture sites in this study were located close to old-growth remnants. Therefore, results from this study likely represent a best-case scenario. Recovery of communities during forest succession has been found to decline with increasing distance to reference sites for plants (Zimmerman et al. 2000). Secondary forest that is located far from reference sites likely will have a slower recovery time for wildlife, especially for species with low vagility like many amphibians and reptiles. The different responses of amphibians and reptiles highlight the importance of considering these species separately in research and conservation management. The trajectory of recovery of secondary forest communities at my sites was dependent on species group and habitat type, which highlights the importance of not only focusing on analysis of the whole community together but also group and species- specific responses, 
across spatial scales to fully understand the dynamics of faunal recovery during forest succession.

Protection of old-growth forests is no doubt an important strategy to maintain biodiversity. However, it is essential that conservation planning extend past only preserving old-growth stands to incorporating other critical components in humantransformed landscapes such as increasing connectivity of forest patches by preserving secondary forests and riparian corridors. My results support that secondary forests are important to maintaining biodiversity in human-transformed landscapes (Chazdon et al 2009). While amphibian and reptile assemblages recover fairly rapidly, the continued success of recovery during early secondary forest succession will also depend on the presence of nearby old-growth forest and old secondary forest patches to foster recovering populations (Cramer et al. 2008). Riparian corridors are important in providing refuge for species in harsh modified or early stages of forest succession and should have high priority in conservation planning.

\section{LITERATURE CITED}

Burton, T. M., and G. E. Likens 1975. Energy Flow and Nutrient Cycling in Salamander Populations in the Hubbard Brook Experimental Forest, New Hampshire. Ecology 56: $1068-1080$.

Chazdon, R. L. 2014. Second Growth: The Promise of Tropical Forest Regeneration in an Age of Deforestation. Page 472.

Chazdon, R. L., C. A. Peres, D. Dent, D. Sheil, A. E. Lugo, D. Lamb, N. E. Stork, and S. E. Miller. 2009. The potential for species conservation in tropical secondary forests. Conservation Biology 23:1406-1417.

Clarke, K.R., 1993. Nonparametric multivariate analyses of changes in community structure. Australian Journal of Ecology 18: 117-143. 
Cramer, V. A., R. J. Hobbs, and R. J. Standish. 2008. What's new about old fields? Land abandonment and ecosystem assembly. Trends in Ecology and Evolution 23:104 112.

Crump, M. L., and N. J. Scott.1994. Visual Encounter Surveys. In Heyer WR, Donnelly MA, McDiarmid RW, Hayek LC, Foster MS (eds) Measuring and Monitoring Biological Diversity: Standard Methods for Amphibians. Smithsoniain Institution Press, Washington DC, pp 84-92.

Dorazio, R.M., and J. A. Royle. 2005. Estimating size and composition of biological communities by modeling the occurrence of species. J. Am. Stat. Assoc. 100: 389398.

Dorazio, R.M., J. A. Royle, B. Soderstrom, and A. Glimskar. 2006. Estimating species richness and accumulation by modeling species occurrence and detectability. Ecology 87: 842-854.

Dunn, R. R. 2004. Recovery of faunal communities during tropical forest regeneration. Conservation Biology 18:302-309.

FAO (Food and Agriculture Organization). 2015. Global Forest Resources Assessment 2015: How are the world's forests changing? Second Edition.

Faria, D., 2006. Phyllostomid bats of a fragmented landscape in the north-eastern Atlantic forest. Brazilian Journal of Tropical Ecology 22: 531-542.

Girão, L. C., A. V. Lopes, M. Tabarelli and E. M. Bruna. 2007. Changes in tree reproductive traits reduce functional diversity in a fragmented Atlantic forest landscape.

Plos one 2: e908.

Gelman A., D. B. Rubin. 1992. Inference from iterative simulation using multiple sequences. Stat Sci 7:457-472.

Gibbons et al. 2006. Remarkable Amphibian Biomass and Abundance in an Isolated Wetland: Implications for Wetland Conservation. Conservation Biology 20: 14571465.

Heinen, J. T. 1992. Comparisons of the leaf litter herpetofauna in abandoned cacao plantations and primary rain forest in Costa Rica : some implications for faunal restoration. Biotropica 24:431-439.

Herrera-Montes, A., and N. Brokaw. 2010. Conservation value of tropical secondary forest: A herpetofaunal perspective. Biological Conservation 143:1414-1422. 
Hernández-Ordóñez, O., N. Urbina-Cardona, and M. Martínez-Ramos. 2015. Recovery of amphibian and reptile assemblages during old-field succession of tropical rain forests. Biotropica 47:377-388.

Hilje, B., and T. M. Aide. 2012. Recovery of amphibian species richness and composition in a chronosequence of secondary forests, northeastern Costa Rica. Biological Conservation 146:170-176.

Hocking, D. J. and K. J. Babbitt. 2014. Amphibian contributions to ecosystem services. Herpetelogical Conservation and Biology 9: 1-17.

Holdridge, L. R. 1971. Forest Environments in Tropical Life Zone: A Pilot Study. Page 747.

Irwin, M. T. et al. 2010 Patterns of species change in anthropogenically disturbed forests of Madagascar. Biological Conservation 143: 2351-2362.

Kearney M., R. Shine, W. P. Porter. 2009. The potential for behavioral thermoregulation to buffer 'cold-blooded' animals against climate warming. Proc Nat Acad Sci USA 106:3835-3840.

Kellner, K. 2015. jagsUI: A Wrapper Around rjags to Streamline JAGS Analyses. R package version 1.3.1. https://CRAN.R-project.org/package=jagsUI

Kéry, M., J. A. Royle, M. Plattner, R. M. Dorazio. 2009. Species richness and occupancy estimation in communities subject to temporary emigration. Ecology 90: 1279-1290.

Lieberman, S. 1986. The ecology of the leaf litter herpetofauna of a neotropical rain forest: La Selva, Costa Rica. Acta Zoológica Mexicana 15:1-72.

Magurran, A. E., 2004. Measuring Biological Diversity. Blackwell Science, Oxford.

McDiarmid, R. W., and J. M. Savage. 2004. The Herpetofauna of the Rincón Area, Península de Osa, Costa Rica, a Central American Lowland Evergreen Forest Site. Pages 366-427 in M. A. Donnelly, B. I. Crother, C. Guyer, and M. H. Wake, editors. Ecology and Evolution in the Tropics A Herpetological Perspective.

McKinney, M. L., and J. L. Lockwood 1999. Biotic homogenization: A few winners replacing many losers in the next mass extinction. Trends in Ecology \& Evolution 14:450-453.

Neckel-Oliveira, S. and C. Gascon, 2006. Abundance, body size and movement patterns of a tropical treefrog in continuous and fragmented forests in the Brazilian Amazon. Biological Conservation 128:308-315. 
Nowakowski, A. J., J. I. Watling, S. M. Whitfield, B. D. Todd, D. J. Kurz, and M. A. Donnelly. 2018. Tropical amphibians in shifting thermal landscapes under land-use and climate change. Conservation Biology 31: 96-105.

Nowakowski A. J., M. E. Thompson, M. A. Donnelly, B. D. Todd. 2017. Amphibian sensitivity to habitat modification is associated with population trends and species traits. Global Ecology and Biogeography 26:700-712.

Olden, J. D., and T. P. Rooney. 2006. On defining and quantifying biotic homogenization. Global Ecology and Biogeography 15:113-120.

Oliveira, M. A., A. S. Grillo, and M. Tabarelli. 2004. Forest edge in the Brazilian Atlantic forest: drastic changes in tree species assemblages. Oryx 38:389-394.

Oksanen, J., Kindt, R., Legendre, P., O’Hara, R.B., 2006. Vegan: Community Ecology Package version 1.6-10 hhttp://cran. r-project.orgi.

Pardini, R., S. M. de Souza, R. Braga-Neto, and J. P. Metzger. 2005. The role of forest structure, fragment size and corridors in maintaining small mammal abundance and diversity in an Atlantic forest landscape. Biological Conservation 124: 253-266.

Pearman, P. B., A. M. Velasco, and A. López. 1995. Tropical Amphibian Monitoring: A Comparison of Methods for Detecting Inter-Site Variation in Species' CompositionNo Title. Herpetologica 51:325-337.

Pinheiro J., D. Bates, S. DebRoy, D. Sarkar, and R Core Team 2017. nlme: Linear and Nonlinear Mixed Effects Models. R package version 3.1-131, https://CRAN.Rproject.org $/$ package $=$ nlme.

Plummer, M. 2003. JAGS: A program for analysis of Bayesian graphical models using Gibs sampling In Hornik K, Leisch F, Zeileis A (eds) Proceedings of the 3rd International.

R Core Team. 2017. R: A language and environment for statistical computing. $\mathrm{R}$ Foundation for Statistical Computing, Vienna, Austria. URL https://www.Rproject.org/.

Rödel, M., and R. Ernst. 2004. Measuring and monitoring amphibian diversity in tropical forests .I. An evaluation of methods with recommendations for standardization. Ecotropica 10:1-14.

Sanford, R. J., P. Paaby, J. Luvall, and E. Phillips. 1994. Climate, geomorphology, and aquatic systems. in L. McDade, K. Bawa, H. Hespenheide, and G. Hartshorn, editors. La Selva: Ecology and natural history of a Neotropical rain forest. 
Sauer, J. R., and W. A. Link. 2002. Hierarchical modeling of population stability and species group attributes from survey data. Ecology 86: 1743-1751.

Savage, J. M. 2002. The Amphibians and Reptiles of Costa Rica: A Herpetofauna between two Continents, between two Seas. University of Chicago Press, Chicago.

Semlitsch, R.D., K. M. O’Donnell, F. R. and F.R. Thompson, III. 2014. Abundance, biomass production, nutrient content, and the possible role of terrestrial salamanders in Missouri Ozark forest ecosystems. Canadian Journal of Zoology 92:997-1004.

Sinervo, B. et al. 2010 Erosion of lizard diversity by climate change and altered thermal niches. Science 328: 894-899.

Suazo-Ortuño, I., J. Alvarado-Díaz, and M. Martínez-Ramos. 2008. Effects of conversion of dry tropical forest to agricultural mosaic on herpetofaunal assemblages. Conservation Biology 22: 362-74.

Tabarelli, M., B. A. Santos, V. Arroyo-Rodríguez, and F. P. Lopes de Melo. 2012. Secondary forests as biodiversity repositories in human-modified landscapes: insights from the Neotropics Bol. Mus. Para. Emílio Goeldi. Cienc. Nat., Belém. 7: 319-328.

Theisinger, O., and M. C. Ratianarivo. 2015. Patterns of biodiversity loss in response to degradation in the spiny forest of southern Madagascar. Herpetelogical Conservation and Biology 10: 273-283.

Thompson, M. E., A. J. Nowakowski, and M. A. Donnelly. 2016. The importance of defining focal assemblages when evaluating amphibian and reptile response to land use. Conservation Biology 30:249-258.

Vázquez-Reyes, L. D., M. del Coro Arizmendi, H. O. Godínez-Álvarez, and

A. G. Navarro-Sigüenza. 2017. Directional effects of biotic homogenization of bird communities in Mexican seasonal forests. The Condor 119:275-288.

Zimmerman, J., J. B. Pascarella, T. M. Aide. 2000. Barriers to forest regeneration in an abandoned pasture in Puerto Rico. Restoration Ecology 8: 350-360.

Zipkin, E.F., A. Dewan, J. A. Royle. 2009. Impacts of forest fragmentation on species richness: a hierarchical approach to community modeling. J. Appl. Ecol. 46: 815822. 
Table 4.1. Species presence absence matrix. For each of three replicates of each forest stagepasture (P), secondary forest $<17$ years old (S1), secondary forest $17-27$ years old (S2), secondary forest> 27 years old (S3), and mature forest (MF) in the Osa Peninsula and Sarapiquí. An "X" indicates a species was sighted during transect surveys, an "O" indicates a species was sighted opportunistically during surveys but not detected within transects.

\begin{tabular}{|c|c|c|c|c|c|c|c|c|c|c|c|c|c|c|c|c|}
\hline \multicolumn{17}{|c|}{ Sarapiquí } \\
\hline \multirow[b]{2}{*}{ Order } & \multirow[b]{2}{*}{ Species } & \multicolumn{3}{|c|}{$\mathrm{P}$} & \multicolumn{3}{|c|}{$\mathrm{S} 1$} & \multicolumn{3}{|c|}{$\mathrm{S} 2$} & \multicolumn{3}{|c|}{$\mathrm{S} 3$} & \multicolumn{3}{|c|}{ MF } \\
\hline & & 1 & 2 & 3 & 1 & 2 & 3 & 1 & 2 & 3 & 1 & 2 & 3 & 1 & 2 & 3 \\
\hline \multirow[t]{22}{*}{ Anura } & Bufonidae & & & & & & & & & & & & & & & \\
\hline & Rhinella marinus & $\mathrm{X}$ & $X$ & $X$ & $\mathrm{X}$ & & $\mathrm{X}$ & & & $\mathrm{X}$ & $\mathrm{X}$ & $\mathrm{X}$ & & & & $\mathrm{X}$ \\
\hline & Incilius melanochlorus & & $\mathrm{X}$ & & & $\mathrm{X}$ & $\mathrm{X}$ & $X$ & $X$ & $\mathrm{X}$ & $\mathrm{X}$ & & & $X$ & & $\mathrm{X}$ \\
\hline & Rhaebo haematiticus & & $X$ & & $\mathrm{X}$ & $\mathrm{X}$ & $X$ & $X$ & $X$ & $\mathrm{X}$ & $\mathrm{X}$ & & $X$ & $X$ & $\mathrm{X}$ & $\mathrm{X}$ \\
\hline & Centrolenidae & & & & & & & & & & & & & & & \\
\hline & Espadarana prosoblepon & & $\mathrm{X}$ & & $\mathrm{X}$ & & $\mathrm{X}$ & & $X$ & & $\mathrm{X}$ & $\mathrm{X}$ & $\mathrm{X}$ & $\mathrm{X}$ & $\mathrm{X}$ & $\mathrm{X}$ \\
\hline & Sachatamia albomaculata & & $X$ & & $\mathrm{X}$ & $\mathrm{X}$ & $\mathrm{X}$ & & & & & & & & & \\
\hline & Sachatamia ilex & & & & & & & & & & & & & & & $\mathrm{X}$ \\
\hline & Teratohyla spinosa & & $\mathrm{X}$ & $\mathrm{X}$ & $\mathrm{X}$ & $\mathrm{X}$ & $\mathrm{X}$ & & $\mathrm{X}$ & $\mathrm{X}$ & $\mathrm{X}$ & $\mathrm{X}$ & $\mathrm{X}$ & $\mathrm{X}$ & $\mathrm{X}$ & $\mathrm{X}$ \\
\hline & Teratohyla pulveratum & & & & & & $\mathrm{X}$ & & & & & & & & & \\
\hline & Hyalinobatrachium valerioi & & $\mathrm{X}$ & & $\mathrm{X}$ & $\mathrm{X}$ & $\mathrm{X}$ & & & $\mathrm{X}$ & $\mathrm{X}$ & & & $\mathrm{X}$ & & \\
\hline & Craugastoridae & & & & & & & & & & & & & & & \\
\hline & Craugastor bransfordii & $\mathrm{X}$ & & $X$ & $X$ & $\mathrm{X}$ & $\mathrm{X}$ & $X$ & $\mathrm{X}$ & $\mathrm{X}$ & $\mathrm{X}$ & $\mathrm{X}$ & $X$ & $\mathrm{X}$ & $\mathrm{X}$ & $\mathrm{X}$ \\
\hline & Craugastor crassidigitus & & & & & & & $X$ & & & & & & $\mathrm{X}$ & & \\
\hline & Craugastor fitzingeri & $\mathrm{X}$ & $X$ & $X$ & $\mathrm{X}$ & $\mathrm{X}$ & $X$ & $X$ & $X$ & $X$ & $\mathrm{X}$ & $X$ & $X$ & $\mathrm{X}$ & $\mathrm{X}$ & $\mathrm{X}$ \\
\hline & Craugastor megacephalus & & & & & & & $X$ & & & $\mathrm{X}$ & $\mathrm{X}$ & & $X$ & & $\mathrm{X}$ \\
\hline & Craugastor mimus & & & & $\mathrm{X}$ & $X$ & & $X$ & $X$ & $\mathrm{X}$ & $\mathrm{X}$ & $X$ & & $X$ & $\mathrm{X}$ & $\mathrm{X}$ \\
\hline & Craugastor noblei & & & & & $\mathrm{X}$ & $X$ & $\mathrm{X}$ & & & & $X$ & & $\mathrm{X}$ & $\mathrm{X}$ & $\mathrm{O}$ \\
\hline & Craugastor talamancae & & & & & & & & & & & & & $\mathrm{X}$ & $\mathrm{X}$ & \\
\hline & Pristimantis cerasinus & & & & $\mathrm{X}$ & $X$ & $X$ & $\mathrm{X}$ & & & $X$ & $X$ & & $\mathrm{X}$ & $\mathrm{X}$ & $\mathrm{X}$ \\
\hline & Pristimantis cruentus & & & & & & & & & & $X$ & $\mathrm{X}$ & & $\mathrm{X}$ & & $\mathrm{X}$ \\
\hline & Pristimantis ridens & & $\mathrm{X}$ & & $\mathrm{X}$ & $\mathrm{X}$ & $\mathrm{X}$ & $\mathrm{X}$ & & & $X$ & $\mathrm{X}$ & $\mathrm{X}$ & $\mathrm{X}$ & $\mathrm{X}$ & $\mathrm{X}$ \\
\hline
\end{tabular}


Dendrobatidae

Dendrobates auratus

Oophaga pumilio

Phyllobates lugubris

Eleutherodactylinae

Diaspora diastema

Hylidae

Boana rufitela

Dendropsophus phlebodes

Dendropsophus ebraccatus

Scinax boulengeri

Scinax elaeochroa

Smilisca baudinii

Smilisca phaeota

Smilisca puma

Smilisca sordida

Leptodactylidae

Leptodactylus melanonotus

Leptodactylus poecilochilus

Leptodactylus savegei

Microhylidae

Hypopachus pictiventris

Phyllomedusidae

Agalychnis callidryas

Agalychnis saltator

Cruziohyla calcarifer

$\begin{array}{lllllllllllllllll}X & X & X & X & X & & X & X & X & X & X & X & X & X & X \\ & & & & & & & & & & & & & & & & \end{array}$

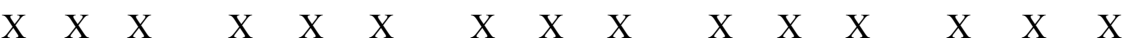

$\begin{array}{lllllll} & X & X & X & X & X \\ X & X & & & & \\ X & & & & \end{array}$

\begin{tabular}{|c|c|c|c|c|c|c|c|c|c|c|c|}
\hline \multirow{3}{*}{$X$} & & & & & & & & & & $X$ & $X$ \\
\hline & $\mathrm{O}$ & $X$ & & & & & $X$ & $X$ & & $X$ & \\
\hline & $\mathrm{X}$ & $X$ & $X$ & $X$ & $X$ & $X$ & $X$ & $X$ & $\mathrm{O}$ & & $X$ \\
\hline & $X$ & & $X$ & $X$ & & & & & & & \\
\hline$X$ & $X$ & $X$ & & & $X$ & & & & & $X$ & $X$ \\
\hline
\end{tabular}

$\begin{array}{lll}\mathrm{X} & \mathrm{X} & \mathrm{X}\end{array}$

$\mathrm{X}$

X X

$X \quad X \quad X$

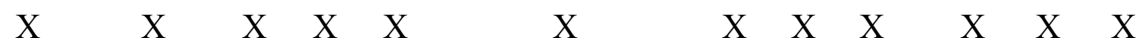

Ranidae

Lithobates vaillant

X

X

X

X 
Caudata

Plethodontidae

Bolitoglossa striatula

Alligatoridae

Crocodylia

Caiman crocodylus

Squamata -

Sauria

Anguidae

Diploglossus bilobatus

Corytophanidae

Basiliscus plumifrons

Basiliscus vittatus

Corytophanes cristatus

Gekkonidae

Gonatodes albogularis

Lepidoblepharis xanthostigma

Thecadactylus rapicauda

Iguanidae

Iguana iguana

Polychrotidae

Norops biporcatus

Norops capito

Norops carpenteri

Norops humilis

Norops lemurinus

Noropslimifrons
$\mathrm{X}$

$\mathrm{X}$

X $\quad$ X

X $\quad \mathrm{X} \quad \mathrm{X}$

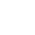


Noropsoxylophus

Scinidae

Mabuya unimarginata

Sphenomorphus cherrei

Teiidae

Holcosus festiva

Xantusiidae

Lepidophyma flavimaculatum

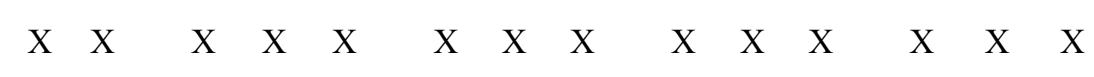

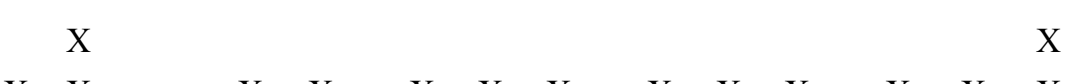

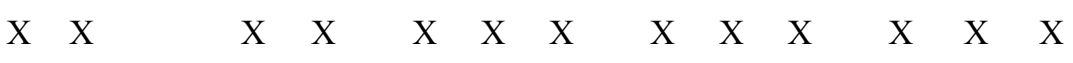

$\begin{array}{lllllllllllllllll}X & X & X & X & O & X & X\end{array}$

X X X

Squamata -

Serpentes Boidae

Corallus annulatus

\section{Colubridae}

Chironius grandisquamis

Drymobius margaritiferus

Enuliophis sclateri

Erythrolampru mimus

Goephis hoffmanni

Hydromorphus concolor

Imantodes cenchoa

Lampropeltus triangulum

Leptodeira septentrionalis

Leptophis ahaetulla

Leptophis depressirostris

Leptophis sp.

Mastigodryas melanolomus

Ninia sebae

Northopsis rugosus
$\mathrm{O}$

X

X

X $\quad$ X

X

X

X

X X O

X

X

X

$\mathrm{X}$

$\mathrm{O}$

X X
O

X

$\begin{array}{cc}\mathrm{X} & \\ \mathrm{X} & \mathrm{O} \\ \mathrm{X} & \mathrm{X} \\ \mathrm{X} & \mathrm{X}\end{array}$


Pseustes poecilonotus

Rhadinaea decorata

Scaphiodontophis annulatus

Sibon nebulatus

Sibon longifrenis

Tantilla reticulata

Tretanorhinus nigroluteus

Urotheca guentheri

Elapidae

Micrurus alleni

Micrurus mipartitus

Micrurus mosquitensis

Micrurus sp.

Viperidae

Bothriechis schlegelii

Bothrops asper

Porthidium nasutum

Testudines

\section{Emydidae}

Rhinoclemmys annulata

Rhinoclemmy funerea

Kinosternidae

Kinosternon leucostmum

$\mathrm{X}$

$\mathrm{O}$

$X$

X X

$\begin{array}{llll}X & & & \\ & X & X & X\end{array}$

X

X

$\begin{array}{llllll}X & X & X & X & X\end{array}$

X

\section{X}

$\begin{array}{cc} & \mathrm{X} \\ & \mathrm{O} \\ \mathrm{X} & \mathrm{X}\end{array}$

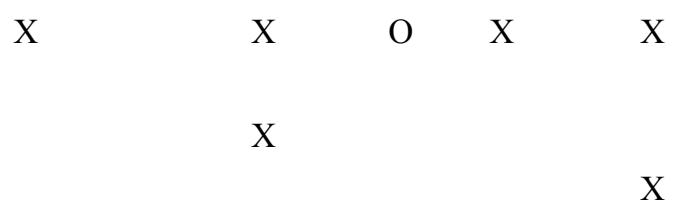

X

X

X

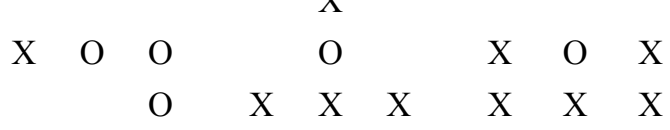

X X X

X 


\begin{tabular}{|c|c|c|c|c|c|c|c|c|c|c|c|c|c|c|c|c|}
\hline \multirow{3}{*}{$\begin{array}{l}\text { Osa } \\
\text { Peninsula }\end{array}$} & & \multirow{2}{*}{\multicolumn{3}{|c|}{$\mathrm{P}$}} & \multirow{2}{*}{\multicolumn{3}{|c|}{ S1 }} & \multirow{2}{*}{\multicolumn{3}{|c|}{ S2 }} & \multirow{2}{*}{\multicolumn{3}{|c|}{ S3 }} & \multirow{2}{*}{\multicolumn{3}{|c|}{ MF }} \\
\hline & & & & & & & & & & & & & & & & \\
\hline & & 1 & 2 & 3 & 1 & 2 & 3 & 1 & 2 & 3 & 1 & 2 & 3 & 1 & 2 & 3 \\
\hline \multirow[t]{23}{*}{ Anura } & Aromobatidae & & & & & & & & & & & & & & & \\
\hline & Allobates talamancae & & & & & & $\mathrm{X}$ & $\mathrm{X}$ & & & & $\mathrm{X}$ & $X$ & & & $\mathrm{X}$ \\
\hline & Bufonidae & & & & & & & & & & & & & & & \\
\hline & Rhinella marina & $\mathrm{X}$ & $\mathrm{X}$ & $\mathrm{X}$ & $\mathrm{X}$ & $\mathrm{X}$ & $\mathrm{X}$ & & & & $\mathrm{X}$ & & & & & \\
\hline & Incilius aucoinae & $\mathrm{X}$ & & & & $\mathrm{X}$ & & $X$ & & & $\mathrm{X}$ & & & $\mathrm{X}$ & & \\
\hline & Rhaebo haematiticus & & & & & & & & & & & & & $\mathrm{X}$ & & \\
\hline & Centrolenidae & & & & & & & & & & & & & & & \\
\hline & Cochranella granulosa & & & & $\mathrm{X}$ & $\mathrm{X}$ & & $X$ & & $\mathrm{X}$ & $\mathrm{X}$ & & & $\mathrm{X}$ & $\mathrm{X}$ & \\
\hline & Espadarana prosoblepon & & & & & & & $\mathrm{X}$ & & $\mathrm{X}$ & & & & & & \\
\hline & Sachatamia albomaculata & & & & & & & $\mathrm{X}$ & & & & & & & & $\mathrm{X}$ \\
\hline & Teratohyla pulveratum & $\mathrm{X}$ & & $\mathrm{X}$ & & & & $\mathrm{X}$ & & $\mathrm{X}$ & $X$ & $\mathrm{X}$ & & $\mathrm{X}$ & & \\
\hline & Hyalinobatrachium valerioi & & & & $\mathrm{X}$ & $\mathrm{X}$ & & & & $\mathrm{X}$ & $\mathrm{X}$ & & & $\mathrm{X}$ & & \\
\hline & Craugastoridae & & & & & & & & & & & & & & & \\
\hline & Craugastor crassidigitus & & & $\mathrm{X}$ & & & & & $\mathrm{X}$ & $\mathrm{X}$ & & & & & & $\mathrm{X}$ \\
\hline & Craugastor fitzingeri & $\mathrm{X}$ & $\mathrm{X}$ & $\mathrm{X}$ & $\mathrm{X}$ & $\mathrm{X}$ & $\mathrm{X}$ & $\mathrm{X}$ & $\mathrm{X}$ & $\mathrm{X}$ & $\mathrm{X}$ & $\mathrm{X}$ & & $\mathrm{X}$ & $\mathrm{X}$ & $\mathrm{X}$ \\
\hline & Craugastor rugosus & & & & & $\mathrm{X}$ & & & $\mathrm{X}$ & $\mathrm{X}$ & & & & $\mathrm{X}$ & & \\
\hline & Craugastor stejnegerianus & $\mathrm{X}$ & & $\mathrm{X}$ & $X$ & $\mathrm{X}$ & $\mathrm{X}$ & $\mathrm{X}$ & $\mathrm{X}$ & $\mathrm{X}$ & $\mathrm{X}$ & $\mathrm{X}$ & $X$ & $\mathrm{X}$ & $\mathrm{X}$ & $\mathrm{X}$ \\
\hline & Pristimantis cruentus & & & & & & & & & & & & & & $\mathrm{X}$ & \\
\hline & Pristimantis ridens & & & & & $\mathrm{X}$ & & & $X$ & $\mathrm{X}$ & & & & $\mathrm{X}$ & & \\
\hline & Dendrobatidae & & & & & & & & & & & & & & & \\
\hline & Dendrobates auratus & & & & & & & $\mathrm{X}$ & & $\mathrm{X}$ & & & $\mathrm{X}$ & & & $\mathrm{X}$ \\
\hline & Phyllobates vittatus & & & & & $\mathrm{X}$ & & & & $\mathrm{X}$ & & & & & $\mathrm{X}$ & \\
\hline & Silverstoneia flotator & & & & & & & & & & $X$ & & & & & \\
\hline
\end{tabular}




Boanarosenbergi
Dendropsophus microcephalus
Dendropsophus ebraccatus
Scinax boulengeri
Scinax elaeochroa
Smilisca phaeota
Smilisca sordida
Trachycephalus venulosus
Eleutherodactylinae
Diaspora diastema
Leptodactylidae
Engystomops pustulosus
Leptodactylus bolivianus
Leptodactylus poecilochilus
Leptodactylus savegei
Phyllomedusidae
Agalychnis callidryas
Agalychnis spurrelli

\section{Caudata Plethodontidae} Oedipinaalleni

Crocodylia

\section{Alligatoridae}

$\begin{array}{lllll}X & X & X & X & X \\ X & X & X & & \\ & X & X & \end{array}$

X

X X

$\mathrm{X}$

X

$\begin{array}{lll}X & X & x \\ X & x & x\end{array}$

$X \quad X \quad X$

$\mathrm{X} \quad \mathrm{X}$

X X X

X

$$
\text { X }
$$

$\mathrm{X} \quad \mathrm{X} \quad \mathrm{X}$

X

X X

X X

X

Squamata -

Sauria
Corytophanidae
Basiliscus basiliscus

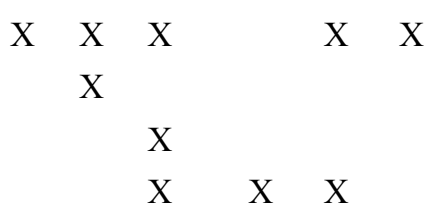

X

X

$\mathrm{X}$

$\begin{array}{llllll}X & X & X & X & X & X\end{array}$

X $\quad$ X $\quad$ X X

$\begin{array}{llllll}X & X & X & X & X & X\end{array}$

X X X

X X

X
$\mathrm{X}$ 


\begin{tabular}{|c|c|c|c|c|c|c|c|c|c|c|c|c|c|c|c|}
\hline Corytophanes cristatus & & & & $\mathrm{X}$ & $\mathrm{X}$ & & $\mathrm{X}$ & $\mathrm{X}$ & $\mathrm{X}$ & $\mathrm{X}$ & & $\mathrm{X}$ & $\mathrm{X}$ & $\mathrm{X}$ & $\mathrm{X}$ \\
\hline \multicolumn{16}{|l|}{ Gekkonidae } \\
\hline Gonatodes albogularis & & & & & & & & & $\mathrm{X}$ & & & & & & \\
\hline Hemidactylus frenatus & & $\mathrm{X}$ & & & & & & & & & & & & & \\
\hline Hemidactylus garnoti & & $\mathrm{X}$ & & & & & & & & & & & & & \\
\hline Lepidoblepharis xanthostigma & & & & & & & & & & & & & $\mathrm{X}$ & $\mathrm{X}$ & $\mathrm{X}$ \\
\hline \multicolumn{16}{|l|}{ Gymnophthalmidae } \\
\hline Leposoma southi & & & $\mathrm{X}$ & $\mathrm{X}$ & $\mathrm{X}$ & & & $\mathrm{X}$ & $\mathrm{X}$ & $\mathrm{X}$ & $\mathrm{X}$ & $\mathrm{X}$ & $\mathrm{X}$ & $\mathrm{X}$ & $\mathrm{X}$ \\
\hline \multicolumn{16}{|l|}{ Iguanidae } \\
\hline Iguana iguana & $\mathrm{X}$ & $\mathrm{X}$ & & & & & & & & & & & & & \\
\hline Ctenosaura similis & & $\mathrm{X}$ & $\mathrm{O}$ & & & & & & & & & & & & \\
\hline \multicolumn{16}{|l|}{ Polychrotidae } \\
\hline Norops biporcatus & & & & & $\mathrm{X}$ & & & & $\mathrm{X}$ & & & & & & \\
\hline Norops capito & & & & & $\mathrm{X}$ & & & $\mathrm{X}$ & $\mathrm{X}$ & & & $\mathrm{X}$ & & & $\mathrm{X}$ \\
\hline Norops limifrons & $\mathrm{X}$ & $\mathrm{X}$ & $\mathrm{X}$ & & $\mathrm{X}$ & & & & & & & $\mathrm{X}$ & $\mathrm{X}$ & & $\mathrm{X}$ \\
\hline Norops polylepis & $\mathrm{X}$ & $\mathrm{X}$ & $\mathrm{X}$ & $\mathrm{X}$ & $\mathrm{X}$ & $\mathrm{X}$ & $\mathrm{X}$ & $\mathrm{X}$ & $\mathrm{X}$ & $\mathrm{X}$ & $\mathrm{X}$ & $\mathrm{X}$ & $\mathrm{X}$ & $\mathrm{X}$ & $\mathrm{X}$ \\
\hline Polychru sgutturosus & & & & & & & & & $\mathrm{O}$ & & & & & & \\
\hline \multicolumn{16}{|l|}{ Scinidae } \\
\hline Mabuya unimarginata & & & & & & & & & & $\mathrm{O}$ & & & & & \\
\hline Sphenomorphus cherrei & & & & $X$ & $\mathrm{X}$ & & $\mathrm{X}$ & $\mathrm{X}$ & $\mathrm{X}$ & $\mathrm{X}$ & & & $\mathrm{X}$ & $\mathrm{X}$ & $\mathrm{X}$ \\
\hline \multicolumn{16}{|l|}{ Teiidae } \\
\hline Holcosus festiva & & & & & & & & $\mathrm{X}$ & & & & $\mathrm{X}$ & & $\mathrm{X}$ & \\
\hline Holcosus leptophrys & & & & $\mathrm{X}$ & $\mathrm{O}$ & & & & & & & $\mathrm{X}$ & & & \\
\hline Holcosus quadralineata & & & $\mathrm{X}$ & & $\mathrm{X}$ & & & & & & & & & & \\
\hline
\end{tabular}

Squamata -

Serpentes

Boidae

Corallus ruschenbergerii

Colubridae 
Coniophanis fissidens

Enuliophi sclateri

Imantodes cenchoa

Leptodeira septentrionalis

Leptophis ahaetulla

Northopsis rugosus

Oxybelis aeneus

Pseustes poecilonotus

Siphlophis compressus

Xenodon rabdocephalus

Elapidae

Micrurus alleni

Micrurus nigrocinctus

Micrurus sp.

Viperidae

Bothrops asper

Unknown sp.

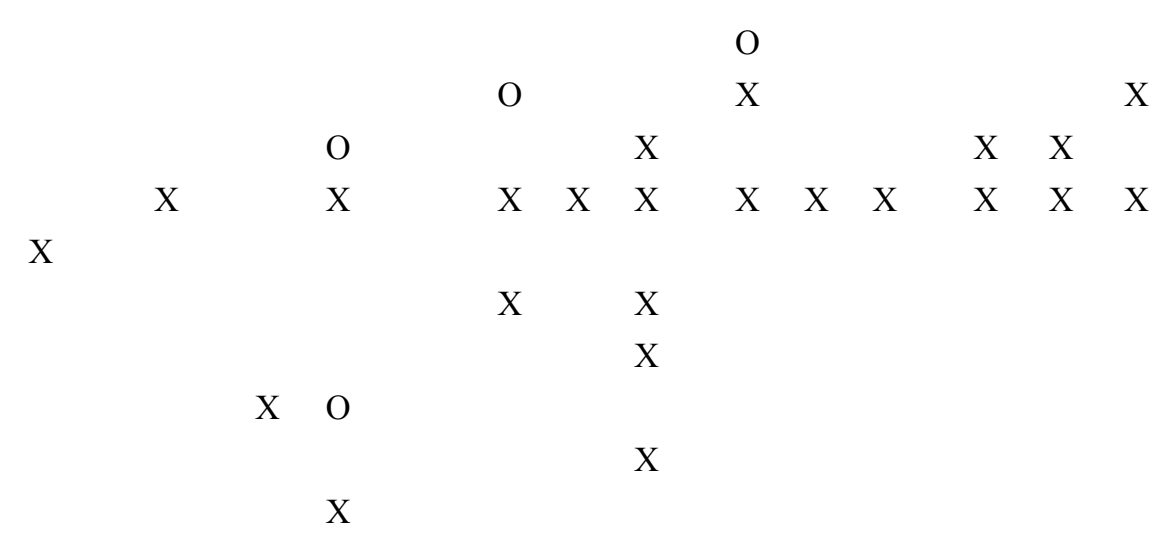

$\mathrm{O}$

X O

X O

X

X
X

Testudines 
Table 4.2. Anuran and lizard species detected during transects surveys and included in multi-species occupancy modeling with general habitat and breeding habitat categories. Species codes represent first three letters of the genus and species. For general habitat, A $=$ primarily arboreal, $\mathrm{T}=$ primarily terrestrial and for breeding habitat, $\mathrm{T}=$ eggs/larvae primarily terrestrial, $\mathrm{LO}=$ eggs/larvae primarily in lotic habitat, $\mathrm{LE}=$ eggs/larvae primarily in lentic habitat.

\begin{tabular}{|c|c|c|c|c|c|}
\hline \multirow[b]{2}{*}{ Region } & \multirow[b]{2}{*}{ Species code } & \multicolumn{2}{|c|}{ Anurans } & \multicolumn{2}{|c|}{ Lizards } \\
\hline & & General habitat & Breeding habitat & Species code & General habitat \\
\hline \multirow[t]{34}{*}{ Sarapiquí } & AGACAL & A & LE & BASPLU & A \\
\hline & AGASAL & A & LE & BASVIT & A \\
\hline & CRABRA & $\mathrm{T}$ & $\mathrm{T}$ & CORCRI & A \\
\hline & CRACRA & $\mathrm{T}$ & $\mathrm{T}$ & DIPBIL & $\mathrm{T}$ \\
\hline & CRAFIT & $\mathrm{T}$ & $\mathrm{T}$ & GONALB & A \\
\hline & CRAMEG & $\mathrm{T}$ & $\mathrm{T}$ & HOLFES & $\mathrm{T}$ \\
\hline & CRAMIM & $\mathrm{T}$ & $\mathrm{T}$ & IGUIGU & A \\
\hline & CRANOB & $\mathrm{T}$ & $\mathrm{T}$ & LEPFLA & $\mathrm{T}$ \\
\hline & CRATAL & $\mathrm{T}$ & $\mathrm{T}$ & LEPXAN & $\mathrm{T}$ \\
\hline & DENAUR & $\mathrm{T}$ & $\mathrm{T}$ & MABUNI & A \\
\hline & DENPHL & A & $\mathrm{LE}$ & NORCAP & A \\
\hline & DIADIA & A & $\mathrm{T}$ & NORHUM & $\mathrm{T}$ \\
\hline & ESPPRO & A & LO & NORLEM & A \\
\hline & GASPIC & $\mathrm{T}$ & $\mathrm{LE}$ & NORLIM & A \\
\hline & HYAVAL & $\mathrm{A}$ & $\mathrm{LE}$ & NOROXY & A \\
\hline & BOARUF & A & LE & SPHCHE & $\mathrm{T}$ \\
\hline & INCMEL & $\mathrm{T}$ & LO & THERAP & A \\
\hline & LEPPOE & $\mathrm{T}$ & $\mathrm{LE}$ & & \\
\hline & LEPSAV & $\mathrm{T}$ & $\mathrm{LE}$ & & \\
\hline & LITVAL & $\mathrm{T}$ & LE & & \\
\hline & LITWAR & $\mathrm{T}$ & LO & & \\
\hline & OOPPUM & $\mathrm{T}$ & $\mathrm{T}$ & & \\
\hline & PRICER & $\mathrm{T}$ & $\mathrm{T}$ & & \\
\hline & PRICRU & A & $\mathrm{T}$ & & \\
\hline & PRIRID & A & $\mathrm{T}$ & & \\
\hline & RHAHAE & $\mathrm{T}$ & LO & & \\
\hline & RHIMAR & $\mathrm{T}$ & LO & & \\
\hline & SACALB & A & LO & & \\
\hline & SACILE & A & LO & & \\
\hline & SCIELE & A & LE & & \\
\hline & SCIBOU & A & LE & & \\
\hline & SMIBAU & A & LE & & \\
\hline & SMIPHA & A & $\mathrm{LE}$ & & \\
\hline & SMIPUM & A & LE & & \\
\hline
\end{tabular}




\begin{tabular}{|c|c|c|c|c|c|}
\hline \multirow{37}{*}{ Osa } & SMISOR & A & LO & & \\
\hline & TERPUL & A & LO & & \\
\hline & TERSPI & A & LO & & \\
\hline & LEPMEL & $\mathrm{T}$ & LE & & \\
\hline & AGACAL & A & LE & BASBAS & A \\
\hline & AGASPU & A & LE & CORCRI & A \\
\hline & ALLTAL & $\mathrm{T}$ & $\mathrm{T}$ & CTESIM & A \\
\hline & COLSIL & $\mathrm{T}$ & $\mathrm{T}$ & GONALB & A \\
\hline & CONGRA & A & LO & HEMFRE & A \\
\hline & CRACRA & $\mathrm{T}$ & $\mathrm{T}$ & HEMGAR & A \\
\hline & CRAFIT & $\mathrm{T}$ & $\mathrm{T}$ & HOLFES & $\mathrm{T}$ \\
\hline & CRARUG & $\mathrm{T}$ & $\mathrm{T}$ & HOLLEP & $\mathrm{T}$ \\
\hline & CRASTE & $\mathrm{T}$ & $\mathrm{T}$ & HOLQUA & $\mathrm{T}$ \\
\hline & DENAUR & $\mathrm{T}$ & $\mathrm{T}$ & IGUIGU & A \\
\hline & DENEBR & A & LE & LEPSOU & $\mathrm{T}$ \\
\hline & DENMIC & A & LE & LEPXAN & $\mathrm{T}$ \\
\hline & DIADIA & A & $\mathrm{T}$ & NORBIP & A \\
\hline & ENGPUS & $\mathrm{T}$ & LE & NORCAP & A \\
\hline & ESPPRO & $\mathrm{A}$ & LO & NORLIM & A \\
\hline & HYAVAL & $\mathrm{A}$ & LE & NORPOL & A \\
\hline & BOAROS & A & LE & SPHCHE & $\mathrm{T}$ \\
\hline & INCAUR & $\mathrm{T}$ & LO & & \\
\hline & LEPBOL & $\mathrm{T}$ & LE & & \\
\hline & LEPPOE & $\mathrm{T}$ & LE & & \\
\hline & LEPSAV & $\mathrm{T}$ & LE & & \\
\hline & PHYVIT & $\mathrm{T}$ & $\mathrm{T}$ & & \\
\hline & PRICRU & A & $\mathrm{T}$ & & \\
\hline & PRIRID & A & $\mathrm{T}$ & & \\
\hline & RHAHAE & $\mathrm{T}$ & LO & & \\
\hline & RHIMAR & $\mathrm{T}$ & LO & & \\
\hline & SACALB & A & $\mathrm{LO}$ & & \\
\hline & SCIBOU & A & LE & & \\
\hline & SCIELE & A & LE & & \\
\hline & SMIPHA & A & LE & & \\
\hline & SMISOR & A & LO & & \\
\hline & TERPUL & A & LO & & \\
\hline & TREVEN & A & LE & & \\
\hline
\end{tabular}


Table 4.3. Anuran community and group parameter estimates (and 95\% credible intervals) for covariates of probability of occurrence (psi) and probability of detection (p). Parameters with strong evidence for a directional effect ( $>95 \%$ of the posterior distribution had the same sign as the median) are shown in bold.

\begin{tabular}{|c|c|c|c|c|c|c|c|c|c|c|c|c|c|c|c|c|c|c|}
\hline \multirow{3}{*}{$\begin{array}{l}\text { Community hyper- } \\
\text { parameter }\end{array}$} & & & & \multicolumn{6}{|c|}{ General habitat } & \multicolumn{9}{|c|}{ Breeding habitat } \\
\hline & \multicolumn{3}{|c|}{ Whole community } & \multicolumn{3}{|c|}{ Arboreal } & \multicolumn{3}{|c|}{ Terrestrial } & \multicolumn{3}{|c|}{ Terrestrial } & \multicolumn{3}{|c|}{ Lentic } & \multicolumn{3}{|c|}{ Lotic } \\
\hline & Mean & \multicolumn{2}{|c|}{$95 \% \mathrm{CI}$} & Mean & \multicolumn{2}{|c|}{$95 \% \mathrm{CI}$} & Mean & \multicolumn{2}{|c|}{$95 \% \mathrm{CI}$} & Mean & \multicolumn{2}{|c|}{$95 \% \mathrm{CI}$} & Mean & \multicolumn{2}{|c|}{$95 \% \mathrm{CI}$} & Mean & \multicolumn{2}{|c|}{$95 \% \mathrm{CI}$} \\
\hline $\mathrm{P}$, upland & -2.66 & -4.75 & -0.67 & -1.48 & -4.18 & 1.02 & -1.90 & -4.07 & 0.35 & -2.87 & -4.91 & -0.97 & -0.72 & -3.24 & 1.46 & 0.13 & -2.54 & 2.76 \\
\hline S1, upland & -1.16 & -2.93 & 0.06 & -1.09 & -3.41 & 0.84 & -0.70 & -2.71 & 1.46 & -0.33 & -2.79 & 2.17 & -1.14 & -3.28 & 0.84 & -1.09 & -3.36 & 1.11 \\
\hline S2, upland & -0.69 & -1.77 & 0.27 & -0.90 & -3.15 & 0.77 & -0.69 & -2.36 & 0.75 & -0.02 & -2.12 & 2.16 & -1.04 & -3.44 & 1.35 & -0.40 & -2.29 & 1.26 \\
\hline S3, upland & 0.01 & -0.85 & 1.00 & 0.08 & -1.28 & 1.28 & -0.24 & -1.27 & 0.76 & 0.66 & -1.07 & 2.29 & -1.44 & -2.88 & 0.10 & 0.06 & -1.88 & 1.88 \\
\hline Habitat & -0.45 & -2.64 & 1.73 & 1.60 & -0.58 & 3.75 & -1.89 & -4.15 & 0.52 & -1.83 & -4.39 & 0.72 & 1.94 & -0.94 & 4.54 & 1.08 & -1.47 & 3.34 \\
\hline $\mathrm{P}$, riparian & 1.82 & 0.71 & 2.84 & 1.29 & -0.32 & 2.75 & 1.47 & 0.20 & 2.96 & 1.51 & -0.20 & 3.24 & 0.54 & -0.98 & 2.91 & 0.88 & -1.20 & 2.78 \\
\hline $\mathrm{S} 1$, riparian & 0.98 & -0.20 & 2.10 & 0.94 & -0.86 & 2.80 & 0.43 & -0.94 & 2.06 & 0.12 & -1.60 & 1.86 & 1.59 & 0.16 & 3.56 & -0.56 & -2.49 & 1.36 \\
\hline $\mathrm{S} 2$, riparian & -0.53 & -1.41 & 0.38 & -0.28 & -2.17 & 1.77 & -0.17 & -1.64 & 0.95 & -0.90 & -2.77 & 0.60 & 0.43 & -1.08 & 2.83 & -0.62 & -2.61 & 1.34 \\
\hline S3, riparian & 0.19 & -0.72 & 1.11 & 0.25 & -1.13 & 1.50 & 0.33 & -0.80 & 1.45 & -0.75 & -2.25 & 0.81 & 0.88 & -1.07 & 3.06 & 0.42 & -1.23 & 2.37 \\
\hline \multicolumn{19}{|l|}{$\mathrm{P}$} \\
\hline Season & -0.27 & -0.61 & 0.06 & -0.48 & -1.10 & 0.05 & -0.01 & -0.48 & 0.33 & 0.02 & -0.52 & 0.52 & -0.36 & -0.94 & 0.20 & -0.90 & -1.91 & -0.16 \\
\hline \multicolumn{19}{|l|}{$\begin{array}{l}\text { Osa Peninsula } \\
\text { Psi }\end{array}$} \\
\hline $\mathrm{P}$, upland & -1.06 & -3.53 & 1.30 & -0.72 & -3.2 & 1.96 & -1.03 & -2.25 & 1.21 & -2.43 & -4.95 & 0.38 & 1.53 & -1.46 & 4.97 & -1.21 & -4.08 & 1.65 \\
\hline $\mathrm{S} 1$, upland & -0.65 & -3.08 & 1.74 & -0.39 & -2.7 & 1.59 & -0.28 & -1.87 & 0.77 & -0.17 & -2.66 & 2.26 & -1.16 & -3.50 & 1.04 & -0.79 & -3.69 & 1.92 \\
\hline S2, upland & -0.40 & -2.46 & 1.41 & 0.02 & -2.47 & 2.22 & 0.32 & -0.74 & 1.30 & 0.61 & -1.93 & 3.06 & 0.32 & -1.97 & 2.64 & -0.46 & -2.94 & 2.76 \\
\hline S3, upland & -0.57 & -2.48 & 1.21 & -0.09 & -2.41 & 1.82 & -0.29 & -1.23 & 0.60 & 0.18 & -2.26 & 2.73 & -1.02 & -3.11 & 0.78 & -0.53 & -3.32 & 1.95 \\
\hline Habitat & 0.91 & -0.60 & 2.63 & 0.55 & -1.70 & 2.47 & 0.56 & -0.76 & 1.88 & 1.02 & -1.42 & 3.45 & 0.36 & -1.83 & 2.45 & 2.47 & 0.03 & 4.80 \\
\hline $\mathrm{P}$, riparian & 0.41 & -1.07 & 1.92 & 1.02 & -0.77 & 3.45 & 0.49 & -0.57 & 1.58 & 0.78 & -1.76 & 3.30 & -0.85 & -2.91 & 1.19 & 0.23 & -1.97 & 2.82 \\
\hline $\mathrm{S} 1$, riparian & 0.37 & -1.11 & 1.96 & 0.03 & -1.93 & 3.45 & 0.10 & -1.01 & 1.22 & -0.55 & -3.05 & 2.02 & -0.05 & -2.65 & 1.92 & 0.65 & -1.64 & 3.14 \\
\hline $\mathrm{S} 2$, riparian & 0.87 & -0.59 & 2.36 & 1.023 & -1.00 & 2.34 & 0.62 & -0.53 & 1.87 & 1.13 & -1.30 & 3.62 & -0.47 & -2.61 & 2.05 & 1.98 & -0.35 & 4.24 \\
\hline
\end{tabular}


Season

$-0.46 \quad-1.05$

$\begin{array}{lllll}-0.46 & -1.06 & 0.06 & -0.39 & -2.24\end{array}$

\begin{tabular}{llllll}
-0.69 & -1.60 & 0.11 & -0.82 & -2.63 & 0.71 \\
\hline
\end{tabular} 
Table 4.4. Lizard community and group parameter estimates (and $95 \%$ credible intervals) for covariates of probability of occurrence (psi) and probability of detection (p).

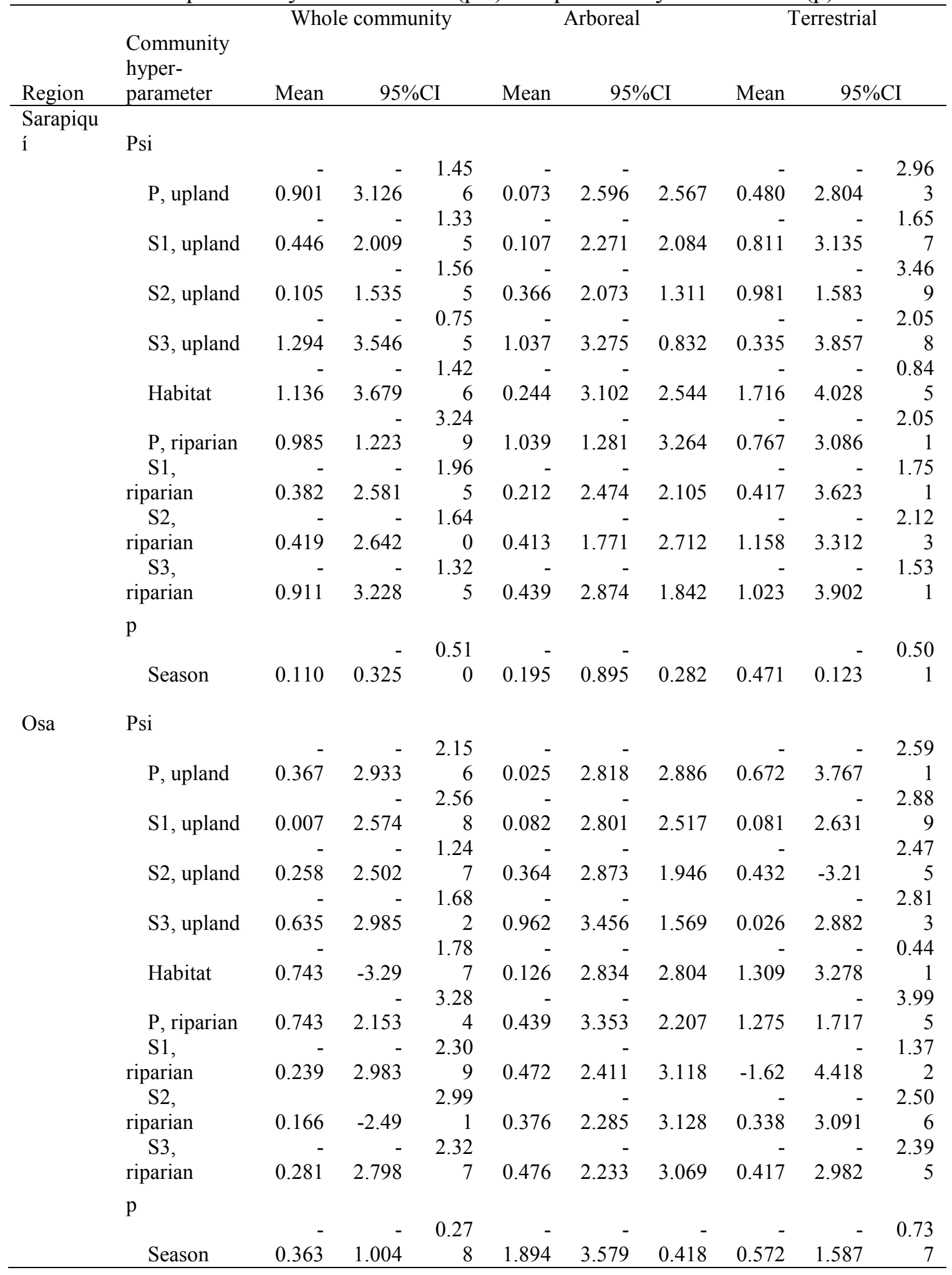




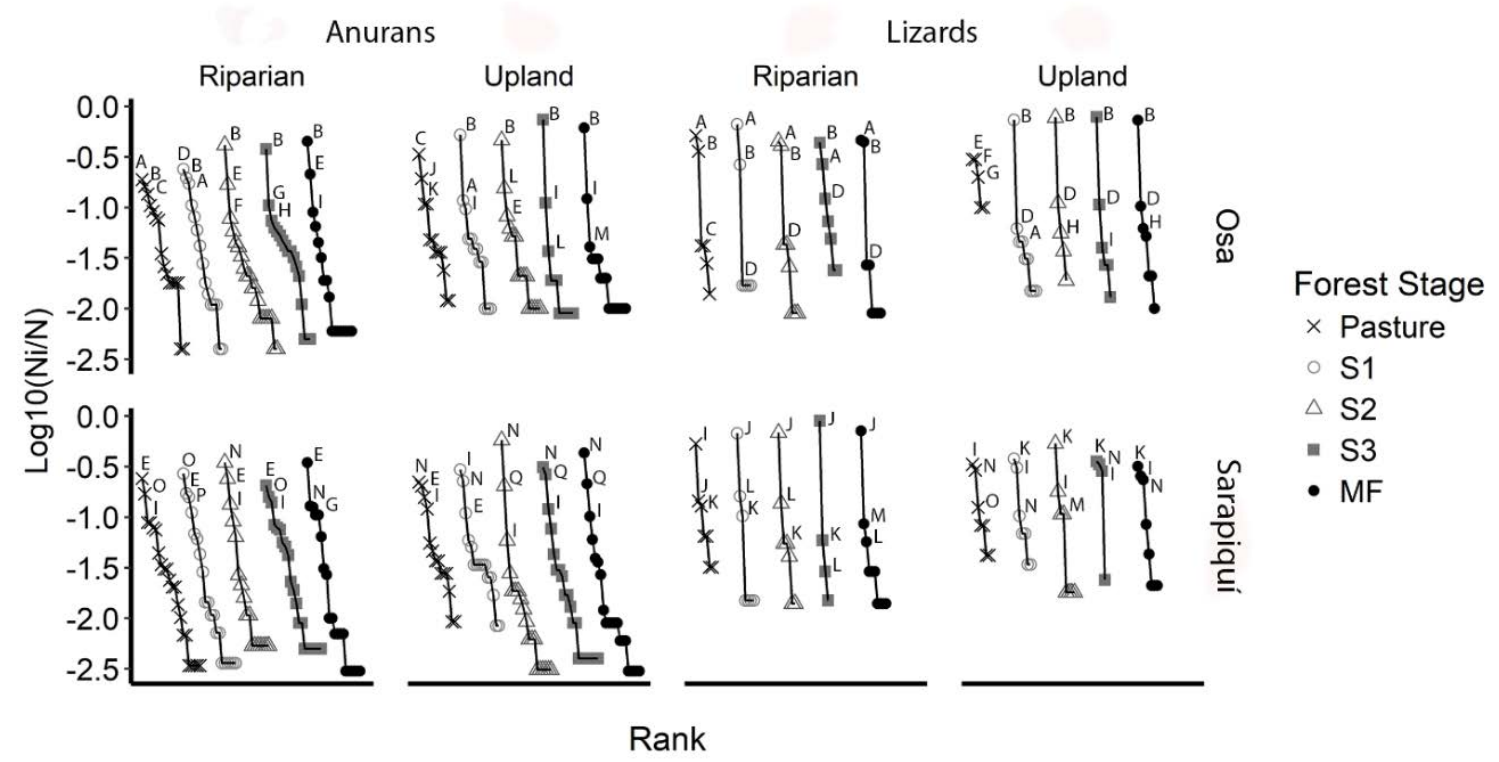

Figure 4.1. Rank abundance plots for anurans and lizards in pasture (P), secondary forest $<17$ years old (S1), secondary forest $17-27$ years old (S2), secondary forest $>27$ years old (S3), and mature forest (MF). The three most common species in each category are labeled by the following letters. Species codes represent first three letters of the genus and species. For anurans: A-RHIMAR, B-CRASTE, C-LEPBOL, D-SMISOR, ECRAFIT, F-CRACRA, G-HYAVAL, H-CONGRA, I-DIADIA, J-DENMIC, KENGPUS, L-ALLTAL, M-LEPSAV, N-OOPPUM, O-TERSPI, P-SACALB, QCRABRA. For lizards: A-BASBAS, B-NORPOL, C-IGUIGU, D-LEPSOU, E-CTESIM, F-HEMGAR, G-HEMFRE, H-CORCRI, I-NORLIM, J-NOROXY, K-NORHUM, LBASPLU, M-HOLFES, N-SPHCHE, O-NORLEM. 
Anurans

a)

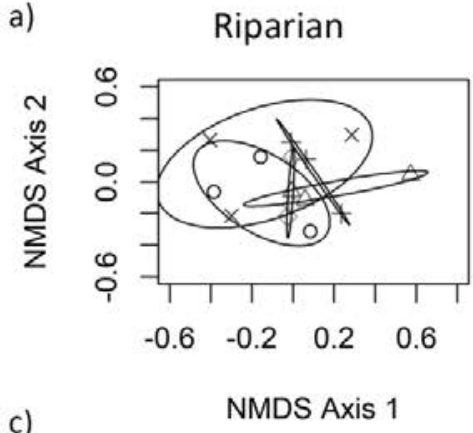

c)

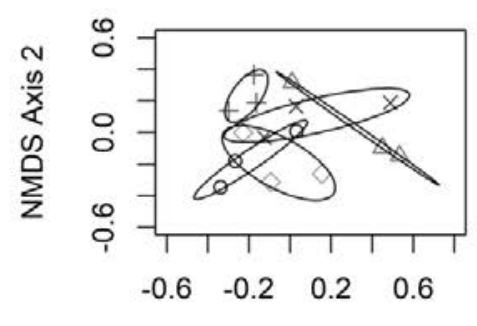

NMDS Axis 1

e)

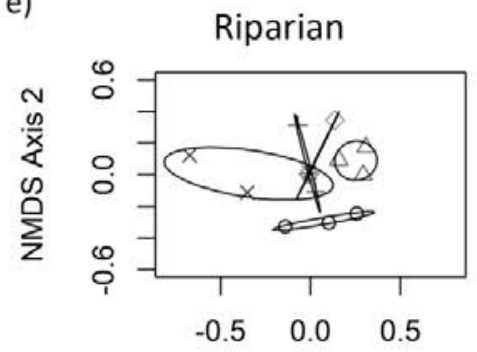

g)

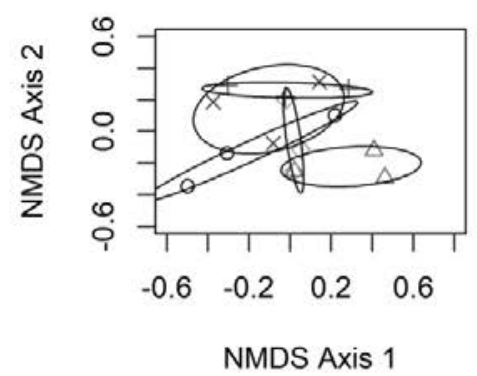

b)

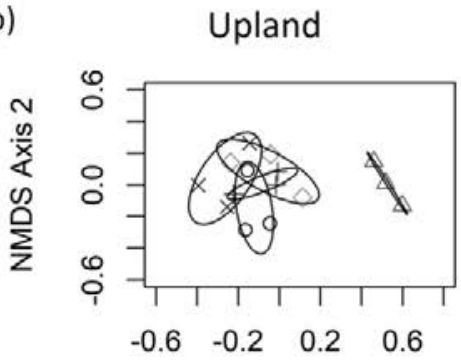

d)

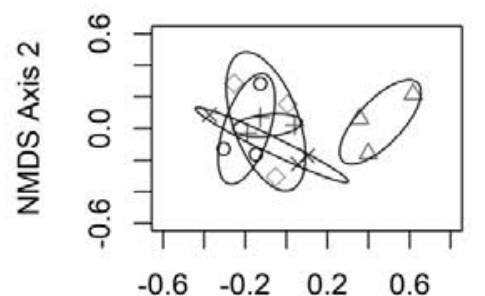

Forest stage

NMDS Axis 1

$\triangle P$

Lizards

f)

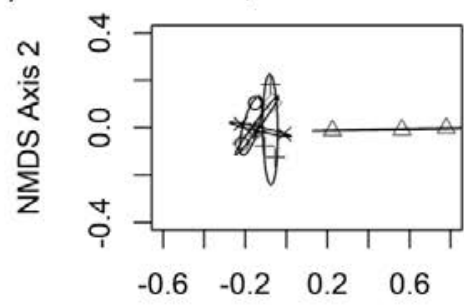

NMDS Axis 1

h)

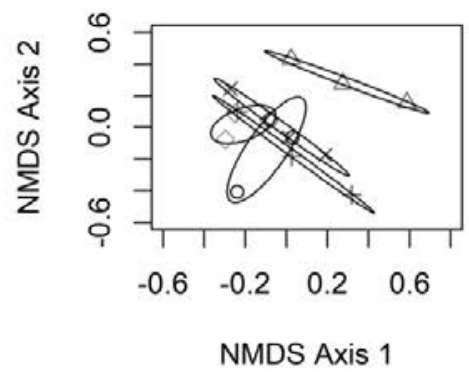

Figure 4.2. Nonmetric multidimensional scaling (NMDS) ordination plots for communities of anurans and lizards. Forest stages are pasture $(\mathrm{P})$, secondary forest $<17$ years old (S1), secondary forest $17-27$ years old (S2), secondary forest $>27$ years old (S3), and mature forest (MF) Osa Peninsula riparian [a)anurans, e) lizards]and upland [b) anurans, f) lizards]sites and Sarapiquí riparian [c) anurans, g) lizards],and upland [d) anurans, h)lizards] sites. 


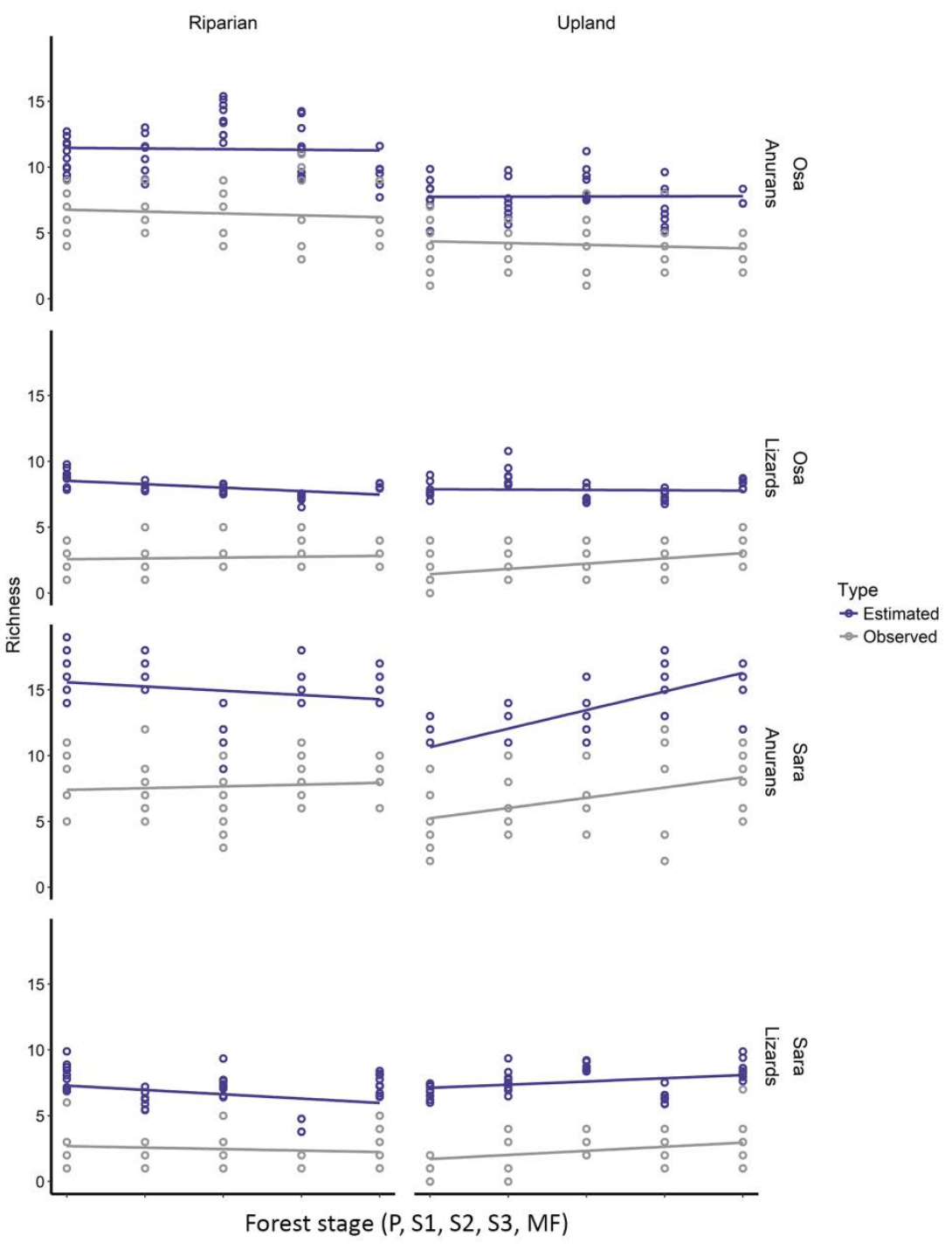

Figure 4.3. Anuran and lizard observed (grey) and estimated (black) species richness from multispecies occupancy models at each transect in riparian and upland habitats (mean species richness $\pm 95 \%$ credible intervals). X-axis of each panel represents forest type from left to right: pasture (P), secondary forest $<17$ years old (S1), secondary forest $17-27$ years old (S2), secondary forest $>27$ years old (S3), and mature forest (MF). Lines represent linear fit. 


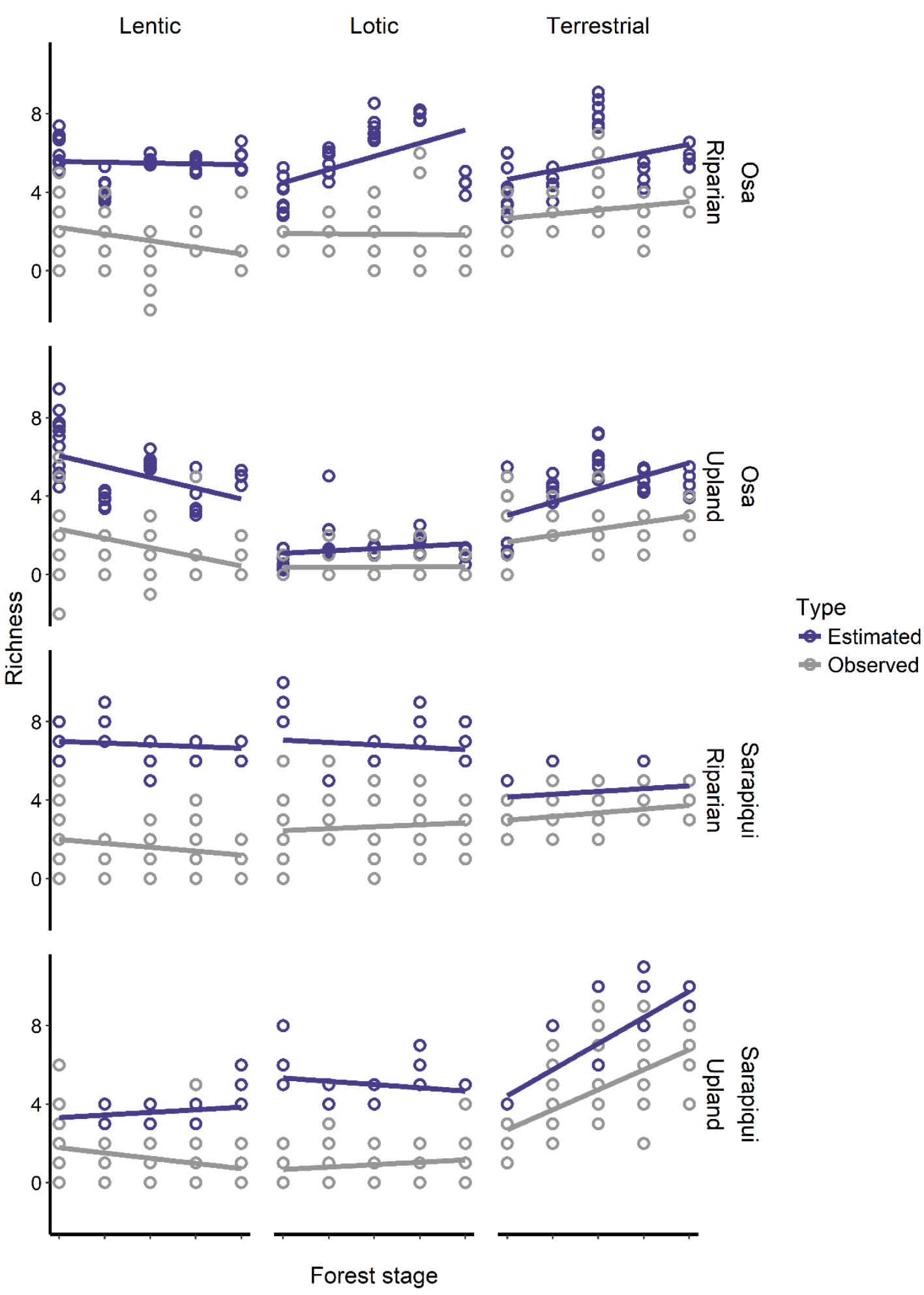

Figure 4.4. Estimated and observed anuran species richness by transect. X-axis of each panel represents forest type from left to right: pasture $(\mathrm{P})$, secondary forest $<17$ years old (S1), secondary forest $17-27$ years old (S2), secondary forest $>27$ years old (S3), and mature forest (MF), grouped by breeding habitat type. Lines represent linear fit. 


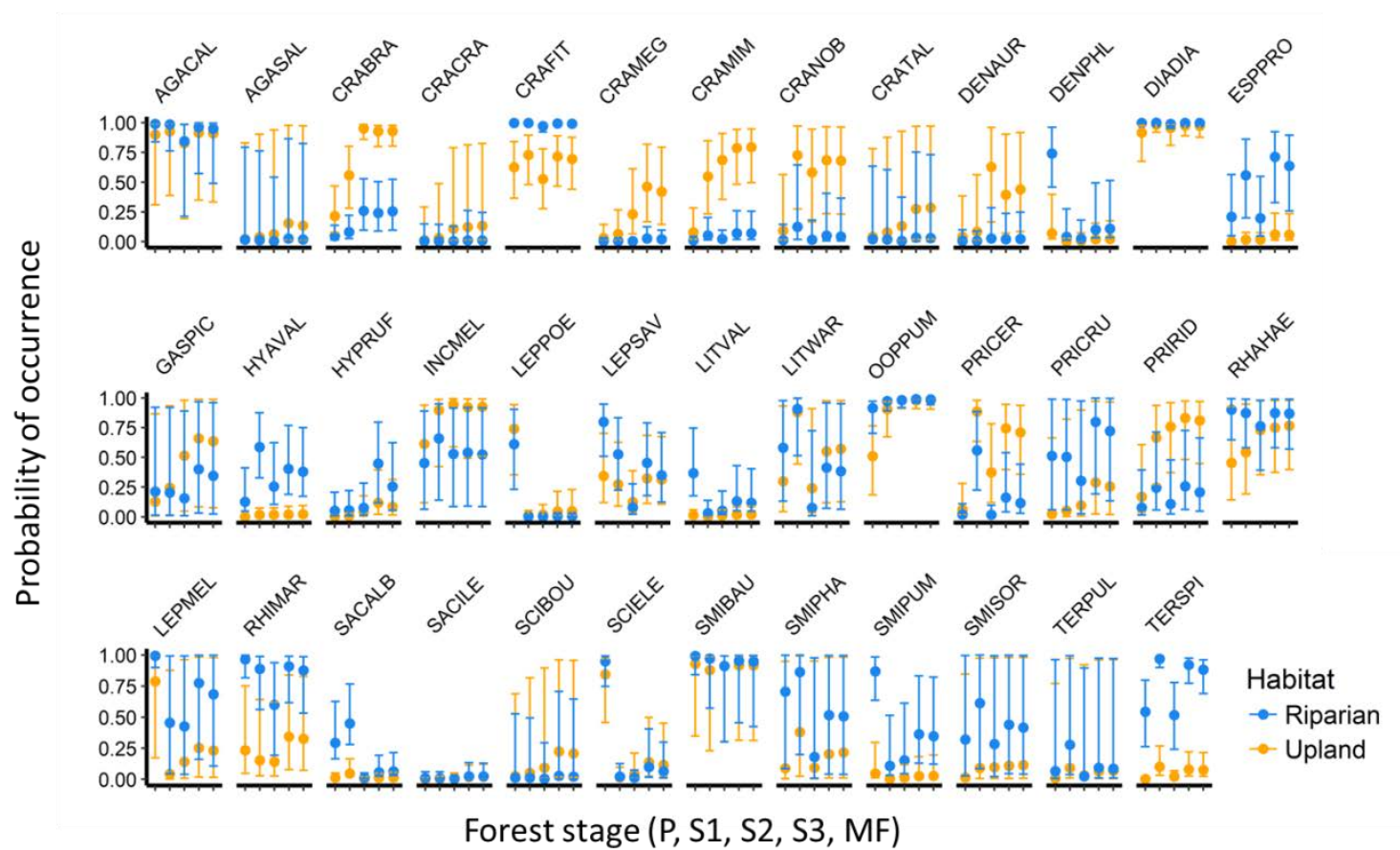

Figure 4.5. Anuran species-specific probability of occurrence in Sarapiquí. Error bars represent $95 \%$ credible intervals in riparian (blue) and upland (orange) habitat. X-axis of each panel represents forest type from left to right: pasture (P), secondary forest $<17$ years old (S1), secondary forest $17-27$ years old (S2), secondary forest $>27$ years old (S3), and mature forest (MF). Species codes refer to the first three letters of the genus and species (Table 4.2.). 


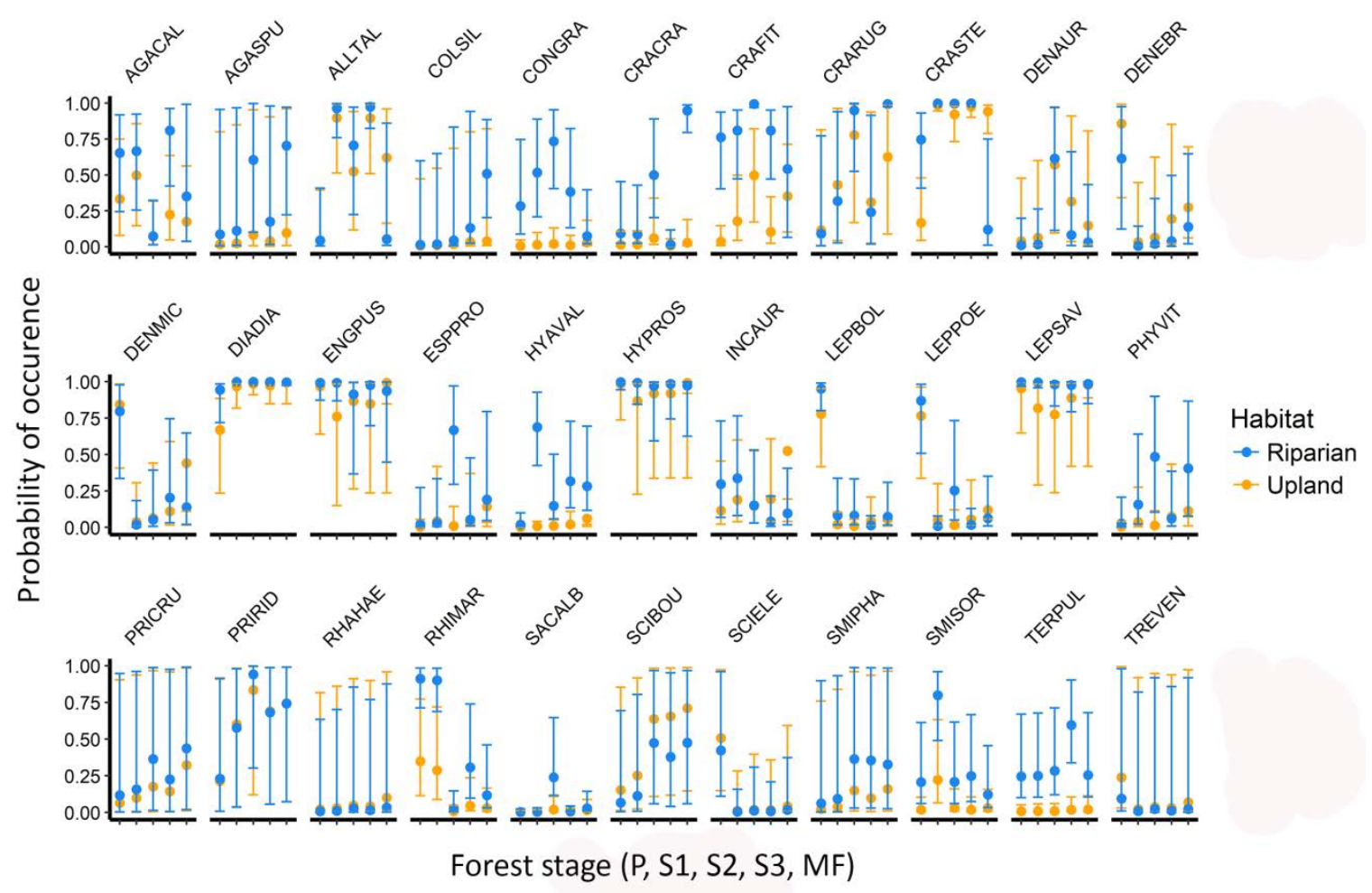

Figure 4.6. Anuran species-specific probability of occurrence in the Osa Peninsula. Error bars represent $95 \%$ credible intervals in riparian (blue) and upland (orange) habitat. Xaxis of each panel represents forest type from left to right: pasture $(\mathrm{P})$, secondary forest < 17 years old (S1), secondary forest $17-27$ years old (S2), secondary forest $>27$ years old (S3), and mature forest (MF) in the Osa Peninsula. Species codes refer to the first three letters of the genus and species (Table 4.2.). 


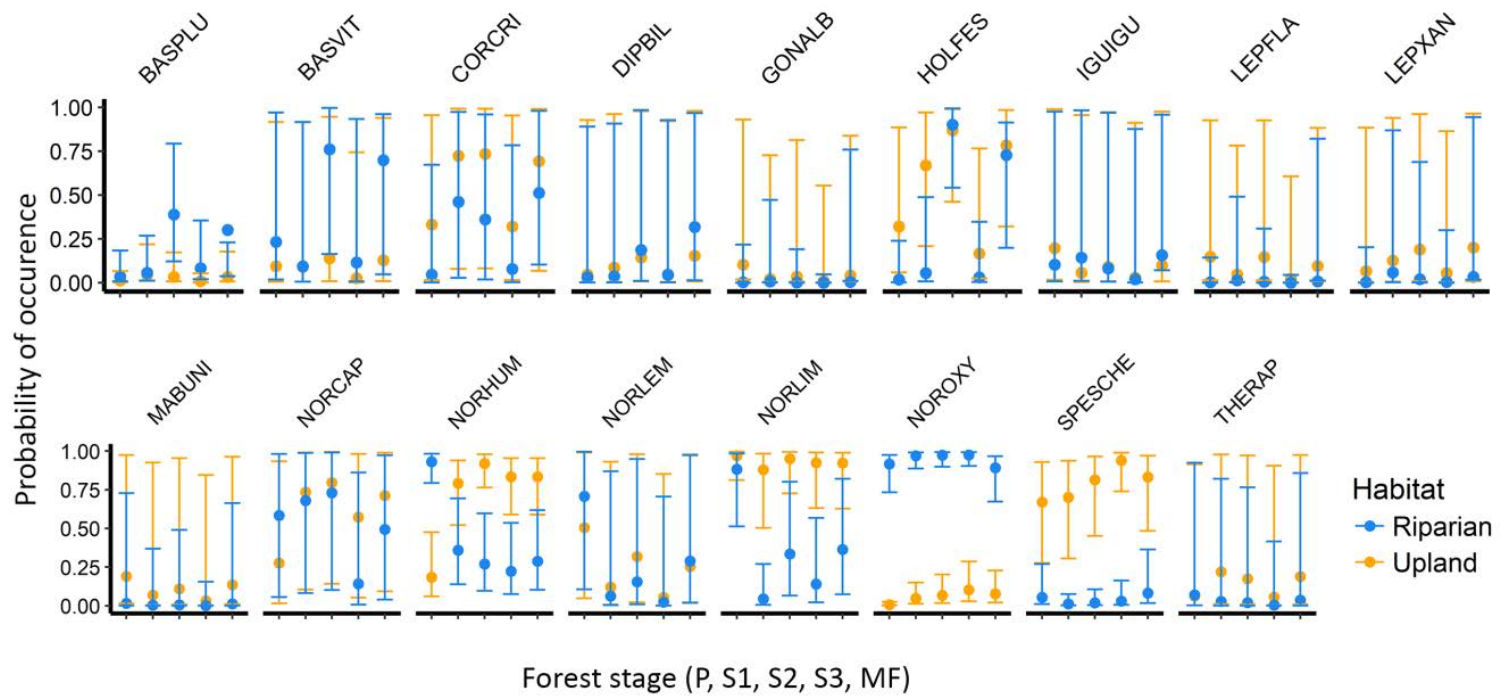

Figure 4.7. Lizard species-specific probability of occurrence in Sarapiquí. Error bars represent $\pm 95 \%$ credible intervals in riparian (blue) and upland (orange) habitat. X-axis of each panel represents forest type from left to right: pasture (P), secondary forest $<17$ years old (S1), secondary forest $17-27$ years old (S2), secondary forest $>27$ years old (S3), and mature forest (MF) in Sarapiquí. Species codes refer to the first three letters of the genus and species (Table 4.2.). 


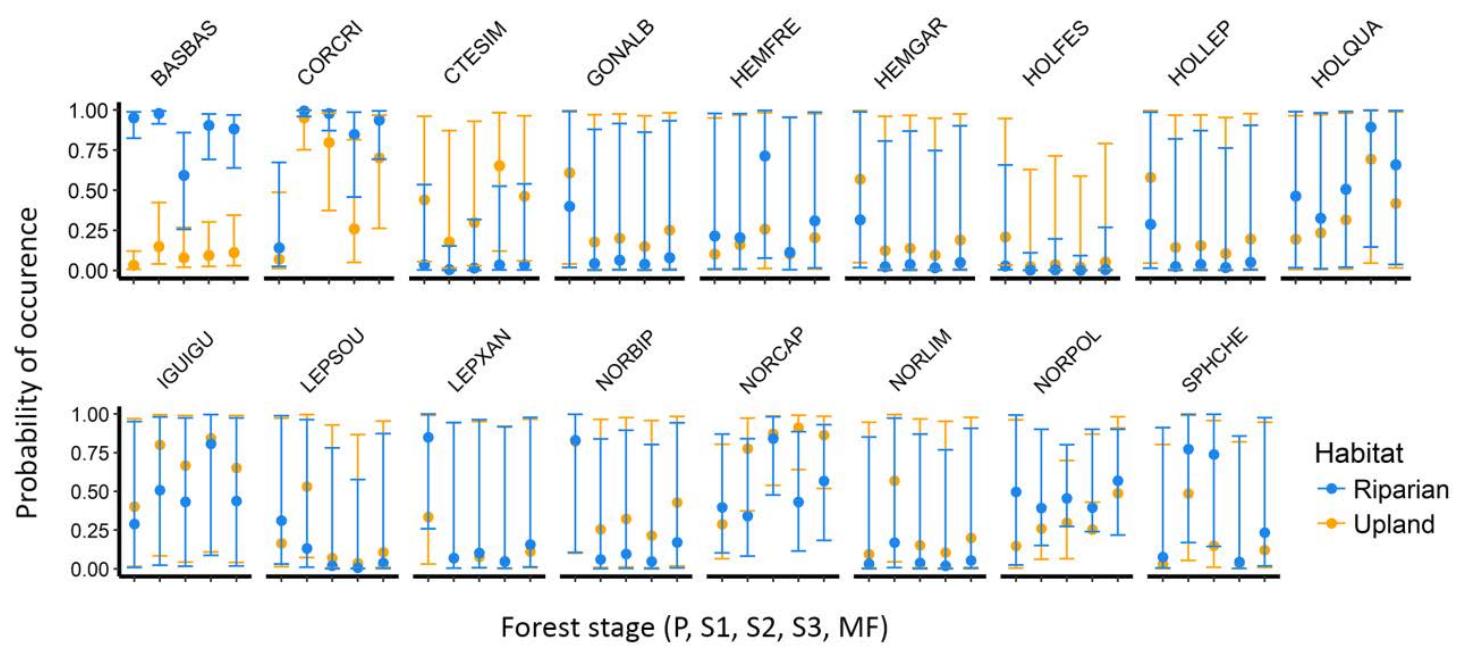

Figure 4.8. Lizard species-specific probability of occurrence in the Osa Peninsula. Error bars represent $\pm 95 \%$ credible intervals in riparian (blue) and upland (orange) habitat. Xaxis of each panel represents forest type from left to right: pasture (P), secondary forest $<$ 17 years old (S1), secondary forest $17-27$ years old (S2), secondary forest $>27$ years old (S3), and mature forest (MF) in the Osa Peninsula. Species codes refer to the first three letters of the genus and species (Table 4.2.). 


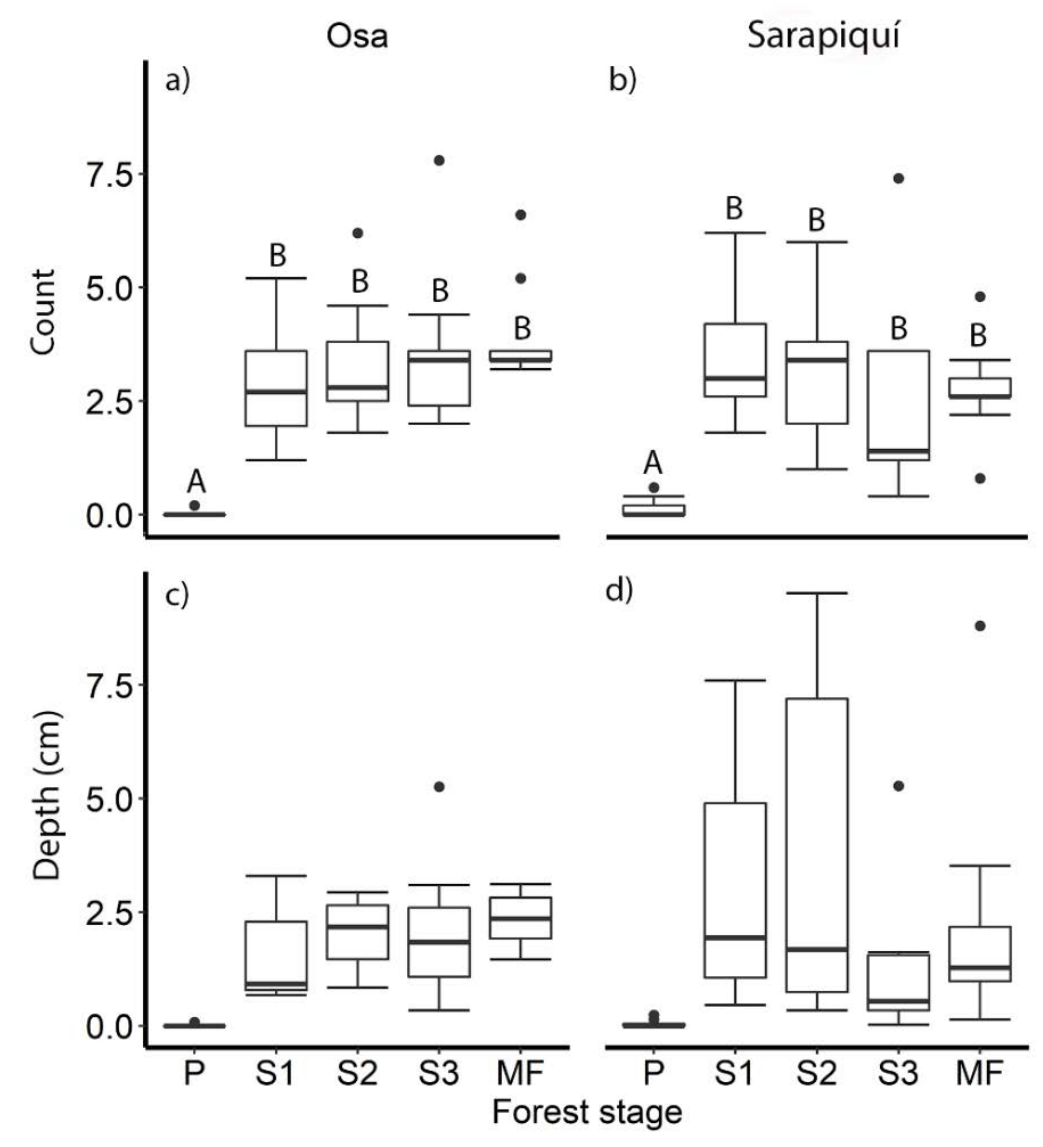

Figure 4.9. Boxplots of leaf litter measurements. Panels a) and b)represent leaf count and c) and d) leaf litter depth in pasture (P), secondary forest $<17$ years old (S1), secondary forest $17-27$ years old (S2), secondary forest $>27$ years old (S3), and mature forest (MF) of Sarapiquí and Osa Peninsula sites. Statistically significant differences are labeled with letters. 


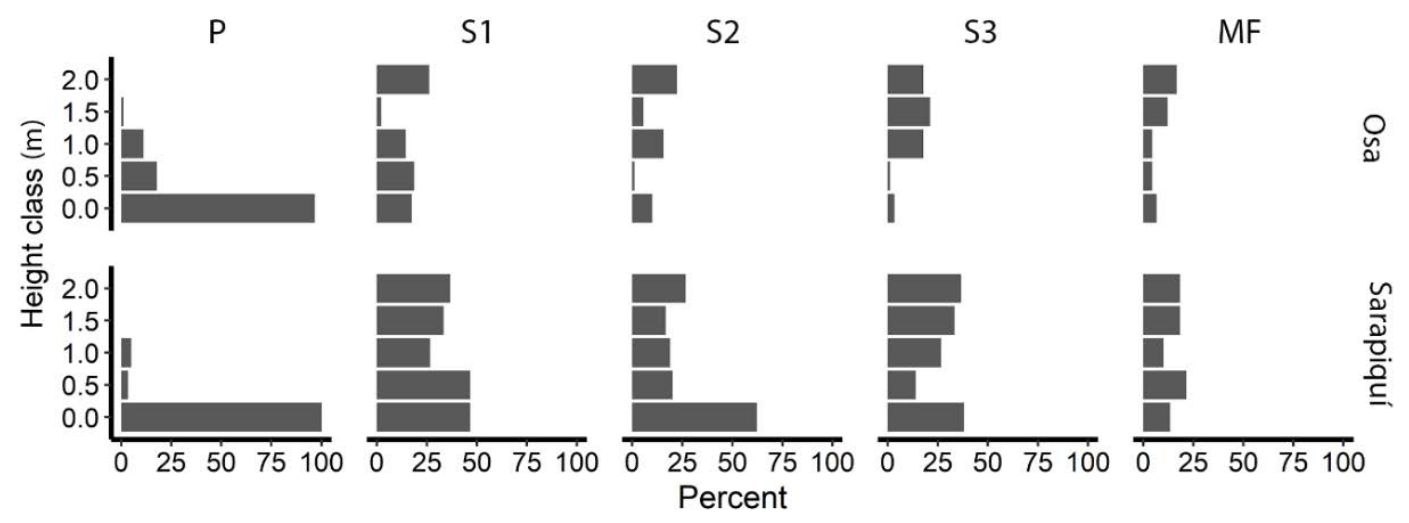

Figure 4.10. Percent of vegetation structure counts at different height classes. Forest types are pasture $(\mathrm{P})$, secondary forest $<17$ years old $(\mathrm{S} 1)$, secondary forest $17-27$ years old (S2), secondary forest $>27$ years old (S3), and mature forest (MF) in the Osa Peninsula and Sarapiquí. 


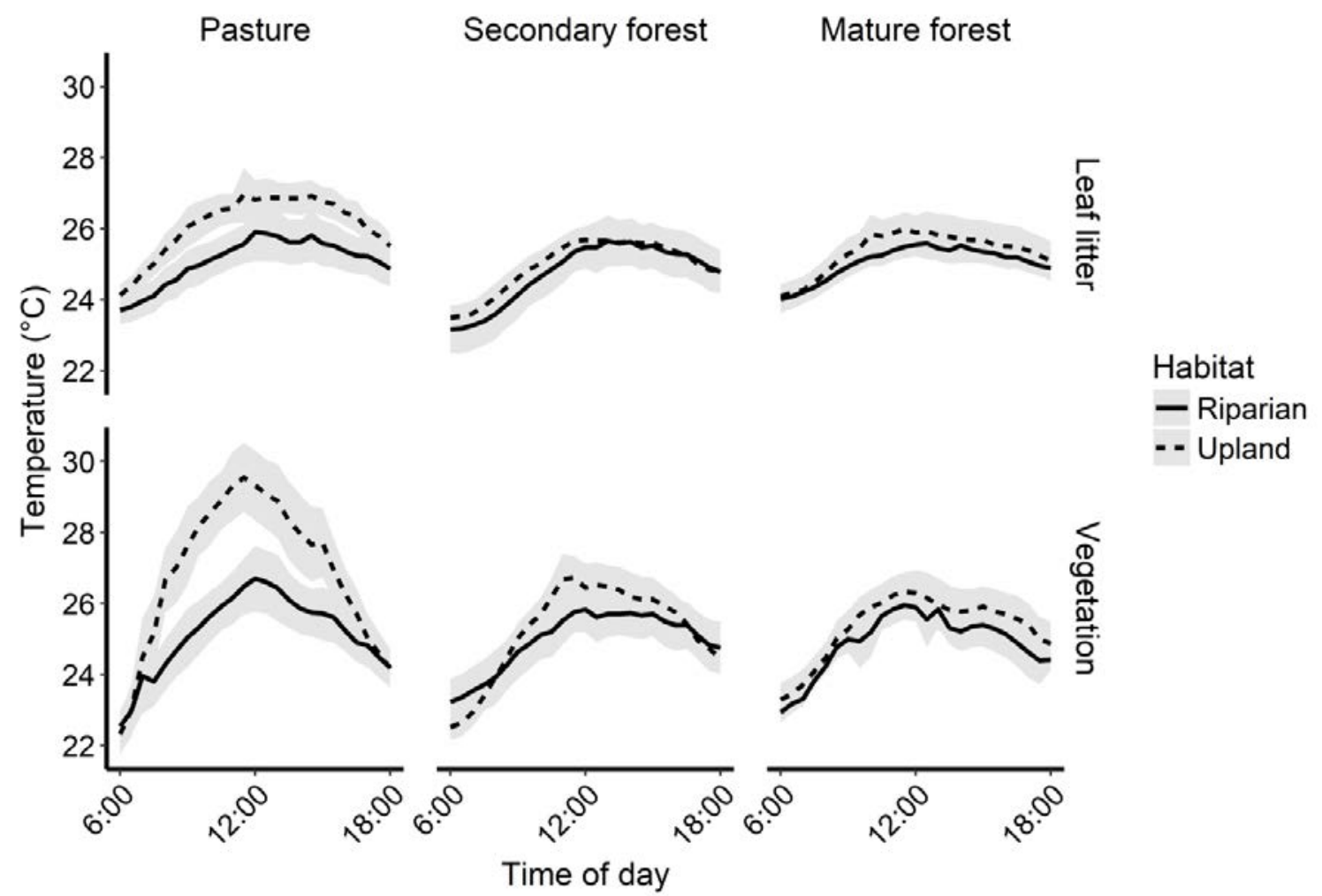

Figure 4.11. Mean daytime (6:00 - 18:00) temperature and 95\% confidence intervals between $8-18$ October, 2014 in two pasture, secondary forest $>27$ years old, and mature forest sites in Sarapiquí. 


\title{
CHAPTER 5: THERMAL QUALITY INFLUENCES HABITAT USE OF TWO
}

\section{ANOLE SPECIES}

\begin{abstract}
Regeneration of secondary forests on previously deforested or degraded land is one of the most dominant forms of land-use change in the tropics. However, the response of animal communities to forest regeneration is poorly understood. To evaluate support for thermal quality as a mechanism driving reptile species distributions during secondary forest succession, I measured operative temperatures and occupancy in three successional forest stages (pasture, secondary forest, and old growth forest) for two anole species common in the landscape (Norops humilis and Norops limifrons). I then measured thermal preference in laboratory experiments and used operative temperature and temperature preference measurements to determine how thermal quality of habitat changes over the course of secondary forest succession, and if occupancy varies as a function of thermal quality. I found that thermal quality was lowest in pasture habitat because of a large frequency of temperatures above the thermal preference range. However, in low thermal quality pasture sites, riparian habitats and remnant trees provided a thermal refuge for both lizard species. My results support thermal quality as a mechanism for reptile species distributions in altered landscapes and highlight the importance of the maintenance of riparian corridors.
\end{abstract}




\section{INTRODUCTION}

Over the past several decades, human transformation of natural landscapes has become unprecedented in intensity and spatial scale (Laurance 2010). Forest habitats and animal communities within forests are among the most highly impacted, globally (Laurance 2010). Forest destruction has been repeatedly documented as a driver of biodiversity loss (Pimm and Raven 2000; Brook et al. 2003; Fearnside 2005). However, little is known about the ways that animal communities respond when altered landscapes are abandoned and left to regenerate into secondary forests. It is thought that the regrowth of secondary forests may help reverse biodiversity loss by restoring habitats to similar conditions prior to land conversion. Of the global forest cover that remains, over half is secondary forest, and in many countries secondary forest cover has been steadily increasing (ITTO 2002; Aide and Grau 2004) and will continue to increase as humans convert forests to other land uses. Therefore, it is important to understand how and if faunal communities recover during secondary forest regeneration.

Suitable thermal conditions are fundamental to habitat quality for ectotherms (Heatwole 1977; Dunham et al. 1989; Huey 1991). Body temperature of amphibians and reptiles affects growth, reproduction (Hillman et al. 2009), ecological interactions, and disease susceptibility (Woodhams et al. 2003; Pounds et al. 2006). While achieving an optimum body temperature may be mediated by behavior, morphology, and physiology, reptiles are ultimately constrained by the distribution of suitable/favorable thermal habitat over space and time (Grbac and Bauwens 2001). Therefore, abiotic conditions may limit species distributions across habitat types, and knowledge of the heterogeneity of thermal microhabitats is imperative to understanding habitat quality, thermoregulatory behavior, 
and demographic costs of living in different environments. Additionally, reptiles in tropical forest systems may be highly sensitive to microclimate because the natural habitat for these species is the relatively stable microclimate of closed-canopy forest (with the exception of gap and edge specialists), and because tropical species tend to have narrow thermal niches. Many tropical ectotherms are already living close to their thermal maximum and small changes in microclimate may cause habitat to become uninhabitable (Janzen 1967; Deutsch et al. 2008; Sinervo et al. 2010; Perez et al. 2016).

Past studies on reptiles over the course of forest succession suggest that temperature likely plays a large role in the described patterns of reptile abundance and diversity during forest succession (Inger and Colwell 1977; Heinen 1992; Rios-Lopez and Aide 2007; Herrera-Montes and Brokaw 2010). As abandoned landscapes regenerate into secondary forest, vegetation structure changes affecting canopy cover, density, and height of vegetation (Terborgh and Petren 1991; DeWalt et al. 2003; Chazdon 2014), and changes in vegetation structure may mediate changes in temperature and humidity that directly affect reptiles. The changes in vegetation during habitat conversion often result in moving from hot, dry, environments in land-uses such as agriculture and pasture to cool and humid environments as secondary forest ages (Newmark 2001; HernándezOrdóñez et al. 2015).

In this study, I examined how changes in thermal quality affect two common lizard species, Norops humilis and Norops limifrons, over the course of forest succession in tropical lowland wet forest in Costa Rica. Specifically, I determined if thermal quality differs among successional forest stages and if occupancy and habitat use by lizards is associated with thermal quality. Because these lizards are naturally found in tropical 
forest habitats, I expect thermal quality to increase from pasture to secondary to old growth habitats, especially for $N$. humilis, which is thought to be a more strict forest specialist than N. limifrons (Savage 2002).

\section{METHODS}

Surveys, species, and study sites: I conducted surveys for Norops limifrons and Norops humilis in tropical lowland wet forest in Sarapiquí, Costa Rica. Survey sites consisted of pasture, 20-30 year old secondary forest regenerating from pasture, and old growth forest ( $\mathrm{n}=3$ for each land use). I conducted lizard surveys using diurnal visual encounter surveys along six randomly placed 50 x 2 m transects (Crump and Scott 1994), three in forest habitat (at least $40 \mathrm{~m}$ from water bodies, hereinafter called "upland") and three in riparian habitat at each site, for a total of 54 transects. I surveyed on three occasions annually for two years, with surveys occurring in the wet, dry, and transition between seasons, for a total of six sampling occasions at each site.

Norops humilis and N. limifrons inhabit lowland and premontane forest throughout their ranges. Norops humilis ranges from Nicaragua to Panama and $N$. limifrons from Mexico to Panama. Both species are generally common throughout Costa Rica (Fitch et al. 1973; Savage 2002). Norops humilis primarily occurs in leaf litter but also perches on low vegetation less than $1 \mathrm{~m}$ in height, especially on buttress roots of large trees. Norops limifrons is most often found perched on low vegetation and has been observed in both forested and disturbed, open habitats (Fitch 1973; Savage 2002; Guyer and Donnelly 2005). Neither species is likely to exhibit basking behavior (Fitch 1973; van Berkum 1986). 
Preferred temperature ( $\left.T_{\text {sel }}\right)$ : I measured preferred temperature for $N$. humilis and $N$. limifrons using shuttle box experiments that consist of enclosures with a linear gradient of temperature, allowing for lizards to select their temperature (Hertz et al. 1993; Angilletta 2009; Sinervo et al. 2010). I captured lizards in the field ( $\mathrm{n}=8$ for each species) and let them acclimate in an ambient lab overnight (18 \pm 4 hours) before using them in experiments.

To create a thermal gradient, in 87 by $26 \mathrm{~cm}$ plywood enclosures I heated one end of the shuttle box using 90-watt halogen light bulbs on the sides and bottom of the shuttle box in an air conditioned room, creating a gradient of $22.8 \pm 0.5$ to $46.4 \pm 1.5^{\circ} \mathrm{C}$ (representing the range of day-time temperatures of lizards in their natural habitat at sample locations). At the beginning of each temperature preference trial, I randomly placed lizards in the thermal arena and allowed 30 minutes for lizards to acclimate to the arena. I recorded $\mathrm{T}_{\text {sel }}$ in one minute intervals for two hours by attaching a thermocouple with tape to the side of the lizard's abdomen during trials and recording temperature every minute with a datalogger (OMEGA OM-DaqPRO). Body surface temperature in small, low mass lizards often approximates core body temperature because heat transfer between the body surface and the core is rapid (Bakken 1992; Luna et al. 2013). I validated this assumption in my study organisms by comparing cloacal and body surface temperature, and found an average difference of $0.49 \pm 0.7{ }^{\circ} \mathrm{C}(\mathrm{n}=12)$. I calculated upper and lower bounds of $\mathrm{T}_{\text {sel }}$ as the central $50 \%$ of all body temperatures selected during the shuttle box experiments (Hertz et al. 1993, Angilletta et al. 2009).

Measurement of thermal environment $\left(T_{e}\right)$ : I measured $\mathrm{T}_{\mathrm{e}}$ by measuring operative temperature, defined as the body temperature of an organism in thermal equilibrium with 
the environment (Bakken et al. 1985). I made operative models by rolling copper sheeting into lizard-sized hollow tubes $($ length $=7.0 \mathrm{~cm}$, diameter $=2.0 \mathrm{~cm})$ and placing a Thermochron iButton datalogger inside (DS1922L-F5). Ends of the copper tubes were sealed by pinching one end and by capping the other with a copper cap (Dzialowski 2005; Angilleta et al.2009). iButton dataloggers were programmed to take temperature measurements every half hour. I measured $T_{e}$ for my nine sample sites $(n=3$ for each land use) for five consecutive day periods, over the course of fifteen days during February 2016 and again in mid-December 2016 to mid-January 2017. During each five day sample period, operative models were deployed in one site of pasture, secondary forest, and old growth forest. At each site, I randomly placed models in both riparian and upland habitat, in each of two microhabitat types (leaf litter: $\mathrm{n}=4$; $1 \mathrm{~m}$ on vegetation: $\mathrm{n}=$ 4) representing the two main microhabitat types used by both of these species (Savage 2002), resulting in a total of 16 random sample locations of five day $T_{e}$ measurements for each site.

Measurement of thermal quality $\left(d_{e}\right)$ : I measured the thermal quality of each forest stage using the quantitative methods proposed by Hertz et al. (1993), where: $\mathrm{T}_{\mathrm{e}}=$ operative temperature $\mathrm{T}_{\mathrm{sel}}=$ preferred or selected temperature range from shuttle box experiments calculated as the set point temperature (central $50 \%$ of body temperatures from temperature preference experiments)

$\mathrm{d}_{\mathrm{e}}=$ thermal quality of the environment (the mean deviations between $\mathrm{T}_{\mathrm{e}}$ and $\mathrm{T}_{\mathrm{sel}}$ ) 
Norops humilis and N. limifrons are diurnal lizards and I therefore measured thermal quality $\left(\mathrm{d}_{\mathrm{e}}\right)$ as mean absolute deviation between $\mathrm{T}_{\mathrm{e}}$ and $\mathrm{T}_{\text {sel }}$ during daytime hours (6:00 -18:00). My data did not meet normality assumptions so I determined if $\mathrm{d}_{\mathrm{e}}$ varied among successional stage, habitat, and species using generalized linear mixed models with site modeled as a random effect (random intercept model, family $=$ gamma, link $=$ inverse). Analysis was performed using package lme4 (Bates et al. 2015) in R 3.3.1 (R Core Team 2016).

Occupancy modeling: To estimate probability of occurrence of $N$. humilis and $N$. limifrons I used single-season occupancy models in a Bayesian hierarchical framework (MacKenzie et al. 2002, 2006; Kéry and Schaub 2011). I conducted a two-step model procedure. The first step was carried out to test the support for the relative importance of thermal quality as a mechanism for observed changed in probability of occurrence. For step 1, I compared a model with the effects of $d_{e}$ (measured as the z-score of the mean $d_{e}$ for each habitat type at each site), habitat (riparian, upland), and the interaction between $\mathrm{d}_{\mathrm{e}}$ and habitat for probability of occurrence $(\psi)$ and effort (z score of person transect hours) for probability detection $(p)$ with a model with the effects of stage (pasture, secondary forest, old-growth forest), habitat, and the interaction between stage and habitat for $\psi$ and effort for $p$. If thermal quality is a main driver of the observed differences in probability of occurrence, I would expect that the model including thermal quality would perform better than, or at least as well as the model including stage, which is a general model implicitly comparing any differences among forest stages. I fit the model for $N$. humilis and N. limifrons separately. To compare evidence for these two models, I placed an indicator variable on coefficients for the main effect of stage and the 
interaction of stage with habitat. I also placed ( 1 - indicator variable) on all the main effect for thermal quality and the interaction of thermal quality with habitat. The indicator variable therefore acted as a switch between the stage model and the thermal quality model. I assigned the indicator variable a Bernoulli(0.5) prior, which provides equal prior probability to both models and hierarchical priors for model coefficients $(\beta \sim$ normal $\left[\right.$ mean $\left.=0, \operatorname{sd}=\sigma_{\beta}\right] ; \sigma_{\beta} \sim$ half-Cauchy[1]; Kruschke 2015) to integrate over model selection sensitivity to prior precision on model coefficients (Link and Barker 2011; Tenan et al. 2014; Kruschke 2015). I then compared the two models using Bayes factors. I placed uniform $(\min =0, \max =1)$ priors on mean $\psi$ and mean $p$, then logit-transformed them to serve as intercepts in the logistic regression models for occupancy and detection, respectively. I placed a normal $(0,1.65)$ prior on the coefficient for effort on $p$. In step 2, I compared the full thermal quality model to all subsets of the full model by using an independent indicator variable with a Bernoulli( 0.5$)$ prior for each model coefficient to determine the probability of each subset of the full model (Kuo and Mallick 1998; Royle and Dorazio 2008). For all model coefficients, I used normal(0, 1.65). I ran analyses in JAGS (Plummer 2003) called from jagsUI (Kellner 2015) in program R 3.3.1 (R Core Team 2016). For each model, I ran 39,000 Markov chain Monte Carlo (MCMC) iterations on two independent chains, discarded the first 9,000 as burn-in, and used a thinning rate of 5, resulting in 12,000 iterations used for inference. I evaluated convergence with visual examination of history plots and with the Gelman-Rubin statistic (Gelman and Rubin 1992). 


\section{RESULTS}

Preferred temperature $\left(T_{\text {sel }}\right)$ and thermal habitat quality: The preferred temperature range of the two species overlapped, although $\mathrm{T}_{\text {sel }}$ for $N$. limifons was marginally higher than it was for N. humilis (Figure 5.1). The lower and upper limits of $\mathrm{T}_{\text {sel }}$ for $N$. humilis and $N$. limifrons were $22.7-25.9{ }^{\circ} \mathrm{C}$ and $23.5-27.3^{\circ} \mathrm{C}$, respectively. Common field body temperatures previously estimated by identifying the range of body temperatures at which lizards are found in the field for these two species fall closely within the $\mathrm{T}_{\text {sel }}$ measured in this study $\left(N\right.$. humilis: $22-27^{\circ} \mathrm{C}, N$. limiforns:25-28 ${ }^{\circ} \mathrm{C}$; Fitch et al. 1993). Forest successional stage and habitat type had a significant effect on $\mathrm{d}_{\mathrm{e}}$. Pasture sites had significantly lower $d_{e}$ than old growth forests $(\beta=-2.06, t=-3.59, p=$ 0.0003; Fig. 2) and $d_{e}$ was lower in upland habitat than in riparian habitat $(\beta=-0.84, t=-$ 2.17, $\mathrm{p}=0.03$; Fig. 2). Deviations from $\mathrm{T}_{\text {sel }}$ were dominated by $\mathrm{T}_{\mathrm{e}}$ lower than $\mathrm{T}_{\text {sel }}$ in old growth forest sites for both $N$. humilis and $N$. limifrons (Table 5.1). In secondary forest and pasture habitats, deviations from $\mathrm{T}_{\text {sel }}$ were dominated by $\mathrm{T}_{\mathrm{e}}$ higher than $\mathrm{T}_{\text {sel }}$ in upland habitats but this trend was not consistent in riparian habitats (Table 5.1).

In upland pasture habitat, $41.0 \%$ and $26.6 \%$ of $\mathrm{T}_{\mathrm{e}}$ were above $\mathrm{CT}_{\max 1}$ (as measured by Brusch et al. 2016) for $N$. humilis and $N$. limifrons, respectively. Using CT $\max 2$ (as measured by van Berkum 1986), less than $1.0 \% \mathrm{~T}_{\mathrm{e}}$ were above $\mathrm{CT}_{\max 2}$ for both anole species. With both measures of $\mathrm{CT}_{\max }$, the frequency of $\mathrm{T}_{\mathrm{e}}$ above $\mathrm{CT}_{\max }$ during the day decreased substantially as forest aged (Figure 5.1).

Occupancy modeling: For both species, I found low support for the global model including the effects of stage on probability of occurrence over the global model 
including the effect of thermal quality on probability of occurrence (N. humilis: B stage, de $=1.33 ;$. limifrons: $\mathrm{B}_{\text {stage, de }}=3.0 ;$ where $\mathrm{B}_{\text {stage, }}$ de $=$ the odds that the model including stage is better than model including thermal quality), indicating that the two models perform equally. I found no support for an effect of effort on probability of detection. Therefore, in subsequent analysis of subsets of the model including thermal quality on the effect of $\psi$, I modeled $p$ as a constant

For both $N$. humilis and N. limifrons, I found higher support for the full model compared to any subset of the models (Table 5.2). For N. humilis I found a significant positive relationship between thermal quality and probability of occurrence and a significant interaction between thermal quality and habitat (Table 5.3; Figure 5.3). Probability of occurrence was 2-3 times higher in upland forested sites than in upland pasture sites; however, I found support for the opposite trend in riparian habitat (Table 5.3; Figure 5.4). For N. limifrons, I did not find any significant trends in the relationship between occupancy and thermal quality or habitat type (Table 5.3; Figure 5.3). Contrary to $N$. humilis, $N$. limifrons had a high probability of occurrence across habitat types in upland habitat. However, in riparian habitat $N$. limifrons showed a similar trend as $N$. humilis with a higher probability of occurrence in riparian pasture sites than riparian forest sites (Figure 5.4). Mean probability of detection (and 95\% credible interval) was $0.24(0.17-0.33)$ and $0.13(0.07-0.19)$ for $N$. humilis and $N$. limifrons, respectively. 


\section{DISCUSSION}

My results support thermal quality as a mechanism for species response to forest succession. Land-use change, such as deforestation of a landscape and converting land to pasture, drastically changes the distribution of thermally suitable habitat for these lizards. However as these denuded landscapes are abandoned and allowed to regenerate, thermal quality of the habitat is restored. I found a difference in thermal quality among successional stages. Pastures had the lowest thermal quality with a high proportion of $\mathrm{T}_{\mathrm{e}}$ above thermal preference ranges of both $N$. humilis and $N$. limifrons, whereas old growth forest and secondary forest years provided a high frequency of suitable thermal habitat. The response of probability of occurrence to change in thermal quality was species and habitat-specific. The probability of occurrence of the species that experienced higher changes in thermal quality among habitat types ( $N$. humilis) showed a stronger relationship with thermal quality than the lizard species with the higher and broader thermal preference range, $N$. limifrons. My results show that integrating physiological experiments with field studies can help better understand species response to habitat change and can help us better understand the differences in responses among species.

I found high variation in operative temperatures in pasture habitat compared to forested sites. It is not that pastures do not provide any suitable thermal habitat but they provide a more variable thermal environment than forests. There is a reduced frequency of suitable thermal habitat in pasture over space and time. While lizards still may be able to occupy these environments, thermal stress, changes in behavior to avoid thermal stress such as shuttling between thermally suitable habitat and suitable foraging habitat, reduction in activity time to short thermally suitable time periods, and limited space use 
to thermally suitable microhabitats within pasture may diminish population sizes (Kearney et al. 2009; Sinervo et al. 2010; Tuff et al. 2016). The preferred temperature range is thought to reflect the optimum range for fitness for a species (Hertz et al. 1993; Martin and Huey 2008). Therefore, the changes in thermal quality of habitat over the course of secondary succession may ultimately affect the fitness of lizard populations. In optimal thermal habitats, lizards can devote energy to reproduction compared to lizards in thermally stressful environments. Apart from the large deviations in $\mathrm{T}_{\mathrm{e}}$ and $\mathrm{T}_{\text {sel }}$ found in pastures, I also found that pastures harbor a substantial amount of uninhabitable habit, with temperatures higher than the $\mathrm{CT}_{\max }$ of $N$. humilis and $N$. limifrons. Although the two past studies that have measured $\mathrm{CT}_{\max }$ for $N$. humilis and $\mathrm{N}$. limifrons differ nearly $10^{\circ} \mathrm{C}$ in their estimates (van Berkum 1986; Brusch at al. 2016), I regard the lower estimate by (Brusch et al. 2016) to, at minimum, reflect a temperature at which these two species become physiologically stressed; therefore, it is unlikely that $N$. humilis and $N$. limifrons inhabit or spend much time in microhabitats at or above the lower $\mathrm{CT}_{\max }$ estimates.

Lizards in my study had a relatively narrow thermal preference range. The narrow thermal preference of these lizards reflect the trend that tropical ectotherms have relatively narrow thermal ranges (Janzen 1967; Deutsch et al. 2008; Perez et al. 2016) Both $N$. humilis and $N$. limifrons are forest-associated species where thermal heterogeneity may be limited compared to other habitat types (Vitt et al. 1997). The link between temperature of habitat and thermal preference has also been found in other reptiles (Ballinger et al. 1969; Qu et al. 2011; Winne and Keck 2005). Forest specialists tend to be more strongly affected by habitat change than habitat generalists (Gardner et al. 2007; Thompson et al. 2016), and one reason is because species with high thermal 
tolerances may be better able to utilize habitats with increased temperatures than those species encountered primarily in forests (Nowakowski et al. 2016). As hypothesized, $N$. humilis, a more strict forest specialist than $N$. limifrons, experienced a higher proportion of thermally unsuitable habitat in pastures and secondary forest and had a thermal preference range and $\mathrm{CT}_{\max }$ lower than that of $N$. limifrons. Norops limifrons, a generalist compared to $N$. humilis, experienced lower changes in thermal quality of habitat among surveyed sites and persisted in upland pasture sites with low thermal quality. However, in pasture sites, $N$. limifrons has an increased use of riparian sites compared to riparian forest sites and observations of this species were restricted to within $10 \mathrm{~m}$ of remnant trees. While remnant trees are commonly left in pasture to provide a cool, shaded area for livestock (Harvey and Haber 1998), they also have been known to serve as refuges for native animals in matrix environments by providing suitable thermal, foraging, and reproductive habitat (Manning et al. 2006; Robinson et al. 2013).

Trends in habitat occupancy by lizards reflected the trends found in thermal quality of habitat. Lizards compensated for lower quality of thermal habitat in upland pasture sites by moving to riparian habitat, where suitable thermal habitat is present in the line of trees found along streams in all three habitat types; this trend was especially strong for N. humilis. Additionally, all N. humilis and N. limifrons found in upland pasture habitats were observed within $10 \mathrm{~m}$ of remnant trees, suggesting that much of the open habitat in pasture is uninhabitable. My results highlight the importance of maintaining riparian corridors and remnant trees when pastures or other human-focused land uses are established. Riparian buffers in my pasture sites are meager, consisting of a thin line of trees, understory shrubs, and herbaceous vegetation, five meters at most in 
width from streams. However, even this small corridor provided a thermal refuge for the small anole species in my study (N. humilis: $\mathrm{SVL}=31.8 \mathrm{~mm}$, mass $=1.1 \mathrm{~g}, \mathrm{~N}=29 ; N$. limifrons $\mathrm{SVL}=34.5 \mathrm{~mm}$, mass $=0.97 \mathrm{~g}, \mathrm{~N}=33$ ). These riparian buffers may be important for maintaining species diversity in modified habitats and help repopulate secondary forests as they regenerate from pastures. Apart from differences in thermal biology, another reason that $N$. humilis may be more sensitive to conversion of forest to pasture than $N$. limifrons may be because of the preference of $N$. humilis for leaf-litter habitat (Fitch et al. 1973; Whitfield et al. 2014). However, the association of $N$. humilis and leaf litter cannot completely explain the increased probability of occurrence I found for this species in riparian habitat at pasture sites because I observed substrate at riparian sites to be dominated by grass and low herbaceous vegetation and largely absent of leaflitter.

The increase in habitat use from upland to riparian in pasture sites may have repercussions for species interactions. The habitat switch may increase the occurrence of interactions between different anole species. Norops humilis and N. limifrons are not known to be stream affiliated although they can be observed near streams in forest on occasion. In tropical lowland forest of Sarapiquí, the riparian habitat niche is dominated by a semi-aquatic anole species, Norops oxylophus (Savage 2002; Guyer and Donnelly 2005). The increase in use of riparian habitat by $N$. humilis and $N$. limifrons in pastures may result in additional behavioral changes such as niche partitioning as riparian habitats are more densely occupied by additional species of anoles.

When faced with a change in frequency of thermally suitable habitat in an altered environment, species can move to favorable thermal habitats; adjust through displays of 
behavioral plasticity, physiological plasticity, or adaptation; or alternatively undergo demographic collapse (Sinervo et al. 2010). Here, I provide evidence of two lizard species responding to a reduction in thermally suitable habitat by shifting their behavior to use of a different habitat within the landscape (riparian versus upland habitat) or by using remnant trees in upland habitat. There may be other drivers such as forest structure, food resources, and predation that also play a role in species assemblage during secondary forest succession. However, because of the physiological characteristics of ectotherms, thermal quality of habitat likely is a main mechanism shaping species distributions in altered habitats and species recovery during natural habitat regeneration. While deforestation continues to be a main driver in the current biodiversity crisis, reforestation of these altered landscapes may restore habitats and communities to a state close to conditions before habitat alteration. Knowledge of the rapid restoration of thermal quality during forest succession and identification of important habitat characteristics useful in the maintenance of species populations such as presence of riparian corridors can help inform conservation management decisions and prioritizations.

\section{LITERATURE CITED}

Aide T. M., and H. R. Grau. 2004. Globalization, migration, and Latin American ecosystems. Science 305:1915-1916.

Angilletta, M. J. Jr, M. W. Sears, R. M. Pringle. 2009. Spatial dynamics of nesting behavior: lizards shift microhabitats to construct nests with beneficial thermal properties. Ecology 90:2933-2939.

Bakken, G. S. 1992. Measurement and application of operative and standard operative temperatures in ecology. Integr Comp Biol 32:194-216. 
Bakken, G. S., W. R. Santee, and D. Erskine. 1985. Operative and standard operative temperature: tools for thermal energetics studies. Integr Comp Biol 25:933-943.

Ballinger, R. E., K. R. Marion, and O. J. Sexton. 1969. Thermal ecology of the lizard, Anolis limifrons with comparative notes on three additional Panamanian anoles. Ecology 51:246-254.

Bates D, Maechler M, Bolker B, Walker S (2015). Fitting Linear Mixed-Effects Models Using lme4. Journal of Statistical Software, 67:1-48. doi:10.18637/jss.v067.i01

Brook, BW, Sodhi NS, Ng PKL (2003) Catastrophic extinctions follow deforestation in Singapore. Nature 424:420-426.

Brusch GA IV, Taylor EM, Whitfield SM (2016) Turn up the heat: thermal tolerances of lizards at La Selva, Costa Rica. Oecologia 180:325-334.

Chazdon RL (2014) Second Growth: The Promise of Tropical Forest Regeneration in an Age of Deforestation. University of Chicago Press, Chicago, IL.

Crump ML, Scott NJ (1994) Visual Encounter Surveys. In Heyer WR, Donnelly MA, McDiarmid RW, Hayek LC, Foster MS (eds) Measuring and Monitoring Biological Diversity: Standard Methods for Amphibians. Smithsoniain Institution Press, Washington DC, pp 84-92.

Deutsch CA, Tewsbury JJ, Huey RB, Sheldon KS, Ghalambor CK, Haak DC, Martin PR (2008) Impacts od climate warming on terrestrial ectotherms across latitude. Proc Natl Acad Sci USA 105:6668-6672.

DeWalt SJ, Maliakal SK, Denslow JS (2003) Changes in vegetation structure and composition along a tropical forest chronosequence: implications for wildlife. Forest Ecol Manag 182:139-151.

Dunham AE, Grant BW, Overall KL (1989) Interfaces between biophysical and physiological ecology and the population ecology of terrestrial vertebrate ectotherms. Physiol Zoo 62:335-355.

Dzialowski EM (2005) Use of operative temperature and standard operative temperature models in thermal biology. J Therm Biol 30:317-334.

Fearnside PM (2005) Deforestation in Brazilian Amazonia: History, rates, and consequences. Conserv Biol 19:680-688.

Fitch HS (1973) A field study of Costa Rican lizards. The University Of Kansas Science Bulletin 50:39-126. 
Gardner TA, Barlow J, Peres CA (2007) Paradox, presumption and pitfalls in conservation biology: the importance of habitat change for amphibians and reptiles. Biol Conserv 138:166-179.

Gelman A, Rubin DB (1992). Inference from iterative simulation using multiple sequences. Stat Sci 7:457-472.

Gibson, L., T. M. Lee, L. P. Koh, B. W. Brook, T. A. Gardner, J. Barlow, C. A. Peres, C. J. A. Bradshaw, W. F. Laurance, T. E. Lovejoy, N. S. and Sodhi. 2011. Primary forests are irreplaceable for sustaining tropical biodiversity. Nature 478:378-383.

Grbac I, Bauwens D (2001) Constraints on temperature regulation in two sympatric Podarcis lizards during autumn. Copeia:178-186.

Guyer C, Donnelly MA (2005) Amphibians and Reptiles of La Selva, Costa Rica, and the Caribbean Slope: A Comprehensive Guide. University of California Press, CA.

Harvey CA, Haber WA (1998) Remnant trees and the conservation of biodiversity in Costa Rican pastures. Agroforest Syst 44:37-68.

Heatwole H (1977) Habitat selection in reptiles. In: C. Gans C, Tinkle DW (eds) Biology of the Reptilia, Vol. 7. Academic Press, London, pp 137-155.

Heinen JT (1992) Comparisons of the leaf litter herpetofauna in abandoned cacao plantations and primary rain forest in Costa Rica: some implications for faunal restoration. Biotropica 24:431-439.

Hernández-Ordóñez O, Urbina-Cardona N, Martinez-Ramos M (2015) Recovery of amphibian and reptile assemblages during old-field succession of tropical rain forests. Biotropica 47: 377-88.

Hertz PE, Huey RB, Stevenson RD (1993) Evaluating temperature regulation by fieldactive ectotherms: the fallacy of the inappropriate question. Am Nat 142:796-818.

Herrera-Montes A., Brokaw N (2010) Conservation value of tropical secondary forest: A herpetofaunal perspective. Biol Conserv 143:1414-1422.

Hillman SS, Withers PC, Drewes RC, Hillyard SD (2009) Ecological and Environmental Physiology of Amphibians. Oxford University Press, Oxford.

Huey, RB (1991) Physiological consequences of habitat selection. Am Nat 137:S91-115.

Inger RF, Colwell RK (1977) Organization of contiguous communities of amphibians and reptiles in Thailand. Ecol Monogr 47:229-253. 
ITTO. 2002. ITTO Guidelines for the restoration, management and rehabilitation of degraded and secondary tropical forests. ITTO Policy Development Series No. 13.

Janzen DH (1967) Why mountain passes are higher in the tropics. Am Nat 101:233-249.

Kuo, L, Mallick B (1998) Variable selection for regression models. Indian J. Stat. 60: 65-81.

Kearney M, Shine R, Porter WP (2009) The potential for behavioral thermoregulation to buffer 'cold-blooded' animals against climate warming. Proc Nat Acad Sci USA 106:3835-40.

Kellner K (2015) jagsUI: A Wrapper Around rjags to Streamline JAGS Analyses. R package version 1.3.1. https://CRAN.R-project.org/package=jagsUI

Kéry M, Schaub M (2011) Bayesian population analysis using WinBUGS: a hierarchical perspective. Waltham:Academic Press.

Kruschke JK (2015) Doing Bayesian data analysis: a tutorial with R, JAGS, and Stan. London:Academic Press.

Laurance WF (2010) Habitat destruction: death by a thousand cuts. In Sodhi NS, Ehrlich PR Conservation Biology for All. Oxford University Press, Oxford, pp 73-87.

Link WA, Barker RJ (2010) Bayesian inference: with ecological applications. London:Academic Press.

Luna S, Font E (2013) Use of an infrared thermographic camera to measure field body temperatures of small lacertid lizards. Herpetol. Rev. 44:59-62.

MacKenzie DI, Nichols JD, Lachman GB, Droege S., Royle JA, Langtimm CA (2002). Estimating site occupancy rates when detection probabilities are less than one. Ecology 83:2248-2255.

MacKenzie DI, Nichols JD, Royle JA, Pollock KH, Bailey LL, Hines JE (2006). Occupancy estimation and modeling: inferring patterns and dynamics of species occurrence. Academic Press, Amsterdam.

Manning AD, Fischer J, Lindenmayer DB (2006) Scattered trees are keystone structures - implications for conservation. Biol Conserv 132:311-321.

Martin TL, Huey RB (2008) Why "suboptimal” is optimal: Jensen's inequality and ectotherm thermal preferences. Am Nat 171:E102-E118. 
McKinney,Newmark WD (2001) Tanzanian forest edge microclimatic gradients: Dynamic Patterns. Biotropica 33:2-11.

Nowakowski AJ, Watling JI, Whitfield SM, Todd BD, Kurz DJ, Donnelly MA (2016) Tropical amphibians in shifting thermal landscapes under land-use and climate change. Conserv Biol 31:96-105.

Perez TM., Stroud JT, Feeley KJ (2016) Thermal trouble in the tropics. Science 351:1392-1393.

Pimm SL, Peter Raven P (2000) Biodiversity: Extinction by numbers. Nature 403:843845.

Plummer M (2003) JAGS: A program for analysis of Bayesian graphical models using Gibs sampling In Hornik K, Leisch F, Zeileis A (eds) Proceedings of the 3rd International Workshop on Distributed Statistical Computing, March 20-22, Technische Universität Wien, Vienna. URL http://www.ci.tuwien.ac.at/Conferences/ DSC-2003/Proceedings/.

Pounds JA et al. (2006) Widespread amphibian extinctions from epidemic disease driven by global warming. Nature 439:161-167.

Qu Y, Li H, Gao J, Xu X, Ji X (2011) Thermal preference, thermal tolerance and the thermal dependence of digestive performance in two Phrynocephalus lizards (Agamidae), with a review of species studied. Curr Zool 57:684-700.

R Core Team (2016) R: A language and environment for statistical computing. $R$ Foundation for Statistical Computing, Vienna, Austria. URL https://www.Rproject.org/.

Rios-López N, Aide TM (2007) Herpetofaunal dynamics during secondary succession. Herpetologica 63:35-50.

Robinson D, Warmsley A, Nowakowski AJ, Reider KE, Donnelly MA (2013) The value of remnant trees in pastures for a neotropical poison frog. J Trop Ecol 29:345-352.

Royle JA, Dorazio RM (2008) Hierarchical modeling and inference in ecology: the analysis of data from populations, metapopulations and communities. Academic Press, London.

Savage JM (2002) The Amphibians and Reptiles of Costa Rica: A Herpetofauna between two Continents, between two Seas. University of Chicago Press, Chicago.

Sinervo B, Méndez-de-la-Cruz F, Miles DB, et al. (2010) Erosion of lizard diversity by climate change and altered thermal niches. Science 328:894-899. 
Tenan, S., R. B. O’Hara, I. Hendriks, G. Tavecchia. 2014. Bayesian model selection: the steepest mountain to climb. Ecol Model 283:62-69.

Terborgh J., and K. Petren. 1991. Development of Habitat Structure through Succession in an Amazonian Floodplain Forest In Bell SS, McCoy ED, Mushinsky HR (eds) Habitat Structure: The Physical Arrangement of Objects in Space, Dordrecht:Springer Netherlands, pp 28-46.

Thompson, M. E., A. J. Nowakowski, and M. A. Donnelly. 2016.The importance of defining focal assemblages when evaluating amphibian and reptile responses to land use. Conservation Biology 30:249-258.

Tuff, K. T., T. Tuff, K. F. Davies. 2016. A framework for integrating thermal biology into fragmentation research. Ecology Letters 19:361-374.

van Berkum, F. H. 1986. Evolutionary patterns of the thermal sensitivity of sprint speed in Anolis lizards. Evolution 40:594-604.

Vitt LJ, Zani PA, Lima ACM (1997) Heliotherms in tropical rainforest: the ecology of Kentropyz calcarata (Teiidae) and Mabuya nigropunctata (Scincidae) in the CuruáUna of Brazil. J. Trop. Ecol. 13:199-220. doi:10.1017/S0266467400010415

Whitfield, S. M., K. Reider, S. Greenspan, and M. A. Donnelly. 2014. Litter dynamics regulate population densities in a declining terrestrial herpetofauna. Copeia 14:454461.

Winne C. T., and M. B. Keck. 2005. Intraspecific differences in thermal tolerance of the diamondback watersnake Nerodia rhombifer: Effects of ontogeny, latitude, and sex. Comp. Biochem. Physiol. A 140: 141-149.

Woodhams D. C., R. A. Alford, and G. Marantelli. 2003. Emerging disease of amphibians cured by elevated body temperature. Dis Aquat Organ 55:65-67. 
Table 5.1. Mean percentage ( \pm SE) of deviations of operative temperatures above or below the preferred temperature range $\left(\mathrm{T}_{\mathrm{sel}}\right)$.

\begin{tabular}{|c|c|c|c|c|c|}
\hline & \multicolumn{3}{|c|}{ Norops humilis } & \multicolumn{2}{|c|}{ Norops limifrons } \\
\hline & $\%$ lowe & & $\%$ higher & $\%$ lower & $\%$ higher \\
\hline \multicolumn{6}{|l|}{ Pasture } \\
\hline Upland & $8.1 \pm$ & 2.9 & $56.6 \pm 11.4$ & $10.8 \pm 4.0$ & $39.5 \pm 12.3$ \\
\hline Riparian & $15.4 \pm$ & 8.4 & $30.9 \pm 16.8$ & $18.6 \pm 7.1$ & $12.7 \pm 9.0$ \\
\hline \multicolumn{6}{|l|}{ Secondary } \\
\hline Upland & $12.3 \pm$ & 3.3 & $22.9 \pm 8.5$ & $19.3 \pm 3.4$ & $8.1 \pm 4.9$ \\
\hline Riparian & $14.7 \pm$ & 4.4 & $11.3 \pm 2.8$ & $22.5 \pm 4.4$ & $1.7 \pm 1.5$ \\
\hline \multicolumn{6}{|l|}{ Old growth } \\
\hline Upland & $22.1 \pm$ & 7.2 & $6.2 \pm 3.5$ & $33.5 \pm 8.5$ & $1.3 \pm 1.2$ \\
\hline Riparian & $23.6 \pm$ & 6.8 & $1.7 \pm 1.6$ & $33.0 \pm 6.4$ & $0.1 \pm 0.1$ \\
\hline
\end{tabular}


Table 5.2. Results for model selection for occupancy of $N$. humilis and $N$. limifrons. A ' 1 ' or ' 0 ' indicates if the variable was or was not used in the model, respectively.

\begin{tabular}{|c|c|c|c|}
\hline \multicolumn{3}{|l|}{ Parameter $(\psi)$} & \multirow{2}{*}{$\begin{array}{l}\text { Posterior } \\
\text { probability } \\
N \text {. humilis }\end{array}$} \\
\hline de habitat & & de*habitat & \\
\hline 1 & 1 & 1 & 0.815 \\
\hline 1 & 1 & 0 & 0.126 \\
\hline 1 & 0 & 0 & 0.021 \\
\hline 0 & 1 & 0 & 0.007 \\
\hline 0 & 0 & 0 & 0.003 \\
\hline & & & N. limifrons \\
\hline 1 & 1 & 1 & 0.217 \\
\hline 0 & 1 & 0 & 0.171 \\
\hline 1 & 1 & 0 & 0.121 \\
\hline 0 & 0 & 0 & 0.105 \\
\hline 1 & 0 & 0 & 0.057 \\
\hline
\end{tabular}


Table 5.3. Parameter estimates for probability of occurrence $(\psi)$. Estimates are for best model: $\psi\left(\mathrm{d}_{\mathrm{e}}+\right.$ habitat $+\mathrm{d}_{\mathrm{e}}$ *habitat $) \mathrm{p}($.$) . Bold values indicate means where credible$ intervals do not include zero.

\begin{tabular}{lllll}
\hline & \multicolumn{2}{l}{ N. humilis } & \multicolumn{2}{l}{$N$. limifrons } \\
Variable & mean & $95 \% \mathrm{CI}$ & mean & $95 \% \mathrm{CI}$ \\
\hline$\Psi$ & & & & \\
$\quad$ intercept & 0.50 & $(-0.68,1.87)$ & 1.97 & $(0.30,4.35)$ \\
$\quad$ thermal quality & $\mathbf{- 2 . 2 3}$ & $\mathbf{( - 3 . 9 8 , - 0 . 8 4 )}$ & 0.15 & $(-1.48,2.44)$ \\
habitat & -1.23 & $(-2.82,0.30)$ & -1.23 & $(-3.40,1.14)$ \\
$\quad$ thermal quality*habitat & $\mathbf{2 . 2 2}$ & $\mathbf{( 0 . 1 9 , 4 . 3 3 )}$ & 1.63 & $(-1.07,4.12)$ \\
\hline
\end{tabular}


(a)

Upland

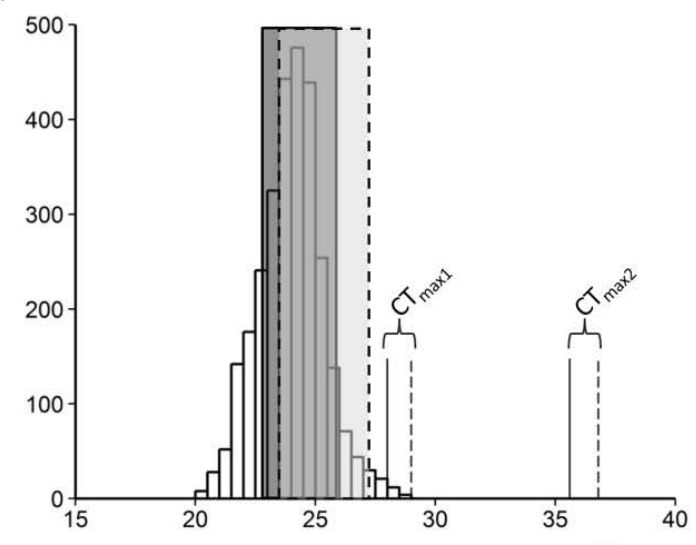

(b)

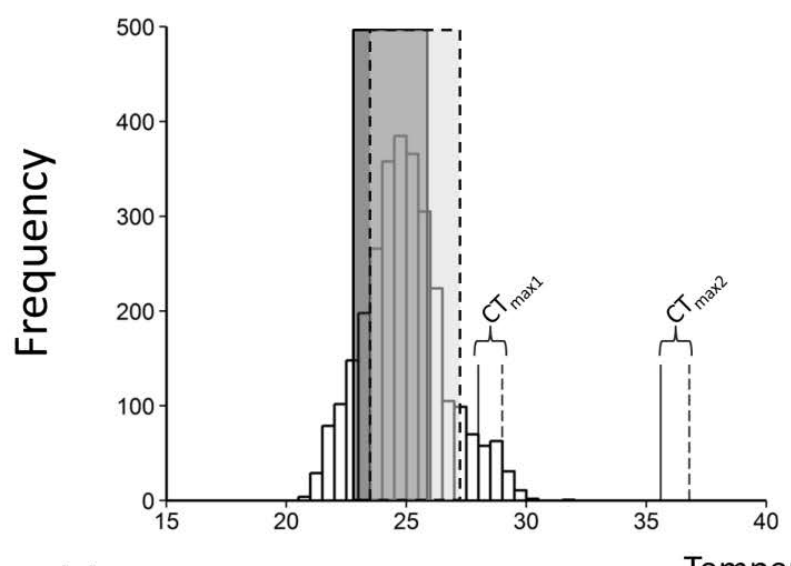

(c)

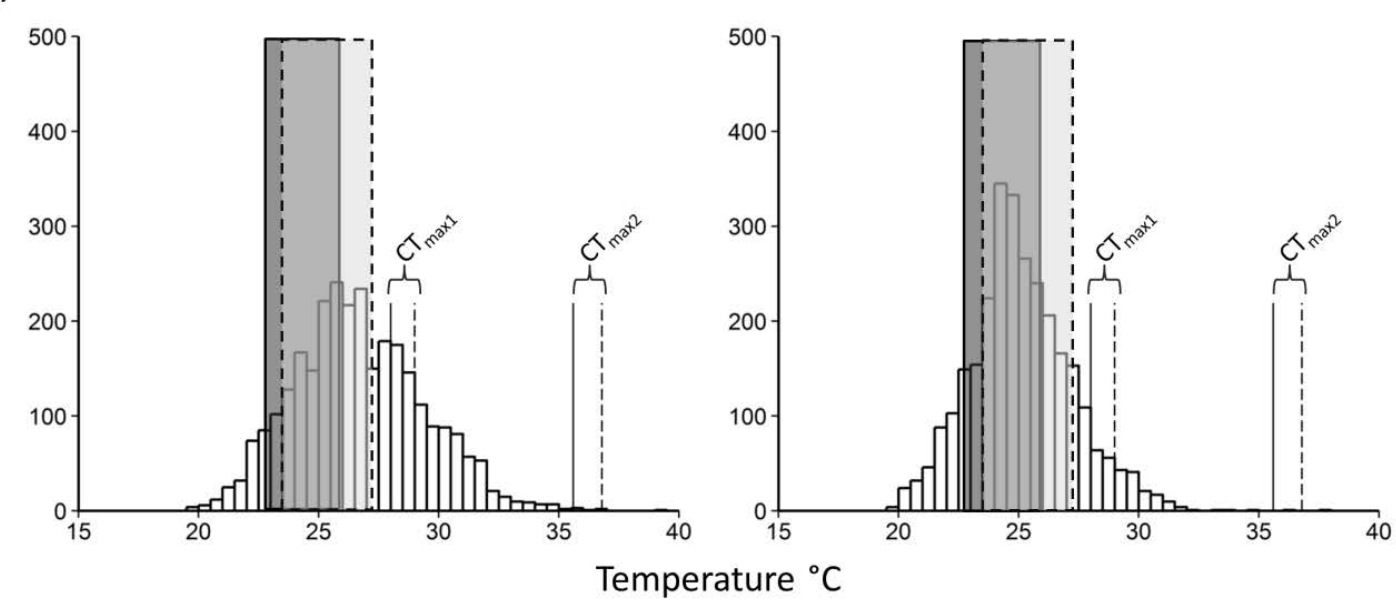

Figure 5.1. Frequency distribution of operative temperatures in a) old growth forest, $b$ ) secondary forest, and c) pasture. Shaded areas represents the temperature preference 
range $\left(\mathrm{T}_{\text {sel }}\right)$ measured as the central $50 \%$ of the distribution of body temperatures selected in a laboratory thermal gradient. Dark shaded area surrounded by solid lines represents $\mathrm{T}_{\text {sel }}$ of $N$. humilis and lighter shaded area outlined by dashed lines represents $\mathrm{T}_{\text {sel }}$ of $N$. limifrons. $\mathrm{CT}_{\max }$ estimates from two different studies $\left(\mathrm{CT}_{\max }\right.$ measured by Brusch et al. 2016 et al; $\mathrm{CT}_{\max 2}$ measured by van Berkum 1986) for $N$. humilis and N. limifrons are shown in solid and dashed horizontal lines, respectively. 


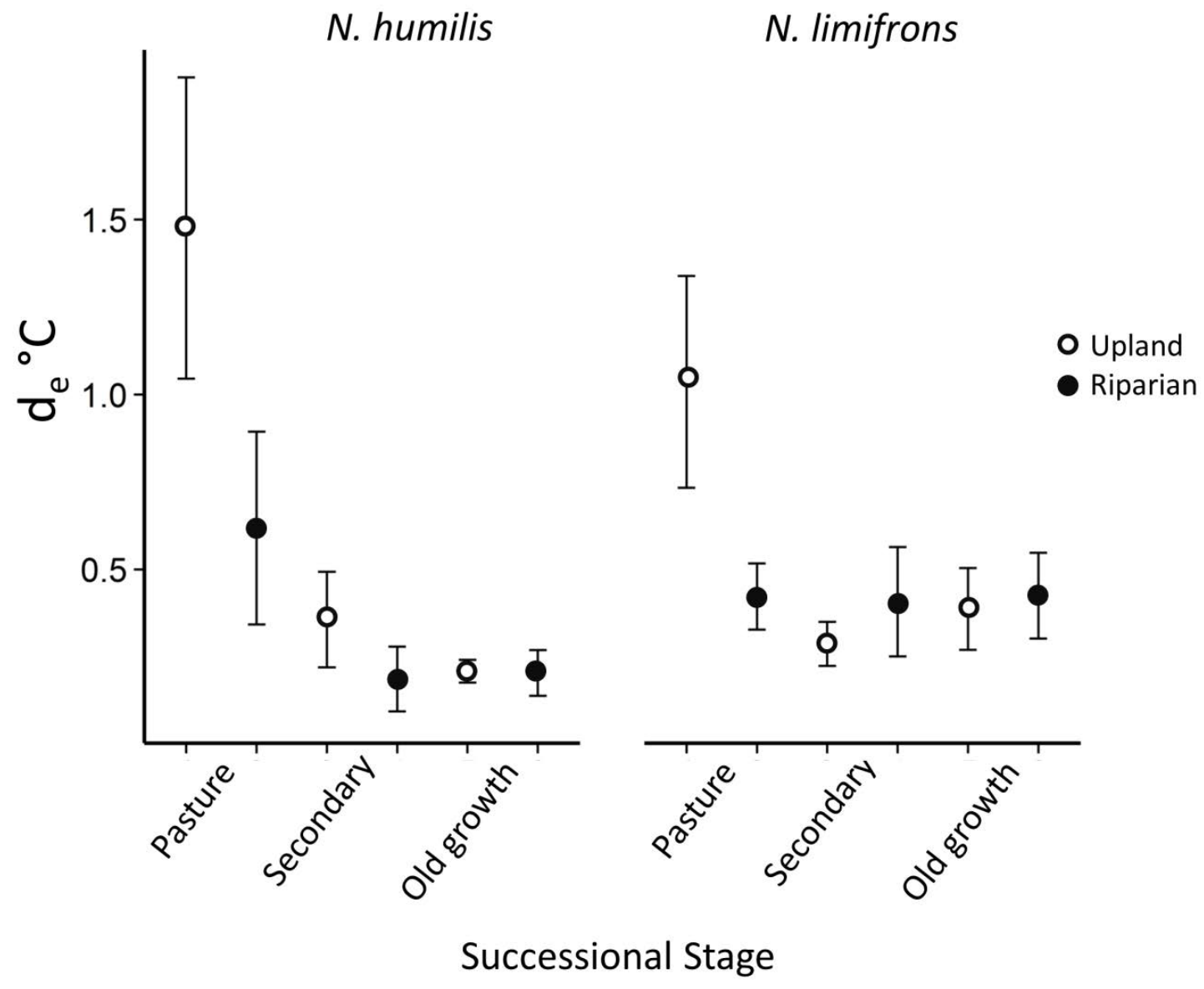

Figure 5.2. Mean $( \pm \mathrm{SE})$ thermal quality $\left(\mathrm{d}_{\mathrm{e}}\right)$ in different successional forest stages for $N$. humilis $N$. limifrons. Higher values of $\mathrm{d}_{\mathrm{e}}$ indicate lower thermal quality. 
(a)

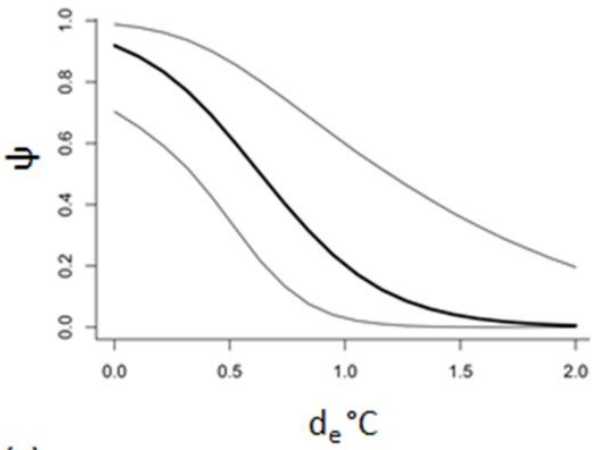

(c)

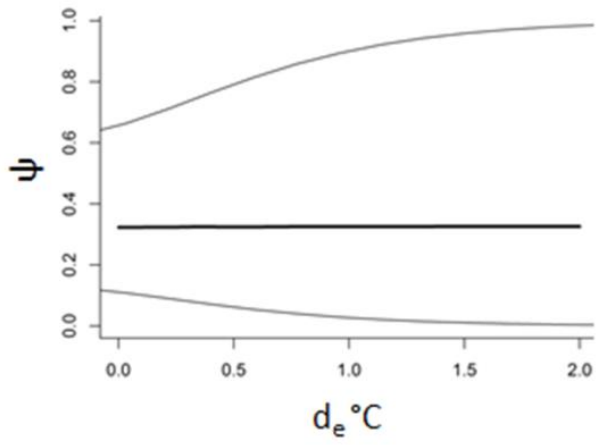

(b)

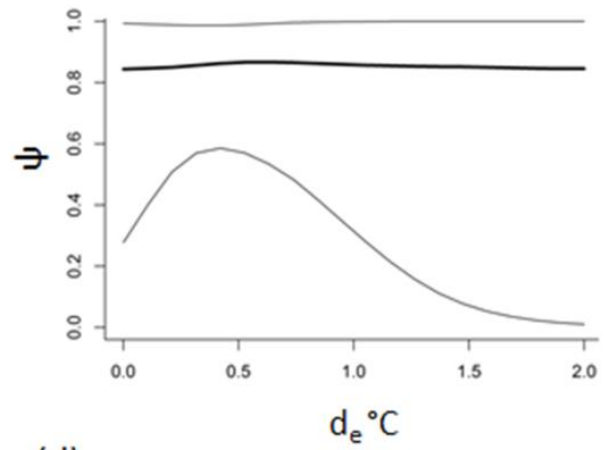

(d)

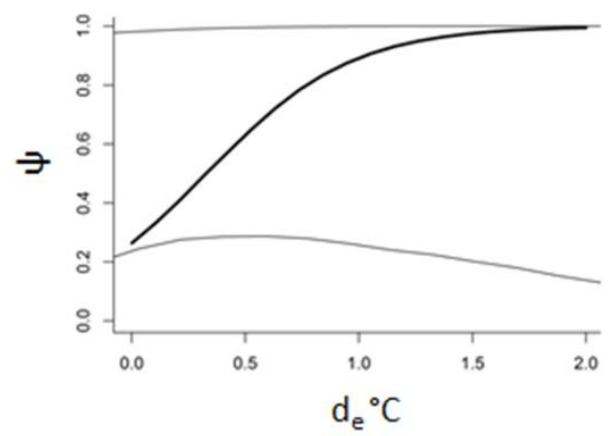

Figure 5.3. Mean probability of occurrence $(\psi)$ in relation to thermal quality $\left(\mathrm{d}_{\mathrm{e}}{ }^{\circ} \mathrm{C}\right)$ for Norops humilis in (a) upland and (c) riparian habitat and Norops limifrons in (b) upland and (d) riparian habitat. Lines represent the posterior mean response and $95 \%$ credible interval of the posterior mean. Higher values of $d_{e}$ indicate lower thermal quality. 


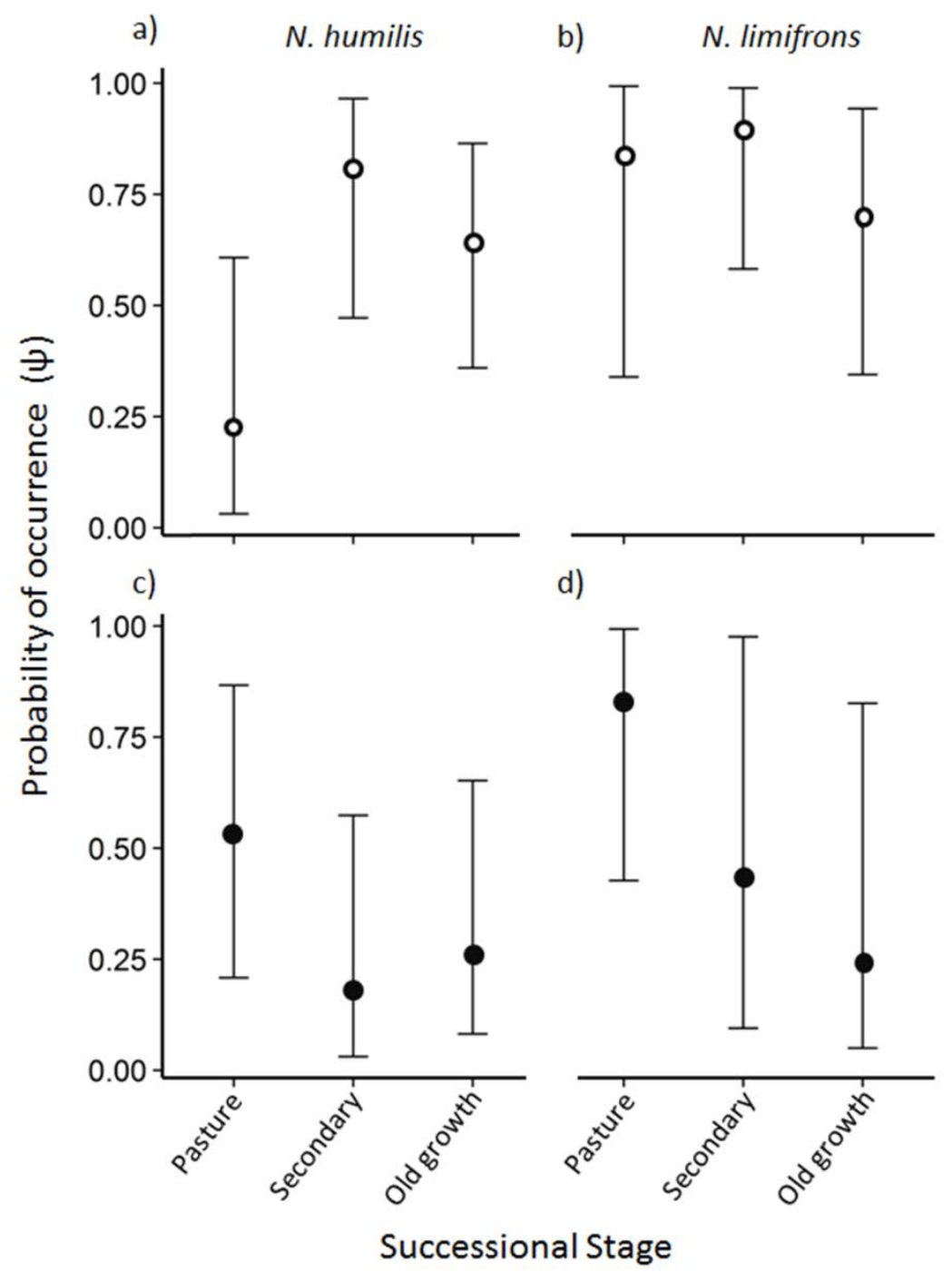

Figure 5.4. Mean probability of occurrence ( $\pm 95 \%$ credible intervals) in different successional forest stages for upland habitat, (a) $N$. humilis and (b) $N$. limifrons, and riparian habitat (c) $N$. humilis and (d) N. limifrons. 


\section{CONCLUSIONS}

To fully understand how to create effective species management and conservation planning, we must have knowledge on how amphibian and reptile communities decline as a result of habitat change, and what their potential is to recover. I synthesized the literature to elucidate the state of understanding of how amphibians and reptiles respond when their habitat is taken away, and if and how amphibian and reptile communities recover when secondary forest is left to regenerate on altered habitats. I then combine field and laboratory based approaches to explore theory of community recovery, describe observed patterns and process of recovery, and test for support for a mechanisms of response of amphibians and reptiles to secondary forest succession.

In Chapter 1, I synthesized existing literature to identify generalized responses of amphibians and reptiles to globally predominant anthropogenic land-use types. In addition to whole community response I analyzed group-specific responses based on species habitat associations (natural habitat specialist, generalist, disturbed habitat specialist) which I assigned using a quantitative method based on reported abundances of species in different habitats in past studies. I found that differences in species richness between natural and disturbed habitats can be influenced by species turnover and the proportion of generalist and disturbance-associated species. This is important to consider because many past studies have reported no statistically significant effect of land use on amphibian and reptile species richness and my results suggest that these non-significant results may not mean that species are not responding to land-use change but that there may be meaningful group-specific responses that differ in magnitude and direction of response. While analyzing whole assemblages is useful in assessing broad effects of 
habitat alteration, care should be taken in making sweeping conclusions about the ability of land uses to support all sub-groups of biota.

In Chapter 2, I synthesized existing literature to identify generalized responses of amphibians and reptiles to secondary forest succession and to identify potential important mechanisms for response to succession. I estimated mean effect size across studies for species richness and abundance in human-modified landscapes (agriculture, pasture, and plantation) and old-growth forests compared to regenerating secondary forests. I found the expected general trend of old-growth forest harboring more species and more individuals than secondary forests and human-modified habitats less species and having fewer individuals than secondary forest. My finding of significant differences in amphibian community response to secondary forest succession but not reptiles may reflect that amphibians and reptiles may be affected differently by environmental factors associated with secondary forest succession and why they should be considered separately in studies. Secondary forests are currently the dominant global forest cover type and are increasing in cover in many regions. One of the most salient results of this chapter is the stark lack of research on the conservation value of secondary forests to amphibians and reptiles (and fauna in general) even though there is dire need for this research to be conducted and trends of species response to be identified in order to make appropriate conservation decisions and predict the potential for secondary forests to maintain current levels of biodiversity and improve the outlook of biodiversity in the future.

In Chapter 3, I evaluated the relative strength of the role of stochastic and deterministic processes in community assembly of amphibians and reptiles over the 
course of secondary forest succession. I found significantly stronger support for deterministic processes in the assembly of communities in regenerating forests. I then determined if the strength of support for environmental filtering, a deterministic process, was dependent on the harshness of the environmental filter (stage of forest regeneration). I found that there are different mechanisms of assembly operating on amphibian and reptile communities based on spatial scale. For amphibians, I found that habitat type (upland or riparian) mediated the strength of environmental filtering that occurred across forest stages. For reptiles, I found more idiosyncratic results suggesting that environmental filtering may not act as strongly on reptiles as amphibians at my study sites. Overall, my results indicate that changes associated with secondary forest succession have a substantial effect on shaping amphibian and reptile communities and support the importance for examining processes of community assembly at different spatial scales.

In Chapter 4, I evaluated the recovery of amphibian and reptile communities in tropical lowland wet forest in two regions of Costa Rica by determining whole community, group-specific and species-specific responses to forest succession conducting field-based surveys and estimating evenness, composition, community, group, and species-specific probability of occurrence, and species richness. Mean occupancy response of anurans to forest stage was positively related to stage but I found no trend in response of reptiles. There was substantial variation in both amphibian and reptile species-specific responses to successional change. I found that riparian habitats consistently maintain high species richness, and in upland habitats probability of occurrence of terrestrial breeding anurans was the most affected by structural changes as 
a result of forest succession. Secondary forests have high conservation value for many species of amphibians and reptiles. In harsh landscapes, such as those generated by landuse change, riparian corridors and other refuge habitats are important in maintaining amphibian and reptile species diversity.

In Chapter 5, I tested for support of a mechanism of response to secondary forest succession. Habitat alteration changes the availability of thermally suitable habitat, and species respond differently depending on their thermal traits (Nowakowski et al. 2018). However, as altered landscapes are abandoned and allowed to regenerate, thermal quality of the habitat is restored. When faced with a change in frequency of thermally suitable habitat in an altered environment, species can move to favorable thermal habitats; adjust through displays of behavioral plasticity, physiological plasticity, or adaptation; or alternatively undergo demographic collapse (Sinervo et al. 2010). My results support thermal quality as a mechanism for species response to forest succession. I found a difference in thermal quality among successional stages. Pastures had the lowest thermal quality with a high proportion of $\mathrm{T}_{\mathrm{e}}$ above thermal preference ranges of both $N$. humilis and $N$. limifrons, whereas old-growth forest and secondary forest provided a high frequency of suitable thermal habitat. The lizard species that had a cooler and narrower thermal preference range ( $N$. humilis) showed a stronger relationship with thermal quality than the lizard species with the higher and broader thermal preference range, $N$. limifrons. I found that species responded to a reduction in thermally suitable habitat by shifting their behavior to use of a different habitat within the landscape (riparian versus upland habitat) or by using remnant trees in upland habitat. My results highlight the importance of 
understanding how habitat features such as riparian zones may be critical in maintaining populations and species diversity of species in marginal habitat.

On a regional scale, my dissertation highlights the importance for creating better incentives to retain secondary forest regeneration in Costa Rica. Few landowners in Costa Rica retain natural regeneration as a result of incentives from payments for environmental services program (Chazdon 2008, Morse et al. 2009). My research highlights the high potential for secondary forests to contribute to maintenance of high biodiversity and past studies have emphasized additional functions of secondary forest such as increased carbon storage (Morse et al. 2009) and use as buffers to prevent degrading of old-growth forest patches (Turner et al. 1997).

On a broad scale, my research highlights the large potential for secondary forests to have positive impacts as components in global land management and conservation of biodiversity. I found that amphibian and reptile community reassembly were closely tied to environmental changes associated with secondary forest succession and that amphibian and reptile diversity largely recovers at a fairly rapid rate. Secondary forests will likely not replace old-growth forests in value (Gibson et al. 2011). However, the integration of preservation of current secondary forests and incentives to increase secondary forest cover on altered landscapes in conservation planning will be important to the preservation of the diversity of future biota. Additionally, the understanding of habitat components that are critical for the maintenance of species diversity in altered habitats should be further explored. I found that riparian habitats maintain high species diversity and provide refuge habitats for species in human land uses such as pasture. The importance of riparian corridors in maintaining high species richness is especially significant because of 
the ease of translation into management plans; increase and restore buffers around riparian areas in altered habitats. Lastly, my dissertation research demonstrates the importance of exploring trends across spatial scale and considering group and speciesspecific responses in addition to whole-community response.

\section{LITERATURE CITED}

Chazdon, R. L. 2008. Beyond deforestation: Restoring forests and ecosystem services on degraded lands. Science 320: 1458-1460.

Gibson, L., T. M. Lee, L. P. Koh, B. W. Brook, T. A. Gardner, J. Barlow, C. A. Peres, C. J. A. Bradshaw, W. F. Laurance, T. E. Lovejoy, N. S. and Sodhi. 2011. Primary forests are irreplaceable for sustaining tropical biodiversity. Nature 478:378-383.

Morse, W. C., J. L. Schedlbauer, S. E. Sesnie, B. Finegan, C. A. Harvey, S. J. Hollenhorst, K. L. Kavanagh, D. Stoian, and J. D. Wulfhorst. 2009. Consequences of environmental service payments for forest retention and recruitment in a Costa Rican biological corridor. Ecology and Society 14:23

Nowakowski, A. J., J. I. Watling, M. E. Thompson, G. A. Brusch IV, A. Catenazzi, S. M. Whitfield, D. J. Kurz, A. Suarez-Mayorga, A. Aponte-Gutiérrez, M. A. Donnelly, B. D. Todd. 2018. Thermal biology mediates responses of amphibians and reptiles to habitat modification. Ecology Letters DOI: 10.1111/ele.12901.

Sinervo, B. et al. 2010. Erosion of lizard diversity by climate change and altered thermal niches. Science 328: 894-899.

Turner, I.M., Y. K. Wong, P. T. Chew, and A. Ibrahim. 1997. Tree species richness in primary and old secondary tropical forest in Singapore. Biodiversity and Conservation 6: 537-543. 
VITA

MICHELLE ELAINE THOMPSON

2006

B.S., Ecology, Behavior and Evolution

University of California, San Diego

La Jolla, California

2011

M.S., Ecology and Systematic Biology

San Francisco State University

San Francisco, California

\section{PUBLICATIONS}

Nowakowski, A. J., L. O. Frishkoff, M. E. Thompson, T. M Smith, and B. D. Todd. Pruning the amphibian tree of life: habitat conversion precipitates phylogenetic homogenization at the global scale. PNAS DOI: 10.1073/pnas.1714891115

Thompson, M. E. and M. A. Donnelly. Effects of Secondary Forest Succession on Amphibians and Reptiles: A Review and Meta-analysis. Copeia 106:10-19.

Nowakowski, A. J., J. I. Watling, M. E. Thompson, G. A. Brusch IV, A. Catenazzi, S. M. Whitfield, D. J. Kurz, A. Suarez-Mayorga, A. Aponte-Gutiérrez, M. A. Donnelly, B. D. Todd. 2018. Thermal biology mediates responses of amphibians and reptiles to habitat modification. Ecology Letters 21:345-355.

Nowakowski, A. J., M. E. Thompson, M. A. Donnelly, and B. D. Todd. 2017. Amphibian sensitivity to habitat loss is associated with population trends and species traits. Global Ecology and Biogeography 26:700-712.

Nowakowski, A. J., S. M. Whitfield, E. A. Eskew, M. E. Thompson, J. P. Rose, B. L. Caraballo, J. L. Kerby, M. A. Donnelly, and B. D. Todd. 2016. Infection risk decreases with increasing mismatch in host and pathogen environmental tolerances. Ecology Letters 19:1051-1061.

Thompson, M. E., A. J. Nowakowski, and M. A. Donnelly. 2016. The importance of defining focal assemblages when evaluating amphibian and reptile responses to land use. Conservation Biology 30:249-258.

Thompson, M. E., C. Ray, and M. A. Donnelly. 2015. Microhabitat use of juvenile Mexican Treefrogs in Palo Verde National Park, Guanacaste Province, Costa Rica. Herpetelogical Review 46:168-170. 
Thompson, M. E., B. J. Halstead, G. D. Wylie, M. Amarello, J. J. Smith, M. L. Casazza, and E. J. Routman. 2013. Effects of prescribed fire on Coluber constrictor mormon in coastal San Mateo County, California. Herpetological Conservation and Biology 8:602615.

Halstead, B. J., G. D. Wylie, M. Amarello, J. J. Smith, M. E. Thompson, E. J. Routman, and M.L. Casazza. 2011. Demography of the San Francisco Gartersnake in Coastal San Mateo County, California. Journal of Fish and Wildlife Management 2:41-48. 